Florida International University

FIU Digital Commons

FIU Electronic Theses and Dissertations

University Graduate School

6-13-2012

\title{
Island Diasporas: Perceptions of Indo-Caribbean Protégés Regarding the Effects of their Cross- Cultural Mentoring Experiences in the United States
}

Rehana Seepersad

Florida International University, rseep001@fiu.edu

DOI: $10.25148 /$ etd.FI12072706

Follow this and additional works at: https://digitalcommons.fiu.edu/etd

\section{Recommended Citation}

Seepersad, Rehana, "Island Diasporas: Perceptions of Indo-Caribbean Protégés Regarding the Effects of their Cross-Cultural Mentoring Experiences in the United States" (2012). FIU Electronic Theses and Dissertations. 670.

https://digitalcommons.fiu.edu/etd/670 


\section{FLORIDA INTERNATIONAL UNIVERSITY}

Miami, Florida

ISLAND DIASPORAS: PERCEPTIONS OF INDO-CARIBBEAN PROTÉGÉS

REGARDING THE EFFECTS OF THEIR CROSS-CULTURAL MENTORING EXPERIENCES IN THE UNITED STATES

A dissertation submitted in partial fulfillment of the

requirements for the degree of

DOCTOR OF EDUCATION

in

ADULT EDUCATION AND HUMAN RESOURCE DEVELOPMENT

by

Rehana Seepersad

2012 


\section{To: Dean Delia C. Garcia \\ College of Education}

This dissertation, written by Rehana Seepersad, and entitled Island Diasporas:

Perceptions of Indo-Caribbean Protégés regarding the Effects of their Cross-Cultural Mentoring Experiences in the United States, having been approved in respect to style and intellectual content, is referred to you for judgment.

We have read this dissertation and recommend that it be approved.

Glenda Droogsma Musoba

Hilary Landorf

Mary Levitt

Tonette S. Rocco, Major Professor

Date of Defense: June 13, 2012

The dissertation of Rehana Seepersad is approved.

Dean Delia C. Garcia

College of Education

Dean Lakshmi N. Reddi

University Graduate School

Florida International University, 2012 
(C) Copyright 2012 by Rehana Seepersad

All rights reserved. 


\section{DEDICATION}

I dedicate this dissertation to my father, Ramnarine Seepersad and to my mother, Tara Seepersad, my son Michael, and my three brothers. Your continuous love, support and inspiration have helped me to make this goal a reality.

I honor the place in you in which the entire universe dwells. I honor the place in you which is of love, of truth, of light and of peace. When you are in that place in you and I am in that place in me, we are one. Namasté. 


\section{ACKNOWLEDGMENTS}

I wish to express my deepest appreciation to the members of my dissertation committee, Drs. Tonette S. Rocco, Dr. Glenda Musoba, Dr. Hilary Landorf and Dr. Mary Levitt for their guidance and support. Special gratitude is extended to my major professor, Dr. Tonette S. Rocco, whose interest in my scholarship and success became evident on my very first day in the program. As a mentor and scholar her dedication to students, social justice and academic excellence has enriched my thinking and outlook.

I also wish to thank Dr. Tom Reio and Dr. Dawn Addy for being supportive and encouraging, willing to listen and to help me clarify my thinking so that I could progress with this study. Thanks also to my peer review team, and members of the Adult Education and Human Resources dissertation group for their review and feedback. I am indebted especially to Antonio Delgado for being supportive, encouraging and pragmatic along the way; this has been a long journey for you too my friend. I also wish to thank Dr. Judy Bernier and Claire Knackoney for their advice and fortitude for walking alongside me and being the voice of wisdom that I so needed.

Special thanks to the staff in the Office of Graduate Studies, Drs. Barbetta, Bliss, and Newman for being diligent in their commitment to serve the students of the College of Education. Especially to Caprila, Katie and Julie, I cherish the short time I worked with you, and I appreciate the kindness, patience, and care that you provide to us all.

To my dearest David, without your kindness, love, generosity, and support, making it through the end game would not have been possible. You have endured the struggles and the tears, yet stood solidly beside me every step of the way. To you I am eternally grateful. And to all my precious nieces and nephews, cousins and friends, now 
that this step of my journey is over, I hope to spend more time enjoying you all, especially my precious niece Steffi who I have yet to hold in my arms. Karin, Barb and Janice, thank you for your confidence and belief in me as I made it to this point.

Finally, I wish to extend my deepest thanks to the participants in this study for being generous and forthcoming about their cross-cultural mentoring relationships. Their insights have informed one of the first studies about Indo-Caribbean culture and experiences as we progress toward achieving our academic and professional goals in the United States. 


\begin{abstract}
OF THE DISSERTATION
ISLAND DIASPORAS: PERCEPTIONS OF INDO-CARIBBEAN PROTÉGÉS

REGARDING THE EFFECTS OF THEIR CROSS-CULTURAL MENTORING

EXPERIENCES IN THE UNITED STATES
\end{abstract}

by

Rehana Seepersad

Florida International University, 2012

Miami, Florida

Professor Tonette S. Rocco, Major Professor

Mentoring is defined as an "intense caring relationship in which persons with more experience work with less experienced persons to promote both professional and personal development" (Caffarella, 1992, p. 38). It is "a powerful emotional, and passionate interaction whereby the mentor and protégé experience...intellectual growth and development" (Galbraith \& Zelenak, 1991, p. 126).

In cross-cultural mentoring, mentors and protégés from different cultures confront social and cultural identities, goals, expectations, values, and beliefs (Cross \& Lincoln, 2005) to "achieve a higher level of potency in education and society" (Mullen, 2005, p. 6). Cross-cultural mentoring research explores attitudes, behaviors, linguistics and motivators of the more visible racial and ethnic groups in the U.S. (Elmer, 1986, Ulmer, 2008). The cross-cultural mentoring experiences of Indo-Caribbeans in the U.S. are obscured from the research despite their rich socio-historic culture.

The purpose of this phenomenological study was to explore the perceptions of Indo-Caribbean protégés regarding the effects of their cross-cultural mentoring 
experiences in the United States. Phenomenology is "the systematic attempt to uncover and describe...the internal meaning structures, of lived experience [by studying the] particulars or instances as they are encountered" (Van Manen, 1990, p. 10).

Criterion and snowball sampling were used to recruit 15 participants. A semistructured interview guide was used to gather data and Creswell's (2007) simplified version of Moustakas's (1994) Modification of the Stevick-Colaizzi-Keen Method of Analysis of Phenomenological Data was used to analyze the data.

Three themes emerged: (a) "Sitting at the feet of gurus" taught protégés how to accept guidance, (b) Guru-Shishya: Learning and Discipleship, ways that protégés perceived mentors' guidance related to work, skill acquisition, and social or emotional support, and (c) Samavartan sanskar: Building Coherence, helped protégés understand, manage and find meaning. Protégés' goals and professional expectations determined what they wanted from cross-cultural mentoring relationships and what they were willing to endure within those relationships. Since participants valued achievement and continuous improvement, mentor support was integral to making meaning and developing a sense of coherence in their lives.

Implications regarding cross-cultural mentoring relationships together with recommendations for future research conclude the study. 


\section{TABLE OF CONTENTS}

CHAPTER

PAGE

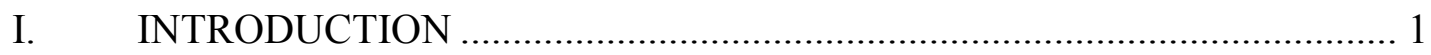

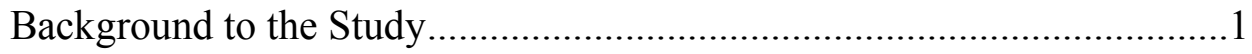

Problem Statement ……………………………………………......10

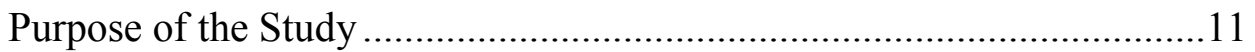

Research Questions ...............................................................................11

Conceptual Framework .........................................................................11

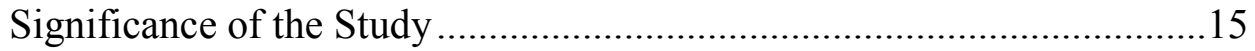

Delimitations of the Study ………………..........................................16

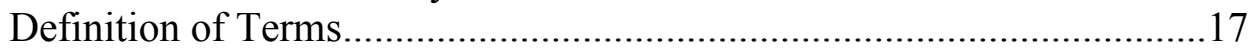

Summary and Organization of the Study ................................................22

II. REVIEW OF THE LITERATURE ……………................................ 23

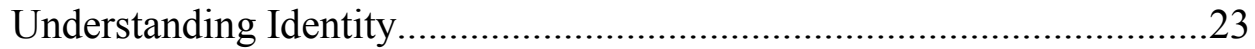

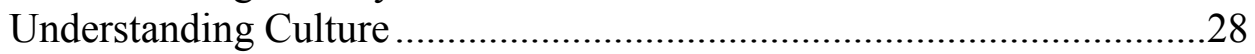

Understanding Mentoring and Cross-Cultural Mentoring .........................33

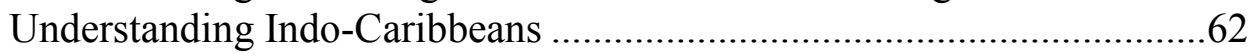

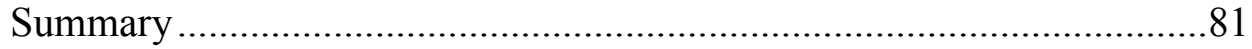

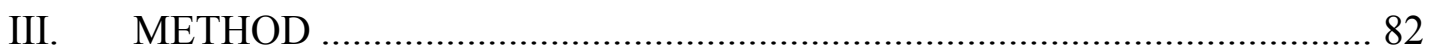

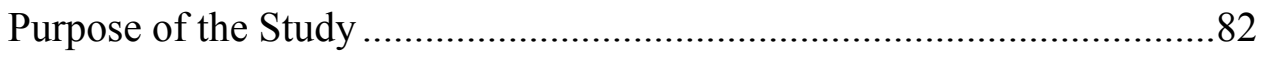

Research Questions ..........................................................................8

Phenomenological Framework …………………………......................83

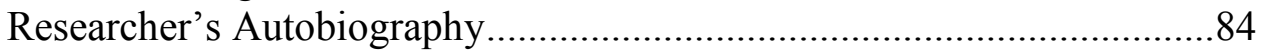

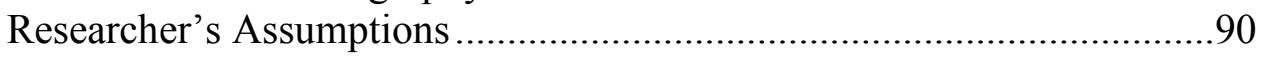

Researcher's Journaling Process ...............................................................91

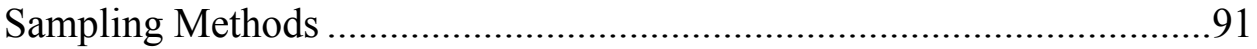

Participant Demographics .....................................................................93

Protection of Participants ....................................................................97

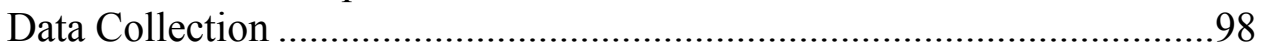

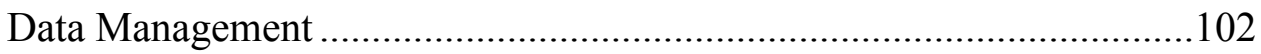

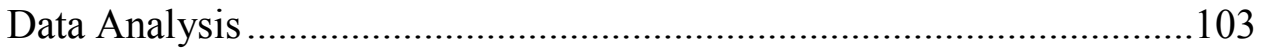

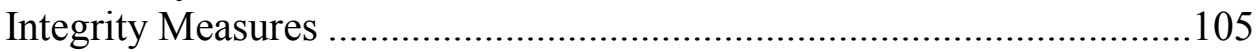

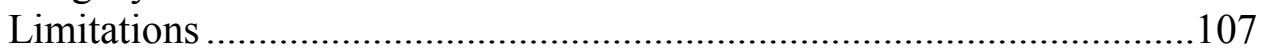

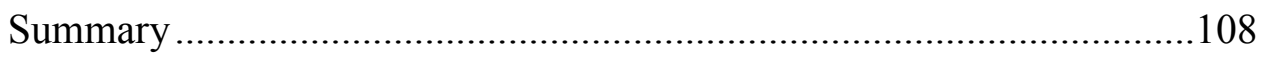

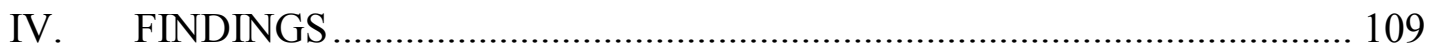

"Sitting at the Feet of Gurus"................................................................111

Guru-Shishya: Learning and Discipleship ..............................................142

Samavartan Sanskar: Building Coherence .............................................182

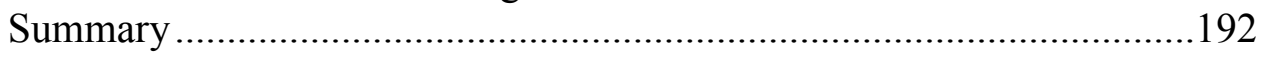




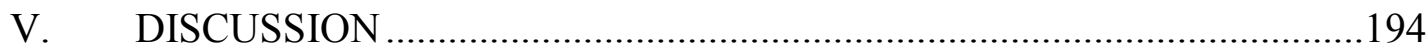

Responses to the Research Questions ..................................................195

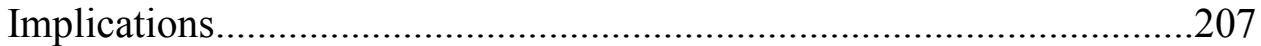

Recommendations for Future Research ..............................................208

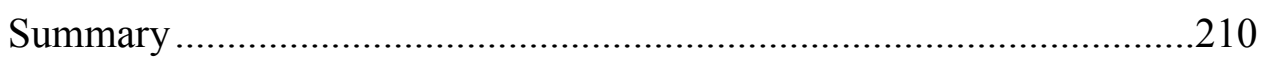

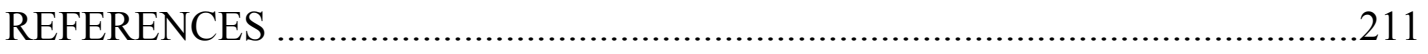

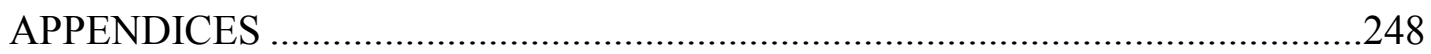

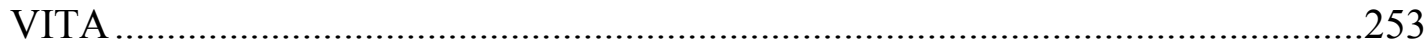




\section{LIST OF TABLES}

TABLE

PAGE

1. Education and Personal and Professional Achievement among Caribbeans, Central, and South American Immigrants in the U.S.

2. Mentoring Phases of Doctoral Students, Novice Teachers, and Junior Managers

3. Summary of Participant Age, Gender and Caribbean Origin .94

4. Summary of Educational Attainment and Profession during Mentorship .95

5. Gender, Race/Ethnicity and Relationship with Mentors. .96

6. Summary of "Sitting at the Feet of Gurus" 141

7. Summary of Guru-Shishya: Learning and Discipleship

8. Summary of Samavartan Sanskar: Building Coherence

9. Summary of Themes 


\section{CHAPTER I}

\section{INTRODUCTION}

Never before has the United States received such diverse groups, immigrants who mirror in their origins and destinies the forces that forged a new world order in the second half of the 20th century, and who are, unevenly, engaged in the process of trying to figure out where they belong in this America that's made up of so many sub-Americas. (Rumbaut, 2005, p. 2)

This phenomenological study explored the perceptions of Indo-Caribbean protégés regarding the effects of their cross-cultural mentoring experiences in the United States. This chapter begins with the background to the study, statement of the problem, purpose of the study, research questions guiding the study, and theoretical framework. Next is the significance of the study, delimitations, definition of terms, summary, and organization of the study.

\section{Background to the Study}

Mentoring is a global phenomenon that creates a "significant path for the sharing of knowledge, skills, and values in a diverse culture" (Cohen, 2003, p. 7) that consists of multiple spiritual, material, intellectual and emotional features. These features stem from varied value systems, traditions and beliefs of individuals and social groups. Mentoring is defined as an intensely caring relationship where an individual with greater experience works with another who has less experience to promote the latter's personal and professional development (Caffarella, 1992). Mentoring relationships occur through relational interactions within learning environments that include academic settings, local and multinational workplaces and other concrete or virtual spaces where learning takes place (Daloz, 1986; Marquardt \& Loan, 2006). 
Mentoring occurs between a mentor and protégé in the form of "advising, assisting, coaching, collaborating, compensating, counseling, guiding, leading, learning, socializing, supporting, teaching, and tutoring" (Mullen, 2007, p. 300). A mentor is more experienced and has greater influence than the protégé within any given environment or organization, provides guidance related to work, skill acquisition, and social or emotional support (Daloz, 1999; Davidson \& Foster-Johnson, 2001; Jacobi, 1991). A protégé is the person being mentored, who benefits from the mentor's knowledge and guidance through interpersonal dialogue, collaborative thinking, planning, reflection, and feedback (Galbraith \& Cohen, 1995). Although the goal of mentoring is to support the protégé's development, mentors themselves gain personal satisfaction, new perspectives, loyalty, organizational support and recognition, knowledge and experience from the relationship (Levinson, Darrow, Klein, Levinson, \& McKee, 1978; Ragins \& Scandura, 1999).

The increase in cultural diversity from high rates of migration to the U.S. (Camarota, 2007; Nieto, 2002) has resulted in cross-cultural mentoring relationships where both participants, that is, mentor and protégé, are from different ethnic cultures (Cheng, 1990; Kochan \& Pascarelli, 2003; Redmond, 1990). Good cross-cultural mentoring relationships require participants' willingness to acknowledge and understand the experiences of those from diverse racial or ethnic backgrounds (Davidson \& FosterJohnson, 2001; Wright-Harp \& Cole, 2008). Understanding diverse backgrounds leads to improved cross-cultural understandings, intercultural communication, enhanced flexibility, adaptability, unity and acceptance, awareness of differences, broader perspectives, emotional satisfaction, and increased creativity and productivity (Battaglia, 1994; Brinson \& Kottler, 1993; Kochan \& Pascarelli, 2003). 
Cross-cultural mentoring relationships encompass participants' "values, beliefs, and behaviors...defined by nationality, ethnicity, gender, age, physical characteristics, sexual orientation, economic status, education, profession, religion, organizational affiliation, and any other grouping that generates identifiable patterns" (Bennett \& Bennett, 2003, p. 150). As a result, mentors and protégés confront a range of thinking styles, social and cultural identities, expertise and aspirations (Cross \& Lincoln, 2005) which influence deference to authority, conflict management, assertiveness, self-concept and relationships (Marquardt \& Loan, 2006).

Cross-cultural mentoring affects both mentors and protégés through interpersonal and organizational relationships (Kochan \& Pascarelli, 2003; Ragins 2002). Organizational culture and structure influence access to the mentoring relationship. The attitudes, skills and backgrounds of both mentor and protégé influence how the relationship initially develops, while perceived similarities between mentor and protégé, and their working relationship affect progression of the relationship (Ragins, 2002). For instance, a protégé may be more receptive to a mentor who respects his/her cultural boundaries or limitations, and subsequently, they may build a more productive relationship. Through culturally responsive mentoring practices mentors may help protégés improve their intellects, social relationships and emotional responses by using cultural referents to help them develop knowledge, skills, and attitudes (Ladson-Billings, 1994).

Knowledge sharing, learning and social interactions that occur within crosscultural mentoring relationships should take into consideration the social and cultural customs of a people, as these are important aspects of the adult learning environment 
(Lave \& Wenger, 1991). Cultural differences that stem from ethnicity and cultural perspectives are ingrained in one's cultural identity and can enable enduring adult learning experiences through social, cognitive and behavioral interactions that form connections, and affirm or contest cultural assumptions (Jeria, 2002; Lee \& Sheared, 2002; Vygotsky, 1979). Understanding unique and often complex aspects of various cultures realistically prepares individuals as they adjust to cultures that are different from their own (Brislin, 1999). Sensitivity to various ethnic and cultural perspectives is needed otherwise mentors from dominant, homogenous cultures may merely perpetuate exclusionary values and culture (Galbraith \& Cohen 1995). Exclusionary values and culture leads to misunderstandings and conflict which distort learning relationships and interactions (Lee \& Sheared, 2002).

Existing cross-cultural mentoring studies show the benefits, challenges, perceptions, gendered and generational challenges, and experiences of African Americans, Latin Americans, Native Americans and Asian Americans in various settings. For African Americans, cross-cultural mentoring increased their self-efficacy, resilience, interest in education, and visibility, (Barker, 2007; Brown, 1988; Chan, 2008; Dickey, 1996; Ishiyama, 2007; Jackson \& Harris, 2007; Rushton, 2003; Schilling, 2008; Wilson, 1999). For Latin Americans, mentors from different cultures have increased protégés' visibility in academic, organizational and political spaces, although they still face academic, career and personal development challenges (Bond, Gray, Baxley, Cason, \& Denke, 2008; Bernal, Alemn, \& Carmona, 2008; Holst, 2006; Jeria, 2002; Okawa, 2002; Roland, 2008; Staikidis, 2006; Stanley, 2006; Vassoler, 2008). For Native-Americans, mentors from different cultures have fostered trust building, communication, and 
empathy regarding cultural difference and tribal beliefs (Anderson, Belcourt, \& Langwell, 2005; De Lapp, Hautman \& Anderson, 2008; Waterman, 2007). Asian Americans however, have experienced difficulty connecting with mentors from other cultures because of conflicting cultural expectations misunderstandings, and subtle discrimination (Henderson \& Chan, 2005; Lew, Chang \& Wang, 2005).

Women are also discriminated against through power relationships, issues of race, class, ethnicity and sexual orientation (Blake-Beard, Murrell, \& Thomas, 2007; Levesque, O'Neill, Nelson \& Dumas, 2005; Hansman, 2003). Cross-gender mentoring, while it does occur, is challenging because of the risks of sexual harassment, unrealistic expectations, or inequitable needs/demands of what essentially becomes a power relationship (Johnson-Bailey \& Cervero, 2002). Women of various races and ethnicities are challenged by their double-minority status from being both female and being a racial or ethnic minority, in academic settings and in the workplace (Blake-Beard, Murrell, \& Thomas, 2007; Hansman, 2003; Johnson-Bailey \& Cervero, 2002; Ragins 1997).

Existing studies have examined the cross-cultural mentoring relationships of Caribbean immigrants together with other immigrant or minority groups (Feldman-Abe, 2002; Johnson, 1992; Mitchell, 2005). In these studies Caribbean protégés are referred to as African Americans, Afro-Caribbeans, Blacks or Caribbean Blacks, as they are ascribed a race in American society based on the color of their skin as well as their native origin (Harris, 1964; Henke, 2001; Rong \& Brown, 2001; Rumbaut, 1994; Vickerman, 2007). In these studies the cultural, social, political and historical contexts of mentors and protégés provided useful information to engender support, community, understanding, 
socialization and development of immigrants in the U.S. (Barrett, 2010; Feldman-Abe, 2002; McKenzie, 1984; Nieto, 2002).

Caribbean immigrants are also referred to as Latin Americans in U.S. research and literature (Awokoya \& Clark, 2008; Boswell \& Jones, 2007; Gilkes, 2002; Mitchell, 2005; Rhone, 2007; Torres, 2004; Vickerman, 2007) as they have been homogenized into this group without any concern for their actual descent. Latin American countries in the Caribbean include Cuba, and the Dominican Republic (Thomas-Hope, 2000; Torres, 2004) whose history, culture and traditions are closely linked to Spanish settlement (Henke \& Reno, 2003) from the British and Spanish colonization that lead to slavery of Africans and indentureship of East Indians, in the English-speaking Caribbean. As a result, research and the mass media have developed the myth that Caribbeans are either Black or Latin, when in fact numerous races and ethnicities exist (Rong \& Brown, 2001; Rumbaut, 1994; Vickerman, 2007). The researcher was not able to locate any studies that examined cross-cultural mentoring experiences of other Caribbean ethnicities in the United States.

The 2008 American Community Survey performed by the U.S. Census Bureau (2008) showed a total Caribbean population of just over 2.5 million, that excluded those of Hispanic origin. Caribbeans, also known as West Indians are from the Englishspeaking nations of the Caribbean region (Foner, 2001; Henke, 2001). The Caribbean includes the chain of islands in the Caribbean Sea, as well the countries on the Central and South American coasts that include Guyana, Suriname and Belize (Henke, 2000; Vertovec, 2001). 
Neither the U.S. Census Bureau, the U.S. Department of Homeland Security, the Digital Library of the Caribbean, individual Caribbean nations and universities, specialist Caribbean research groups nor special interest groups maintain numerical data that reflect ethnicities of Caribbean immigrants in the United States.

Although ethnic classification is absent from both national and regional data, Caribbean immigrants as a whole experience similar struggles as other immigrant groups in the United States. Table 1 shows a comparison of educational levels, and personal and professional achievement in the U.S. among the Caribbean and Central, Latin and South Americans to warrant further research and understanding regarding ethnically diverse immigrants in the U.S. (Waldinger, \& Der-Martirosian, 2001).

Table 1

Education and Personal and Professional Achievement among Caribbeans, Central, and South American Immigrants in the U.S.

\begin{tabular}{lccc}
\hline & \multicolumn{3}{c}{ Region of Origin } \\
\cline { 2 - 4 } Attribute & Caribbean & $\begin{array}{c}\text { Central } \\
\text { America }\end{array}$ & $\begin{array}{c}\text { South } \\
\text { America }\end{array}$ \\
\hline Bachelor's Degree or higher & $19 \%$ & $10 \%$ & $29 \%$ \\
High school completion & $29 \%$ & $24 \%$ & $28 \%$ \\
Less than High School (25 yrs. and older) & $28 \%$ & $49 \%$ & $19 \%$ \\
Below poverty threshold & $17 \%$ & $17 \%$ & $12 \%$ \\
Labor force participation & $75 \% \mathrm{M}$ & $90 \% \mathrm{M}$ & $84 \% \mathrm{M}$ \\
Management and business* & $64 \% \mathrm{~F}$ & $64 \% \mathrm{~F}$ & $66 \% \mathrm{~F}$ \\
Cleaning and maintenance* & $.8 \%$ & $.4 \%$ & $.7 \%$ \\
Median household Income* & $.7 \%$ & $1.4 \%$ & $.8 \%$ \\
Home ownership* & $\$ 40,000$ & $\$ 40,000$ & $\$ 50,000$ \\
\hline
\end{tabular}

Sources: Congressional Research Service, 2011; *Pew Hispanic Center, 2011. 
Differences among Caribbean immigrants in the U.S. and other minority immigrants stem from culture, distinctions in education and ambition, and White favoritism or comfort because of Caribbeans' mannerisms, beliefs and lifestyles (Model, 2008). Caribbean immigrants are sometimes referred to as a "model minority" possessing a good work ethic, economic aspirations, employment flexibility, respect for family and kinship, and high regard for formal education exemplified in their pursuit of professional degrees and careers (Henke, 2001). Because of their model minority status and homogenized ethnicity (Awokoya \& Clark, 2008; Boswell \& Jones, 2007), the experiences of Caribbean immigrants of various ethnicities are obscured within the literature.

Caribbean immigrants in the U.S. include descendants of Europeans, Africans, East Indians, Hispanics, Indonesians, Javanese, Chinese and native or Aboriginal Indians (Premdas, 1995). Their religious affiliations include "Christians, Hindus, Muslims, Jews, Rastafarians, Santería, Winti, and Vudun" (Premdas, 1995, p. 2). They speak "Spanish, English, Dutch, French, English [sic], and creole dialects such as papiamentu, sranan tongo, ndjuka, saramaccan, kromanti, kreyol, [as well as Eastern dialects] like Hindustani, Bhojpuri, [and] Urdu" (Premdas, 1995, p. 2).

Among the Caribbean immigrants who come to the U.S. each year in search of education, work and an improved life are Indo-Caribbeans, a Caribbean ethnicity that is noticeably absent from U.S. literature (Henke, 2001; Model, 2008). Over 336,000 of the Caribbean immigrants presently in the U.S. are from Guyana, Suriname and Trinidad (U.S. Department of Homeland Security, 2010), where the Indo-Caribbean population totals $50 \%, 37 \%$, and $40 \%$ of the population respectively (The CIA World Factbook, 
2009). The U.S. Census Bureau however does not differentiate ethnicity within the Caribbean or West Indian population, and has stated that anyone who writes in the term Indo followed by their country or area of origin, e.g., Indo-Guyanese or Indo-Caribbean, in an attempt to self-identify on census documents will be counted as Asian Indian or will be tabulated in the Two or More Races category (Humes to P. Murthy, August, 31, 2009). This further adds to the obscurity of Indo-Caribbeans living in the United States, especially when many Indo-Caribbeans, like myself, are over 200 to 300 years removed from their ancestral Indian roots. The Indo-Caribbean Task Force for Census 2000 believes that Indo-Caribbeans were misclassified within the 1990 census, and they are convinced there are over 100,000 Indo-Caribbeans in the U.S. (Hum, 2004). As a people, Indo-Caribbeans have been described as "racially Asian Indian, ethnically West Indian, and religiously Hindu, Muslim, Christian, or Sikh" (Butterfield, 2004, p. 285) which further confounds their identity.

Indo-Caribbeans are the descendants of East Indian indentured laborers who were recruited from India, and shipped to Caribbean nations from 1838 to 1917 (Roberts \& Byrne, 1966; Singaravelou, 1990; Tinker, 1974; Verma, 2008), and who were paid to serve for a contracted duration. Their circumstances were different from the African slaves in the Caribbean who were taken forcibly from their homeland and brutally subjugated without remuneration (Henke, 2001). Descendants of these indentured laborers later chose to migrate to the U.S. because of educational, economic or social circumstances (Henke, 2001; Verma, 2008; Vertovec, 2000). Indo-Caribbeans employ an instrumental and opportunistic approach to education, knowledge, and self-development leading to steady academic and professional development (Vertovec, 2000). 


\section{Problem Statement}

The majority of mentoring studies in the U.S. have been conducted using Western or Eurocentric samples (Alfred, 2002; Chalmers, 2002; Crutcher, 2007; Johnson-Bailey \& Cervero, 2002; Rose, 2000; Scandura \& Pelligrini, 2007). There are also mentoring studies on the more visible racial and ethnic groups such as African Americans, Latin Americans and sometimes Asians (Allahar, 2005; Beyene, Anglin, Sanchez \& Ballou, 2008; Dolan, 2007; Henke, 2001; Krase \& Hutchinson, 2004; Roeder, 2006; Torres, 2004; Vertovec, 2000). Although Indo-Caribbean immigrants participate in mentorships within academic settings, local and multinational workplaces and other concrete or virtual spaces where learning takes place, there is no research regarding their mentoring relationship. As a result, there is a gap in the literature regarding the perceptions of IndoCaribbeans regarding the effects of their cross-cultural mentoring experiences, and consequently the cross-cultural mentoring experiences of Indo-Caribbeans are overlooked within the discourse of adult education.

Too often the Caribbean is viewed as a monoracial and monocultural entity that is predominantly Black or of African American descent (Allahar, 2005; Birbalsingh, 1997; Premdas, 1995). Consequently, Indo-Caribbean culture, traditions, contexts, practices, social tools, values, beliefs and representations are prone to cultural misrepresentation as they are excluded from the socio-cultural discourse of adult education literature (Mehta, 2004; Rogoff \& Chavajay, 1995). Cultural misrepresentation compromises how certain immigrant groups may be treated in the workforce and in various learning environments and can negatively influence the human development, thinking, reasoning and problem solving that takes place (Rogoff, 2003; Rogoff \& Chavajay, 1995). Unless we as adult 
educators and adult learners broaden our understanding of the less visible immigrant cultures in the U.S. we may unconsciously ascribe inaccurate cultural assumptions (Delpit, 1995) and misleading or inaccurate beliefs and stereotypes (Clutterbuck, 2002) regarding Indo-Caribbean immigrants.

\section{Purpose of the Study}

The purpose of this phenomenological study was to examine Indo-Caribbean protégés' perceptions regarding the effects of their cross-cultural mentoring experiences in the United States. The aim of the study was to examine the cross-cultural mentoring experiences of Indo-Caribbean protégés to understand the effects of their mentoring relationships in the work force and in various learning environments.

\section{Research Questions}

The primary research question was: How do Indo-Caribbean protégés in the U.S. perceive the effects of their cross-cultural mentoring experiences? Secondary research questions were:

1. What factors do Indo-Caribbean protégés report that facilitate their successful cross-cultural mentoring relationships?

2. What challenges do Indo-Caribbean protégés encounter within their cross-cultural mentoring relationships?

3. What mentoring strategies and practices do Indo-Caribbean protégés believe will help to enhance their professional development?

\section{Conceptual Framework}

Mentoring is often considered "a slippery concept" (Daloz, 1986, p. ix) because of multiple definitions which revolve around caring, understanding, nurturing, 
interaction, appreciation of another's beliefs, social learning, identity and context (Anderson \& Shannon, 1988; Bandura, 1977; Merriam, 1983; Noddings, 2005; Zachary, 2000). Merriam (1983) has posited that mentoring is not clearly conceptualized and holds varied meanings in psychological, corporate and academic arenas. Mentoring relationships, however, build intrinsic value for both mentor and protégé (Newby \& Corner, 1997) in the form of development, relationship and understanding that occurs through constructivist, socio-cultural and psychological frameworks.

\section{Constructivist Framework}

The constructivist framework serves as a good lens to use to understand mentoring experiences. This framework develops as mentors provide opportunities for protégés to internalize new processes and construct their own knowledge and understanding to try out ideas, skills, and roles with minimal risk (Kaye \& Jacobson, 1996). Through socially constructed, experiential, situated learning experiences protégés' construct meanings, and gain new knowledge and skills (Kerka, 1998). By internalizing knowledge through accommodation protégés reframe what they already know, and through assimilation, they align new learning, within existing frameworks. Assimilation and accommodation within the learning context connect to elements within learners' own experiences as they construct new knowledge (Piaget, 1950).

Mentors and protégés learn from each other through interdependent, self-other relationships. These relationships include networking, counseling, guiding, instructing and modeling in the sense that both construct, create, invent and develop their own knowledge (Beyene, Anglin, Sanchez, \& Ballou, 1996; Dirkx \& Deems, 1994). The collaborative nature of the relationship increases the sense of mutuality and 
interdependence, and enhances the opportunity for those who traditionally do not seek support (Mullen, 2007). Specialized knowledge as a key feature of human development results from the social interaction that develops. Shared cognition through personal and group interactions extends knowledge structures and enables a cognitive representation of mentoring within dyadic or individual and group mentorships.

Protégés' experiences serve as a lens for observations of the mentors' actions and allows protégés to form their own interpretation of situations from a more subjective stance, offering more meaningful, dependable, memorable beliefs and perspectives (Mezirow, 1991; van Manen, 1991). Protégés are able to reframe what they see and learn, and therefore obtain understandings that are more representative of themselves as learners (Mezirow, 1991).

\section{Socio-Cultural Framework}

The socio-cultural framework of mentoring is grounded in collaborative learning which emphasizes that "the world about us defines who and what we ought to be as adults” (Merriam \& Caffarella, 1999, p. 118). The protégé's world includes social supports, assistance, guidance and interactions with peers, experts, and teachers, that is physical contexts (Shi, Mishra \& Bonk, 2004), as well as classroom and institutional culture (Tisdell, 2000). This also extends to family members, friends and spouses who influence relational adjustments (Ward, 2004). As such, individuals thinking, feeling and beliefs, interpersonal interactions, and environment become aspects of a shared developmental relationship (Rogoff, 1995).

Learning through collaborative relationships such as mentoring, builds confidence in navigating new scenarios in language, concepts and creativity (Vygotsky, 
1962). "Human beings come into existence, attain consciousness and develop throughout their lives in relationship to others (Mahn \& John-Steiner, 2002, p. 48). Historical and generational experiences stored and passed through generations, are used to create or to recreate learning situations designed around one's culture (Vygotsky, 1962).

Learning occurs within a social structure of "cultural contexts...mediated by language and other symbolic systems, and can be best understood when investigated in their historical development" (John-Steiner \& Mahn, 1996, p. 191). Learning is situated within the individual's cultural identity which serves as a tool that mediates and also transforms as one learns (Perez, 1998). Similarly, social experiences provide new insight which enhances interaction within various groups and environments. Without conscious awareness of historical, generational and social experiences active learning could not exist (Vygotsky, 1997).

Socio-cultural factors that are characteristic of some minority groups may form barriers that lead to mistrust, caution, power relations, oppression, discrimination, judgment, and reduced opportunities (Brinson \& Kottler, 1993). As a result, minorities may feel a sense of isolation that could lead them to relinquish certain aspects of their cultural identity in efforts to fit in. Mentors' genuine concern, cultural sensitivity, and appreciation of protégés' worldviews, individuality, and background, enable effective communication, thereby enhancing the relationship.

\section{Psychosocial Framework}

The psychosocial framework provides a lens to examine the internal value which develops through ongoing interpersonal dialogue, collaborative critical thinking, planning, reflection, and feedback (Galbraith \& Cohen, 1995) between mentor and 
protégé. By serving as a role-model, encouraging and supporting new behaviors, providing safe and trustworthy counsel, and through shared or informal interaction, mentors enhance protégés' sense of competence, identity, and effectiveness (Kaye \& Jacobson, 1996; Kerka, 1998; Kram, 1985).

By using a transformative learning approach, the mentor can facilitate deeper levels of learning or emancipatory learning, which challenges the protégé to become aware of limiting habits of mind, values or actions (Cranton, 2002). The resulting personal agency, the "freedom of adults to act toward their own growth and development" (Clark, 1993, p. 50), enables the protégé to feel empowered while maintaining his/her autonomy. Effective mentors, empathetic to protégés' challenges, can enhance learning by helping protégés find ways to overcome personal resistance emanating from unconscious, internalized dimensions, lack of empowerment or feelings of inequity.

Through interactive, intensely interpersonal contact, verbal encouragement, emotional support at stressful moments or situations, and recognition of accomplishments mentors may enhance individuals' efficacy, enabling them to execute actions toward desired goals or outcomes (Bandura, 1977). The mentor serves as a catalyst to transform the protégé's perspectives through new meanings, transitions, shifts in paradigms, and active learning (Mezirow, 1991; Zachary, 2000).

\section{Significance of the Study}

This study enhances our understanding of cross-cultural mentoring and may help adult educators, trainers and human resource development practitioners understand the effects of cross-cultural mentoring given the values, beliefs, attitudes and culture of a less 
visible immigrant population. Our knowledge of the constructivist, socio-cultural and psychosocial dimensions of cross-cultural mentoring now includes the cultural contexts and cross-cultural mentoring experiences of Indo-Caribbeans.

The study also extends the research on cross-cultural mentoring among individuals of diverse cultures since understanding the cultural worlds of immigrants' influences etic views and interpretations of their cultural identity (Perez, 1998). The findings of this research foster increased understanding regarding cross-cultural mentoring of a less visible immigrant group so that decision makers and proponents of diversity may enhance multicultural integration and responsiveness in organizational and academic settings (Rodriguez, 1995).

Examining the cross-cultural mentoring experiences of protégés from less visible cultures creates a more holistic and in-depth understanding of mentoring (Scandura \& Pellegrini, 2007) that enhances mutual support, community, socialization and development in academic and professional spheres. Understanding the attitudes, beliefs, values, communication styles and behaviors (Lee, McCauley, \& Draguns, 1999) that influence immigrant cultures enhance interaction within learning relationships. This is particularly important since immigrant cultures in the U.S. are increasing exponentially due to globalization (Kochan \& Pascarelli, 2004). Through this study adult educators and practitioners may help learners and professionals from less visible cultures build a more authentic and productive life in the United States.

\section{Delimitations of the Study}

In cross-cultural mentoring relationships mentors and protégés confront a variety of experiences, social and cultural identities, expectations, values and beliefs (Cross, 
2005). Although a wide range of ethnically diverse immigrants participate in crosscultural mentoring relationships in the U.S., the scope of this study was limited to IndoCaribbean protégés who migrated to the U.S. from selected Caribbean nations.

\section{Definition of Terms}

The following definitions are provided for clarity on terms as they are used by the researcher throughout the study.

\section{Caribbean}

The Caribbean includes the chain of islands in the Caribbean Sea, as well the countries on the Central and South American coasts (Henke, 2000; Vertovec, 2001). These islands and countries include Anguilla, Antigua and Barbuda, Aruba, Bahamas, Barbados, Belize, British Virgin Islands, Caribbean Netherlands, Cayman Islands, Colombia, Costa Rica, Cuba, Curaçao, Dominica, Dominican Republic, French Guiana, Grenada, Guadeloupe, Guyana, Haiti, Honduras, Jamaica, Martinique, Mexico, Montserrat, Nicaragua, Panama, Puerto Rico, Saint Barthélemy, Saint Kitts and Nevis, Saint Lucia, Saint Maarten, Saint Martin, Saint Vincent and the Grenadines, Suriname, Trinidad, Tobago, Turks and Caicos Islands, U.S. Virgin Islands, and Venezuela.

\section{Context}

Context is a constitutive factor in the social construction of meaning for those who seek to understand the cultural worlds within which individuals grow and develop, interpret their relationships, process, interpret, and encode their worlds (John-Steiner, Panofsky \& Smith, 1994; Perez, 1998). 


\section{Cultural Competence}

Cultural competence refers to the capacity for those in the adult learning environment and in cross-cultural mentoring relationships to intellectually and emotionally accept, appreciate, and learn about all cultures through diverse cultural lenses (Gudykunst \& Kim, 1984; McAllister \& Irvine, 2000).

\section{Cross-Cultural Mentoring}

Cross-cultural mentoring refers to the mentoring relationship between a mentor and protégé who are from different cultures in an effort to better understand, motivate and support each other (American College Personnel Association, 1996; Newby \& Corner, 1997).

\section{Culture}

Culture is viewed as an expression of the spiritual, material, intellectual and emotional features that constitute the lifestyles, relationships, value systems, traditions and beliefs that stem from one's heritage (United Nations Educational, Scientific and Cultural Organization, 2002). It is also considered the behavioral and symbolic mechanisms individuals cultivate to define themselves, to relate, communicate, interpret and adapt to their environments (Giles, 1998).

\section{English-Speaking Caribbean}

The English-speaking Caribbean according to the Caribbean Community Secretariat includes Anguilla, Antigua and Barbuda, Barbados, Belize, British Virgin Islands, Cayman Islands, Dominica, Grenada, Guyana, Jamaica, Montserrat, St Kitts and Nevis, Saint Lucia, St Vincent and the Grenadines, Trinidad and Tobago, Turks and Caicos Islands (Caribbean Community Secretariat, 2011). 


\section{Ethnicity}

Ethnicity is a socially constructed, self-asserted categorization based on claims of shared history, symbols and descent that shape social and cultural habits. It is distinguished from race which is based on perceived physical differences typically assigned by others (Cornell \& Hartmann, 1998).

\section{Ethnic Groups}

Ethnic groups are those whose members identify with each other through a shared social or cultural heritage (Rothenberg, 2005).

\section{Eurocentric}

Eurocentric refers to the implicit positioning that fundamentally misrepresents multicultural views justified by European nationalistic lenses which sanitize Western history while patronizing and even demonizing the non-West. Eurocentric views are considered noble, scientific, humanistic and progressive, and led to class stratifications, feudalism, capitalism and the industrial revolution (Shohat \& Stam, 1995).

\section{Identity}

Identity is a self-determined social construct of individuals or groups that can be fluid and multidimensional, and develops over time through social interaction and sensemaking (Frable 1997; Phinney, 1996a).

\section{Immigrant}

An immigrant is defined as a person who resides in a particular country, but was born in another country (Loveless, McCue, Surette, \& Norris-Tirrell, 1996). Due to the confidential nature of immigrant status, it will be assumed that participants in this study 
are lawful, permanent residents or naturalized citizens of the United States, and they were not asked to disclose any information related to immigration status.

\section{Indo-Caribbeans}

Indo-Caribbeans are "East Indians" of the Caribbean, and Caribbean rim countries of Guyana, and Suriname and Belize who are descendants of indentured laborers from the Indian sub-continent (World Directory of Minorities, 2008).

\section{Indentured Laborers}

In this dissertation the term indentured laborers refers to East Indians who were first brought from India to the Caribbean from the mid-1840 through to 1917 to work on White-owned sugar plantations to replace the newly freed African slaves. They were paid to serve for a contracted duration of 5 years and could purchase land after they fulfilled their contracts (World Directory of Minorities, 2008).

\section{Intercultural Sensitivity}

Intercultural sensitivity enables mentors to be more understanding and perceptive toward "subtle differences in nonverbal behavior or communication style[s]...[so they

can] see a culturally different person as equally complex" (Bennett, 2004, p. 73) as themselves.

\section{Mentee/Protégé}

The mentee/protégé is the less experienced person in the mentoring relationship (Daloz, 1986). Female mentees are typically referred to as protégées however in this study the term mentee or protégé references both male and female participants. Refer to Table 3 for participants' genders. 


\section{Mentor}

Mentor is defined as a role model or guide who assists a protégé in building developmental and experiential skills (Merriam, Thomas, \& Zeph, 1987).

\section{Mentoring Relationship}

Mentoring relationships are relationships between a mentor and protégé that include "advising, assisting, coaching, collaborating, compensating, counseling, guiding, leading, learning, socializing, supporting, teaching, and tutoring” (Mullen, 2007, p. 300).

\section{Minority}

Minority refers to an individual or group of individuals who are collectively less in number than other groups in the United States (Jeria, 2002).

\section{Salutogenesis}

Salutogenesis is the study of health origins and causes that focuses on ways to "create, enhance, and improve physical, mental and social well-being" (Becker, Glascoff, \& Felts, 2010) and typically informs issues related to health and wellness.

\section{Stereotypes}

Stereotypes are defined as oversimplified, rigid, and generalized beliefs about groups of people, in which all individuals from the same group are regarded as having the same set of leading characteristics (Harre \& Lamb, 1986).

\section{Trust}

Trust is an underlying sense of interpersonal comfort that provides the feeling that one can interact freely and express thoughts, or opinions without fear of blame, or repercussions (Rusbult, Martz, \& Agnew, 1998). 


\section{Summary and Organization of the Study}

This chapter included the background to the study, the statement of the problem, the purpose statement, and the theoretical framework. The significance of the study, delimitations, and definition of terms were also presented. Chapter 2 includes a review of the literature relevant to cross-cultural mentoring. Chapter 3 includes the method and research design using the phenomenological framework, followed by my autobiography and assumptions related to the study. Sampling criteria and procedures for data collection, data analysis, data management, integrity measures, and limitations to the study are also discussed. The findings on cross-cultural mentoring relationships of IndoCaribbean students are presented in Chapter 4. Discussion, implications, and recommendations for further research are provided in Chapter 5. 


\section{CHAPTER II \\ REVIEW OF THE LITERATURE}

Culturally responsive mentoring practices within the learning environment may empower protégés “intellectually, socially, emotionally, and politically by using cultural referents to impart knowledge, skills, and attitudes" (Ladson-Billings, 1994, p. 18). This chapter includes a review of relevant literature surrounding cross-cultural mentoring and Indo-Caribbean culture. The chapter is divided into four main sections: (a) understanding identity (b) understanding culture (c) understanding mentoring and cross-cultural mentoring, and (d) understanding Indo-Caribbeans.

\section{Understanding Identity}

This section begins with a definition of identity, and includes three aspects of identity: (a) cultural identity, (b) socio-cultural identity, and (c) ethnic identity. The section concludes with a discussion on immigrant identity.

\section{Definition of Identity}

Identity is the social categorization of a person or group, built upon membership rules, expected behaviors, and unique differences that set us apart from others (Appiah 2005; Fearon, 1999). Such categorization can be inherited or obtained through societal or cultural experiences that feed into our "emotions, feelings, and desires....[forming] social, political, economic, cultural, historical, and ideological structures" (Freire, 1998, p. 70). Identity may also be based on "genders and sexual orientations, ethnicities and nationalities, professions and vocations" (Appiah, 2005, p. xiv), which people claim and create within their lives. It can be viewed from the perspective of a single individual, or 
as collective groupings which allow us to combine our beliefs and behaviors with those of others (Appiah, 2005).

Identity helps to establish one's sense of "self, character, goals, and origins" (Fearon, 1999, p. 10), essentially, one's self-image. Self-image can be viewed as role or type identity, the former based on actions, behaviors, routines, or functions in particular situations. The latter, type identity, being shared "characteristics, in appearance, behavioral traits, beliefs, attitudes, values, skills (e.g., language), knowledge, opinions, experience, historical commonalities (like region or place of birth), and so on" (Fearon, 1999, p. 17). Each person's identity fills a significant role as it provides meaning and purpose to the individual, allowing him/her to become more engaged, enthusiastic and participative in everyday life (Wayne, Randel \& Stevens, 2006).

According to Erikson (1968), identities are discovered within social contexts, rather than created. By observing and reflecting, people become more complex and develop a global sense of self, within which they fill different roles, each holding a separate identity, such as a student, employee or leader (McEwen, 2003). Social roles, positions and functions allow us to create knowledge, become motivated, and actively engaged, and in doing so, also shape identity, because of our understandings, behaviors and interpretations (Holland \& Lachicotte, 1998).

As learners develop according to Chickering's (1969) model, they become more involved, begin to appreciate and accept differences, to cope with emotions, to build strong relationships, and to work toward their goals. As they develop, their identity is enhanced and they build a stronger sense of self-esteem and self worth. How they see themselves can be linked directly to their cultural, socio-cultural, and ethnic identity. 
Cultural identity. Cultural identity is the individualized foundation that holds specific and significant meanings for each individual (Holland \& Lachicotte, 1998). It is the social and cultural portal through which persons participate in activities, learn, behave, plan and act (Holland \& Lachicotte, 1998). People become who they are based on how their identity fits into their culture, and helps them participate in activities that are meaningful and relevant to them (Holland \& Lachicotte, 1998). Cultural identity stems from the behaviors, beliefs, values, norms, and political and economic struggles as members of an ethnic group (Sparks, 2002; Perez, 1998). This concept of identity applies across multiple disciplines, and intersects whenever there is an impetus for social and cultural change.

Individuals' concepts of what they believe or stand for are shaped by their own histories and cultural group memberships that should ideally build stable, consistent, and enduring identities (Erikson, 1990). People respond differently as they adjust to changes in their environments depending on the pressures within their own lives. Immigrants in particular, struggle with "marginality" that results from how they feel within dominant cultures or classes (Sparks, 2002).

The struggle to make meaning, to develop and grow, and to become engaged in learning is based on interpretations through cultural lenses (Perez, 1998). The extent to which people engage in learning is a function of their cultural identity, in that their culture serves as a filter for information (Perez, 1998). Information is interpreted and becomes contextualized through the learner's culture. Learning therefore results from connections formed between new knowledge, and existing social-cultural and historical contexts (Alfred, 2003). 
Socio-cultural identity. Socio-cultural identity develops from historical ideals that stem from social differences, resistance to boundaries, and group membership (Levinson, Bradley, Foley, \& Holland, 1996). It is socially constructed from history, internalized, and reframed to form impressions based on new circumstances, activities and interactions, leading to self-direction and stronger social relationships (Graf, Mullis \& Mullis, 2008).

Transitions through activities, times and places affect the identity of minority persons in that they learn to identify the other, to form an identity themselves, and begin to differentiate themselves from others (Craftera \& Abreau, 2010). One's sense of identity can be reframed as a result of social or cultural changes and other major events, indicating that it is both fluid and multi-dimensional (Frable, 1997). Such shifts in identity help to us to adapt to life experiences, and motivate us to take action within our social spheres, and within various contexts (Katzenstein, 1996; Phinney, 1996b).

By taking action, we are able to manage our lives, and form stronger relationships with others. Social identity in this sense values others in the environment by how they view us, and by how we view ourselves, through their eyes. Based on observations and interpretations of past situations, the individual can determine what recourse is suitable or ideal for future scenarios (Holland \& Lachicotte, 1998).

Ethnic identity. Ethnic identity refers to the sense of belonging and pride that one feels from membership within a specific ethnic group (Phinney, 1992). Ethnic identity builds upon individuals' self-concepts, derived from the value and emotional significance of knowledge of membership within a particular group (Phinney, 1992). Ethnic identity may lead to emotional and motivational responses, that can enhance self- 
esteem, optimism, and accomplishment (Phinney, 1991; Phinney \& Alipuria, 1990) and build a sense of in-group belonging. Commitment to ethnic identity may be represented through practiced activities and group traditions.

Identity formation among ethnic minorities is more complex in Western society as they are confronted with differences between the values of their own ethnicity versus the values of the majority culture (Phinney, 1991). Those who do not identify with an ethnic group, or experience confusion or conflict over their ethnic group identity may develop feelings of inferiority, anxiety and depression (Parham \& Helms, 1985; Phinney, 1996b).

In-depth exploration of one's identity builds a stronger sense of self, and commitment in one's ethnic identity (Phinney \& Alipuria, 1980). "Meaningsembedded in unstated norms, institutional or standardized practices, and unspoken prejudices" (Minow, 1990, p. 374) can arise as a result of a person's ethnic identity and can lead to a sense of inequity and the demand for social change (Appiah, 2005).

Immigrant identity. Immigrant identity enables individuals to define themselves, regardless of how they are perceived by others, thereby building selfdeterminism and self-esteem, and maintaining control of their lives (Branch, 1994). For immigrants, "the dynamic nature of identity creates a space within which change is possible, a space where struggle can take place" (Sparks, 2002, p. 70). In this sense struggle can elicit change, adjustments and interactions which lead to different responses and behaviors. Challenges to identity occur when there is opposition within the dominant culture, issues of class, or subordination (Sparks, 2002).

Challenges that stem from international migration among immigrants and their descendants lead to social change and possibly oversimplification of their ethnic and 
cultural identities (Brubaker, 2004; Rumbaut, 2004). "Where social mobility is blocked by prejudice and discrimination, lower status group members may instead reaffirm their ethnic identity or adopt a panethnic [or overarching ethnic] label" as opposed to those who hold a higher status, and may tend to retain their parents' ethnic identity (Rumbaut, 1994, p. 756).

Identity points to that which is "allegedly deep, basic, abiding, or foundational... to be valued, cultivated, supported, recognized, and preserved" (Brubaker, 2004, p. 34). Conceptions of identity vary among theorists, scholars, researchers and immigrants indicating that identity is "multiple, unstable, in flux, contingent, fragmented, constructed, negotiated, and so on" (Brubaker, p. 38). It can be sought after, discovered, mistaken, sacrificed, or submerged (Brubaker, 2004; Foner, 1999). Understanding identities built upon historical narratives are crucial to understanding shared dispositions, collective activity and culture.

\section{Understanding Culture}

Culture has the "capacity for constantly expanding the range and accuracy of one's perception of meanings" (Dewey, 1916, p. 145). Culture may be viewed as a foundation for mentoring relationships since mentoring is a learning relationship in which understanding, interaction, and appreciation of another's beliefs, identity and culture (Zachary, 2000) are critical. This section includes a definition of culture, followed by an examination of how culture is connected to identity, emic and etic views of culture, and socio-cultural contexts. 
Definition of culture. Culture is defined as "the behavioral, symbolic, and belief systems shared by a group of people in order to define themselves, to relate to one another, to communicate, to interpret experiences, and to cooperate in adapting to their environment" (Giles, 1998, p. 13). In a more expansive view, culture is built upon the collective ideas, conditioned responses, and habitual patterns that are either learned or copied (Linton, 1936). It includes beliefs, art, morals, customs, and other habits acquired by man (Taylor, 1871) developed over time, that emerges through interaction within a particular society. Culture includes the general and specific guidelines about life and the decisions it entails, passed down through generations (Patterson, 2000), to help members gain acceptance within a particular society or environment.

Culture derives primarily from the ethnic backgrounds of individuals and is viewed as distinct spiritual, material, intellectual and emotional features or any given group, that includes their lifestyles, interactions, value systems, traditions and beliefs (United Nations Educational, Scientific and Cultural Organization, 2002). It is socially transmitted through generations, and serves as a mechanism for decision-making through all life experiences (Patterson, 2000).

Culture evolves over time primarily because of occurrences between the present and the past (Levine, 1977). This leads to social and cultural formations, allowing individuals to interact and learn, collaborate and function in relation to others (Holland \& Lachicotte, 1998) as it shapes the internalized self-meaning of individuals.

Value of culture. Thinking, beliefs and values, although a crucial aspect of learning relationships, has in some instances remained distinct from the culture and background of those involved (Banks \& Banks, 1995). Since individuals may identify 
with more than one culture, they may hold multiple identities, however, they need to recognize one unified culture in order to avoid conflict in the face of challenge (Holland \& Lachicotte, 2007). In the United States for instance, culture is influenced by the backgrounds and traditions retained and practiced by the different races and ethnicities that converged from decades of immigration and consequently is slow to change because it is deeply ingrained into members of any given group.

Although culture may elicit multiple interpretations and behaviors, it has the capacity to engender social and cultural change when specific cultural groups work collectively (Holland \& Lachicotte, 2007). Individuals within the same culture may have different cultural values or interpretations based on their life experiences and events in their environment. Hence, in order to determine the content of a culture, it is necessary to examine life experiences and events distinctly among the personalities of a general society (Linton, 1936). Understanding life experiences and events within one's environment builds cultural awareness through learned behaviors and beliefs, also known as enculturation.

Culture enhances social character and consciousness as individuals become more aware of their relationship to others, and how they adjust their perceptions, emotions, motives, needs, memories and feelings based on increased or newfound awareness (Ratner, 1991). Individuals remain voiceless unless they are defined or interpreted through others. Education as a cultural practice should offer a sense of identity, place and hope, where "recognition of the uniqueness of each voice...can be heard" (hooks, 1994, p. 186). 
Emic and etic views. The concept of emic versus etic approaches to culture developed in the early 1960s, from the linguistic usage of the terms phonemic and phonetic coined by Kenneth Lee Pike (Goodenough, 1970; Harris, 1980). Those within a culture provide an emic or internal, subjective view, whereas those with etic views are more likely outsiders, who provide objective or universal accounts based on what they have read or observed. Emic views contain more meaningful information, whereas etic details may be more neutral, and more generalized, hence applicable to other cultures. In spite of the different views, however, emic and etic views may also intersect.

Although multiple cultural values are viewed as beneficial, in some instances they were considered hindrances which lead to poverty, injustice and underachievement among certain ethnic groups (Patterson, 2000). Cultural history, experiences, or life which differs from the more dominant ideologies are typically considered threats (Freire $\&$ Macedo, 1987). Attempts to examine and fully define culture raises questions of struggle, transformation, dominance, social identity, subordinate voices, and the issue of subjective difference within social groups (Giroux, 1992).

Cultural values influence whose voice is heard, who obtains the resources they need (Tisdell, 1995), and ultimately who progresses. By disregarding the cultural needs of others via education practice, industry, or media, we may unintentionally disempower, oppress, silence or marginalize them (Freire \& Macedo, 1987).

Culturally responsive education practices should accommodate cultures motivated by both intrinsic and extrinsic rewards, the former being meaningful learning, the latter, being grades, increased salary or status (Wlodkowski, 1997). By closely examining culture, we can identify insights that may enhance relational development. In order to 
build and sustain motivation among all cultures, culturally responsive educators should create a respectful atmosphere, develop personable dispositions, consider all learners' perspectives and values, and build competence related to learner values (Freire, 1987; Wlodkowski, 1997).

Socio-cultural contexts. Understanding the socio-cultural contexts of learners, within their various spaces, and through their life experiences gives voice to and contextualizes their multiple perspectives within the socio-cultural learning environment (Perez, 1998). "We need to develop an alternative discourse...of how ideology, culture, and power work within...societies to limit, disorganize, and marginalize...individuals" so that we may help others reclaim the authorship of their own lives (Freire \& Macedo, 1987, p. 6). Individuals' cultures are a gateway for their beliefs, attitudes and values which serve to reinforce academic achievement. As such, cultural identity should remain intact within the learning environment and should serve to reinforce or validate students' beliefs (Alfred, 2002).

Cultural sensitivity is an understanding that cultural differences and similarities exist, without considering one better than the other or that one is right or wrong (National Maternal and Child Health Center on Cultural Competency, 1997). Cultural sensitivity applies to "feelings, thoughts, nonverbal behaviors, and ideas [that] are important in interpersonal communication and are culturally influenced and learned" (Wittmer, 1992, p. 3). Learning cultural sensitivity enhances mentors' and mentees' "empathy, interest in others, caring, personal awareness... and understanding" (p. 3). Cognitive empathy, or knowledge of others' culture builds an understanding of their history, values, lifestyles, 
thinking and opinions (Wittmer, 1992). A lack of awareness of others' values and beliefs affects how we interact and communicate with them.

\section{Understanding Mentoring and Cross-Cultural Mentoring}

This section begins with a definition of mentoring followed by a discussion on the functions and benefits of mentoring. Next are the educational, social and relational functions of mentoring, mentoring phases, a chronological review of mentoring models, and a discussion of the literature on cross-cultural mentoring and cross-cultural mentoring of minority groups in the United States. The section concludes with a discussion of the literature related to how culture affects mentoring relationships.

\section{Definition of Mentoring}

Mentoring is defined as an "intense caring relationship in which persons with more experience work with less experienced persons to promote both professional and personal development” (Caffarella, 1992, p. 38). A more inclusive definition describes mentoring as "a powerful emotional, and passionate interaction whereby the mentor and protégé experience...intellectual growth and development" (Galbraith \& Zelenak, 1991, p. 126). A mentoring relationship typically occurs between 2 individuals, the mentor who provides support and guidance, and a mentee or protégé who participates and collaborates with the mentor in activities or interactions related primarily to the protégé's growth and achievement.

Mentors possess more experience, influence, and achievement than protégés within a particular organization or environment (Jacobi, 1991) and can provide guidance related to work, skill acquisition, and social or emotional support (Davidson \& FosterJohnson, 2001). Protégés benefit from the mentor's knowledge, contacts and guidance 
and also find value from interpersonal dialogue, collaborative critical thinking, planning, reflection, and feedback (Galbraith \& Cohen 1995).

\section{Functions and Benefits of Mentoring}

Mentors facilitate learning, by challenging, stimulating, and provoking critical thinking, to help protégés become aware of any limiting habits of mind, values or actions (Cranton, 2002) amid diverse environments or contexts. Effective mentors are empathetic to challenges while helping the protégé find ways to enhance learning and development. "The idea of learning as a transaction--an interactive and evolving process between mentors and adult learners--is considered a fundamental component of the adult mentoring relationship" (Galbraith \& Cohen, 1995, p. 17).

The role of a mentor is quite similar to the role of a teacher in a student's life. A mentor may often be referred to as a "coach, trainer, instructor, tutor, guide, friend, counselor, and even guru” (Cooper, \& Miller, 1998, ๆ 5). An authentic mentor should challenge the creative freedoms and autonomy of the protégé by allowing the protégé's "life, dreams, and aspirations" to remain entirely his own, not those of the mentor, a dangerous and paternalistic possibility (Freire 1997, p. 324). Ideally, the mentor should fill a libertarian role, enabling protégés to take their own journeys, and create their own their histories rather than become replicas of their mentors (Parks, 1986). A true mentor should realize that the protégé has his own goals and aspirations, and that the mentor should serve as a catalyst for helping the protégé develop his personal and professional goals, by increasing opportunities and potential for self-direction and empowerment.

Mentorships within higher education currently expand across the arts, business and sciences, across age levels and long distances, and recently, amid diverse cultures 
and expanding technology (Bierema \& Merriam, 2002; Brown, 2003; Hargreaves \& Fullan, 2000; Mujtaba, 2006). The concept stems from Greek mythology where Odysseus trusts Mentor to raise his son Telemachus (Cohen, 1995). Students, faculty, staff, administration, and the wider community constitute the complex ecology of higher education in a mentoring environment that can provide knowledge, challenge, support, and inspiration (Daloz, Keen \& Parks, 1996). In the last quarter of the 20th century economic, cultural and global trends intensified financial pressures, employer demands and ethnic diversity (Lovett, 2002), thereby increasing the challenge of preparing skilled, specialized graduates to thrive in a largely multicultural environment.

Career functions of mentoring are reflected in the care mentors take to help protégés become more learned, and more autonomous (Greenleaf, 1977). Mentors engage protégés with challenging work and assignments, coach them through knowledge sharing, relationship and skill building, sponsorships, and even by shielding them from potential threats within the environment (Kram, 1985). This enables the protégé to perform specific tasks more readily, to become more confident, to seek new goals and to interact more dynamically within the organization (Hersey \& Blanchard, 1995). Mentoring relationships enhance career development and leadership skills (Blake-Beard, 1999; Falconer \& Hays, 2006), adjustment within organizational cultures (Stevens, 1990; Taporek, 2005), and support succession planning and gender equity (Ingram, Bruning, \& Mikawoz, 2009; Mattis, 2001) for both mentor and protégé.

Mentors and protégés learn from each other through networking, counseling, guiding, instructing and modeling, guided by constructivist thought where "learning means constructing, creating, inventing and developing our own knowledge" (Beyene, 
Anglin, Sanchez, \& Ballou, 1996, p. 100). The collaborative nature of mentoring relationships increases the sense of mutuality and interdependence, and enhances the opportunity for those who traditionally do not seek support (Mullen, 2007). Shared cognition through personal and group interactions extends knowledge structures and enables a cognitive representation of mentoring within dyadic and group mentorships, whether formal, or informal.

Dyadic mentoring is a one-on-one mentoring relationship whereas group mentorships are lead by one mentor, with multiple protégés. Dyadic mentoring is especially helpful as it provides the positive role modeling and personalized attention protégés need to succeed in the university environment and beyond (Hurte, 2002).

Formal mentoring occurs when a third party or entity manages activities between the mentor and protégé, for a specified amount of time, and requires specific goals or outcomes (Kram, 1988), often on a contractual basis. Formal mentoring may include some aspects of informal mentoring relationships such as voluntary participation, choice in the matching process, and focus on the protégé (Ragins, Cotton, \& Miller, 2000). Informal mentoring occurs based on mutual interests or developmental needs of a protégé (Kram, 1988), and may be for an unstructured duration or outcome. Informal mentoring "involves greater commitment and risk" yet it builds a more enduring sense of relationship (Mullen, 2007, p. 304).

\section{Educational Functions of Mentoring}

Mentoring in higher education focuses on personal, professional, and career concerns of the protégé. At the undergraduate level mentoring focuses on engagement, campus integration, and socialization among students and administration (Astin, 1985b; 
Pascarella \& Terenzini, 1991). In graduate and post-graduate programs mentoring relationships ideally refer to interactive partnerships that evolve, building a strong sense of self-awareness and fulfillment, toward a fruitful academic experience (Luna \& Cullen, 1998; Nettles \& Millett, 2006). Specifically, the experience should support students' development of cognitive maps, to understand their programs and disciplines as they progress toward future careers (Lovitts, 2001). Best practices of mentoring relationships include "co-mentoring, cohort learning [and] cross-cultural mentoring" as these enhance "quality learning and performance" (Mullen, 2007, p. 300).

Relationships with faculty and advisors who serve as mentors and role models encourage active and authentic participation and integration into learning communities (Herzig, 2002). Mentoring by faculty, advisors, and peers are critical factors toward students' engagement in professional activities, successful research productivity and publication, overall program satisfaction and degree completion (Davidson \& FosterJohnson, 2001; Nettles \& Millett, 2006; Nielsen \& Rocco, 2002). The nature and degree of mentoring, together with persistence, institutional support and student integration into social and academic communities support students' goals and enhance their commitment toward degree completion.

Faculty. Faculty mentors or faculty advisors provide "critical mentoring" by helping to resolve stressful situations, mediating against culture shock, making contacts and helping students gain entry into professional and academic communities (Paglis, Green, \& Bauer, 2006, p. 452). The faculty mentor should be a successful researcher with a progressive research agenda, who is willing to share research responsibilities and rewards with the protégé, while demonstrating genuine interest in the growth and 
development of the protégé and his work (Green, 1991; Wright-Harp, 2008). Students are able to share intellectual ideas, research methodologies, research productivity and publication success with faculty mentors (Gentry, 2004; Lyons \& Scroggins, 1990).

Faculty support enhances student achievement of their academic goals, (White, 2006). Faculty mentors participate in "advising, assisting, coaching, collaborating, compensating, counseling, guiding, leading, learning, socializing, supporting, teaching, and tutoring" (Mullen, 2007, p. 300), at a greater level of intensity. They can also help protégés reduce the stresses of time management issues, selecting and narrowing their research topics and increasing scholarly activity.

The dearth of tenured faculty members from ethnic minority groups requires recruitment of more minority faculty (Hughes, 2002). Faculty who can be sensitive, sympathetic toward the needs of minority students, can provide feedback without being biased, can accompany students to conferences, can provide job hunting strategies and oral advocacy are greatly needed (Greene, 2002; Smith, 2001).

In cross-race relationships, mentors' basic beliefs and worldviews, understanding of cultural differences surrounding perceptions, personal power, and recognition of differences in communication and conflict management styles can benefit minority protégés (Jackson, 2001; Singh \& Stoloff, 2003). Faculty mentors can teach students of color in graduate schools how to handle racism -- both conscious and unconscious, how to educate their future colleagues and peers about privilege, and how to serve as mentors to students of color (Reyes, 2004). Understanding perceptual biases, attitudes, judgments and the differences of culture and language that students bring to campus leads to stronger support networks for students of color (Shultz, 2001). 
Peers. Peers who may be further on into their programs, or along a similar academic path, can also serve in a mentoring capacity by providing support and encouragement to new students as they transition into doctoral programs (Wright-Harp, 2008). An ideal peer mentor should possess strong interpersonal skills and understand the value of confidentiality, assist in a reliable and disciplined manner and be able to share personal strategies around obstacles or challenges. The exchange of information from peer mentors can be motivating for both peer mentor and the protégé as they both benefit from the shared discussion and insights. Peer mentors themselves improve their own mentoring and leadership skills through these interactions.

Graduate students. For graduate level students, mentorship presents opportunities for establishing publishable forms of research (Nielsen \& Rocco, 2002), and encouraging commitment to success in higher education (Cole, 2001). Graduate programs should emphasize a high-quality research experience, matching students with faculty mentors in networking forum (Roach, 2001). Programs that incorporate collaboration, fellowship, support and networking are able to produce long-term results through "cognitive intellectual stimulation derived from a shared vision" (Menchaca, Estrada \& Cavazos, 2000, p. 12). Graduate level minority students are often underrepresented in the biological and physical sciences, as they choose business/management, engineering, law and medicine, because these areas present deeper historical community links, and advocacy for social and political change (Hayes, 2002; Softky, 2000).

Surveys reflecting satisfaction with doctoral programs and mentoring support from advisors and faculty reflect the largest area of satisfaction from "meaningful advice, 
encouragement, and availability" (Washbern-Moses, 2008, p. 259). These students valued the individual guidance and encouragement they received during their programs but would have appreciated support is navigating the hurdles that they experienced. Although some students have reported engaging mentoring relationships, there are reports on less than satisfying and even disappointing mentoring and support from faculty (Nyquist \& Woodford, 2000). This is unfortunate since there are students who considered mentoring relationships as the most important aspect of graduate education (Henrich 1991).

Minorities. Low-income students, first-generation students, specific immigrant groups, women and students of color often complete degrees at unacceptably low rates (Davidson \& Foster-Johnson, 2001; Freeman, 1999; Lee, 1999; Meritosis, 2005; Nettles, 1999). Mentoring serves to increase aspirations, persistence and achievement of minority students who would otherwise not attend or succeed in college (NATN, 2002; Fields, 2002; Hurte, 2002; Mayo, Murguia, \& Padilla, 1995; Shutlz, Coulton \& Coulton, 2001; Tinto, 1993). Through proactive and personalized academic advising and encouragement mentors help minority students through the educational process, to take advanced courses, and to improve overall degree completion as they deal with the intricacies of the institutions they attend (Hurte, 2002; Mayo et al, 1995; Shultz et al, 2001; Tinto, 1993; Young, 2003). Mentoring is also included among resiliency factors such as scholarship monies, familial support, opportunity to serve as a role model, and friends/peer support which enhance the success of minority students (Holt, Mahowald \& DeVore, 2002).

Women. Women encounter mentoring challenges as students within the university environment when they seek mentors from among faculty, staff, deans, senior 
leadership, alumni, and community leaders (Rosser, 2007). Upon entering the workplace in many instances they have difficulty initiating and building mentoring relationships with male leadership; or finding a female leader to serve as a mentor (Bauer, 1999; Hansman, 2003; Ragins 1997). Unfortunately, when a female seeking a mentor is Black, or some other minority, there is the risk that her double-minority status of being both a minority and a female further confounds availability of good mentors (Johnson-Bailey \& Cervero, 2002).

Cross-gender mentoring, while it does occur, appears challenging because of the risks of sexual harassment, unrealistic expectations, or inequitable needs/demands of what essentially becomes a power relationship (Johnson-Bailey \& Cervero, 2002). Cross-gender mentoring requires open discussion on power, biases, and interests of both participants to ascertain that goals and expectations are met. Although female mentors are available, they tend to provide psychosocial support in the form of advocacy, or to defend against discrimination, while male mentors focus on career-related support (Levesque, O'Neill, Nelson \& Dumas, 2005).

Women in particular experience discrimination, and therefore those participating in mentoring relationships should consider sensitivity training so that both mentors and protégés learn about positions of power, issues of race, class, gender, ethnicity and sexual orientation (Hansman, 2003). This averts the possibility of mentors being ill equipped to handle issues of unfairness or inequity (Bauer, 1999).

\section{Social and Relational Functions of Mentoring}

Social and relational functions of mentoring include the meaning making and value outcomes of mentoring diverse populations. Social exchange within mentoring 
relationships refers to the quality and depth of the mentoring relationship based on attention, mutual interest, protégé contribution, support, reduced stress, shared identity and interpersonal comfort (Ugrin, Odom, \& Pearson, 2008). Researchers found that academic versus career participants' goals and relational outcomes were positively affected by strong social exchange.

Proximal mentoring draws from Vygotsky's zone of proximal development to define a proximal mentor as one who provides content and feedback, clarifies objectives, guides and models necessary expertise through educational processes (Gunn, 2008). Pluralistic mentoring links human diversity to mentoring by way of etic or theoretical presuppositions and philosophical positions and emic issues related to leadership culture and socialization (Wilks, 2008). The premise is that mentors can lead protégés to reflect on their thinking to become more tolerant, trusting, empowered, and democratically conscious so as to improve behaviors, attitudes, and relationships, and in so doing, enhance their development.

Intercultural mentoring uses implicit leadership theory that a culture's beliefs are shared by its leaders, to understand the relationships of spiritual leaders with Latin American protégés (Irvin, 2007). Shared moral and spiritual values are viewed as significant in personal relationships and daily life and work to support organizational commitment and productivity. Shared congruent values of love, joy, peace, patience, kindness, goodness, faithfulness, gentleness and self-control are viewed as necessary qualities to lead others toward improvement of the human condition, ethnic strife, economic development, and spiritual value. 


\section{Development of Mentoring Relationships}

Mentoring relationships generally become more developed over time, and vary according to the nature of the relationship. Table 2 shows how mentoring relationships among protégés as doctoral students (Mutchnick \& Mutchnick, 1991), novice teachers (Katz, 1995), and junior managers (Kram, 1985), and their mentors develop.

Table 2

Development of Mentoring Relationships

\begin{tabular}{|c|c|c|}
\hline $\begin{array}{l}\text { Mentor - faculty advisor } \\
\text { Protégé - doctoral student }\end{array}$ & $\begin{array}{l}\text { Mentor - teacher educator } \\
\text { Protégé - novice teacher }\end{array}$ & $\begin{array}{l}\text { Mentor - senior manager } \\
\text { Protégé - junior manager }\end{array}$ \\
\hline $\begin{array}{l}\text { Assessment of situation -- } \\
\text { becomes acclimated to } \\
\text { institution, department, and } \\
\text { faculty, considers relevant }\end{array}$ & $\begin{array}{l}\text { Initiation-chooses field, } \\
\text { defines relationship, goals, } \\
\text { roles, logistics, and } \\
\text { commitment to vocation. }\end{array}$ & $\begin{array}{l}\text { Initiation -- relationship } \\
\text { begins, coaching, role- } \\
\text { modeling, challenges to } \\
\text { meet pre-determined goals. }\end{array}$ \\
\hline $\begin{array}{l}\text { Filtering and identification } \\
\text { - determine research } \\
\text { interests, projects, and }\end{array}$ & $\begin{array}{l}\text { Consolidation -- deeper } \\
\text { understanding of role and } \\
\text { characteristics of individual } \\
\text { children. }\end{array}$ & $\begin{array}{l}\text { Cultivation - deeper } \\
\text { emotional bond, increased } \\
\text { interactions, deep } \\
\text { friendship. }\end{array}$ \\
\hline $\begin{array}{l}\text { Selection, recruitment, and } \\
\text { affiliation -- formally work } \\
\text { on joint research project/s. }\end{array}$ & $\begin{array}{l}\text { Renewal-functions } \\
\text { competently, seeks new } \\
\text { challenges and new } \\
\text { knowledge. }\end{array}$ & $\begin{array}{l}\text { Separation -- autonomy } \\
\text { challenged, blocked } \\
\text { opportunities, } \\
\text { incompatibility. }\end{array}$ \\
\hline $\begin{array}{l}\text { Nourishment and } \\
\text { maintenance -- } \\
\text { professional guidance on } \\
\text { role of faculty, tenure or } \\
\text { promotion, career and } \\
\text { work/life balance. }\end{array}$ & $\begin{array}{l}\text { Maturity -- continued } \\
\text { interest, expertise, ideas, } \\
\text { philosophy, and the } \\
\text { teaching profession. }\end{array}$ & $\begin{array}{l}\text { Redefinition -- } \\
\text { development of a peer-like } \\
\text { relationship. }\end{array}$ \\
\hline $\begin{array}{l}\text { Separation -- student } \\
\text { completes degree and } \\
\text { graduates. Relationship } \\
\text { continues via email, } \\
\text { telephone or otherwise }\end{array}$ & & \\
\hline
\end{tabular}

Sources: Katz, 1995; Kram, 1985; Mutchnick \& Mutchnick, 1991 
At the initial stages mentoring relationships begin, and mutual understandings and goals are determined. Relationships mature based on protégés' needs in each learning environment, and may end, or may become peer-like friendships.

\section{Evolution of Mentoring Models}

Levinson, Darrow, Klein, Levinson, and McKee (1978) designed one of the earliest mentoring studies based upon the developmental works of Freud, Erikson and Jung. In this study 40 older men from various occupations guided, supported and eased the transition into adulthood for younger men in the novice phase of their lives. Mentoring later became a popular practice in the fields of business and education (Daloz, 1999), and has now expanded into a multidimensional developmental phenomenon.

Mentoring models have evolved over the years starting with Kram's classic model, to the present models which are multicultural, complex and technological. The following section includes a description of published mentoring models from the past three decades.

Kram (1985) developed a classic mentoring model on the premise that mentoring functions "differentiate developmental relationships from other work [centered] relationships" (Kram, 1985, p. 22). The classic mentoring model (Kram, 1985), focused on career and psychosocial functions that built sponsorship, exposure, coaching, and challenge to enhance protégés' advancement through mentoring relationships with senior managers. Mentors promoted protégés' self confidence, identity and efficacy through role modeling, acceptance, confirmation, counseling and friendship. Elements of this classic model are reflected in Daloz (1986) Dimensions of Response to Environmental Variation, seen in Figure 1, which shows how mentors influence the environments of 
adult learners, based on their interactions within these environments, and the constant changes, or dynamics within these environments.

Figure 1. Daloz (1986) Dimensions of Response to Environmental Variation

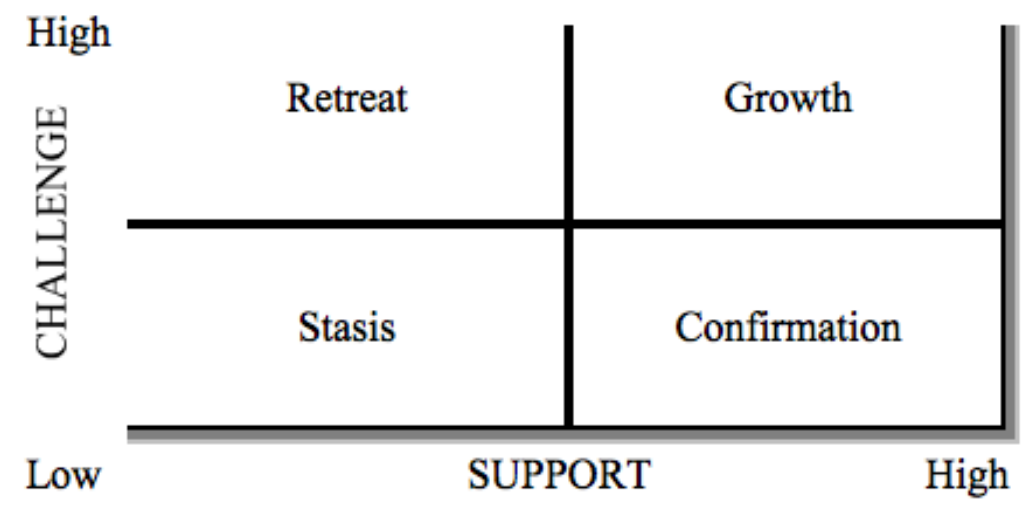

Figure 1. Support and challenge are key factors which allow mentoring relationships to either meet or conflict with learners' needs (Daloz, 1986).

Mentors' experiences here offered maps that protégés could use to navigate their new environments. A bridge is built across environments allowing, growth, transition, and meaning making because of the connections and encouragement along the way (Kegan, 1982; Lave \& Wenger, 1991).

Mentors' and protégés' responses within the various environments create dialogues or silences, which can either assist or hinder as they develop insights, vision, shifts in perception and growth. Mentors can provide support which holds the protégé in a safe place, where trust and growth develops. This affirms the protégé's sense of worth, and convinces her to stay where she is, described as stasis, or to move forward, described as confirmation or growth (Daloz, 1986). Mentors' empathy helps the protégé feels that he/she is understood, and there is congruence between them, which leads to trust in the 
relationship. Mutual trust and support enable the mentor to move forward. Growth that stems from basic trust enables the protégé to take risks in defining the self, sharing and giving to others, and finding meaning out of uncertainty (Erikson, 1963).

Kalbfleisch and Davies (1993) later developed an interpersonal model of mentoring built upon close, interactive, strategic and routine communication that personalized and intensified mentoring relationships. This model was expanded in the Kalbfleisch and Keyton (1995) model of characteristics of mentoring relationships which focused on relational, interpersonal and communication perspectives to develop women's career paths, work environments, same-sex mentoring needs, and authentic involvement. Kalbfleisch and Keyton believed same sex mentoring averted the challenges caused by cross-gendered pairings, however the lack of females to serve as mentors was problematic.

Women, culture and multiculture, particularly became the focus when age, career path development and family/work life became a challenge (Schweibert, Deck, Bradshaw, Scott, \& Harper, 1999). Women who began careers later because of family oriented responsibilities required more intense mentoring, and non-hierarchical same-sex relationships. Alternatively, gender related career development models based upon both heterogeneous and homogenous mentoring relationships showed that male mentors of female mentees provided greater levels of support in career development than did a same sex combinations (Sosik \& Godshalk 2000).

The multicultural feminist model (MFM) of mentoring was designed to include ethnicity (Benishek, Bieschke, Park, \& Slattery, 2004). The MFM model identifies differences between mentor and protégé, determines their relevance to the mentorship 
and to participants' professional development, builds a relational exchange that respects the differences, and examines gendered or cultural tensions that may exist and addresses them. This model is a revision of Fassinger's (1997) feminist model of mentoring which harnesses the power differentials between mentor and protégé, acknowledges those power differences and uses them to empower the protégé.

Globalization, technology and constantly changing work environments have inspired new models of mentoring (Marquardt \& Loan, 2006) designed for e-mentoring, academic settings, global environments, racial dynamics, expatriation, multiple mentoring, and diversity. For instance Single and Single (2001) developed a model of structured e-mentoring which uses electronic interfaces across three mentoring phases: planning, program structure and assessment. Firstly planning would require recruiting participants, managing expectations, then matching dyads. Program structure required training, coaching and group mentoring, while assessment included involvement, formative, and summative evaluations. Later on, Rickard (2007) developed a multidimensional systems approach to e-mentoring designed to increase and evaluate effectiveness given the complexity involved. This model considered the nature and quality of the partnership, program structure and content, use, satisfaction and impact of the e-mentoring relationship.

Kunselman, Hensley and Tewskbury (2003) developed three mentoring models for new or veteran academicians to establish mentoring relationships. They suggested continuing a mentoring relationship with a graduate school mentor or a dissertation advisor, building a relationship within the new environment, or building a relationship in the same field, but at a different institution. Wright-Harp and Cole (2008) later 
developed a more representative multiple mentor model designed to reduce attrition, to enhance student success in academic environments, and to ease transitions into professional careers. This required mentors at various ages, with different experiences with varied skill sets and included academicians, researchers, clinicians, peers, and career or professional development mentors. Although this model was developed to enhance minority and male success in the discipline of human communication sciences and disorders, it is applicable in all fields especially those that lack minority participation. Crocitto, Sullivan and Carraher (2005) developed a global mentoring model to demonstrate how expatriates, career workers employed across international locations progress through learning cycles when aided by multiple mentors. Since expatriates' career cycles last 1 to 4 years versus traditional lifetime career stages, the expatriate learning cycle was developed to include pre-departure, onsite and repatriation and as such requires mentors at various locations with information, advice and support.

Blake-Beard, Murrell and Thomas (2007) developed a revised process model of racial dynamics in developmental relationships which further extended Thomas' (1993) model on racial dynamics in cross-race development. In Thomas' model, cross-race perspectives could be either complementary, in that they were mutually supportive, or non-complementary, and required strategies for managing racial differences. BlakeBeard, Murrell and Thomas' (2007) revised model seeks to remedy denial and suppression, and to enhance direct engagement or advocacy as four distinct interaction strategies that could result from developmental relationship characteristics. Balance in work group relational demography, race relations, power dynamics and diversity relations within organizational cultures, power and race relations, racial awareness, trust, and 
racial group identity serve as precursors to cross-racial relationships. The outcomes are interaction strategies for when denial or suppression arise, and to enhance direct engagement and advocacy. Denial and suppression are viewed as strategies used to avoid cross-racial interactions, often because of negative attributions which stem from group or organizational culture. Direct engagement and advocacy are proactive strategies which encourage positive relationships characteristics. Advocacy requires a process of change throughout the organization, as opposed to mere engagement.

Existing mentoring models speak to relational practices designed to build advocacy and to enhance development in various setting. Globalization has however impacted communities of practice within organizations, business units and across company boundaries such that mentoring relationships require "shorter connections...to multiple mentors, successive or simultaneous" (Marquardt \& Loan, 2006, p. 34). Workplace trends are evolving to create learning organizations, technological, global and diverse enterprise, knowledge systems, emergent and innovative leadership practices (Marquardt \& Loan, 2006), and consequently, mentoring models have been and continue to be adapted to meet expanding mentoring needs. There remains a need to expand mentoring models and research based on new paradigms of combined antecedents such as gender, race, ethnicity and personality in conjunction with mentoring processes and desired outcomes (Kram \& Ragins, 2007).

\section{Cross-Cultural Mentoring}

Cross-cultural mentoring occurs when both mentor and protégé in the mentoring relationship are from different cultures. Cross-cultural mentoring relationships encompass participants' “values, beliefs, and behaviors...defined by nationality, 
ethnicity, gender, age, physical characteristics, sexual orientation, economic status, education, profession, religion, organizational affiliation, and any other grouping that generates identifiable patterns" (Bennett \& Bennett, 2003, p. 150). Mentors and protégées from different cultures confront varied experiences, mental models, identities, and goals all of which increase the capacity for conflict (Stanley \& Lincoln, 2005).

Benefits. Cross-cultural mentoring offers distinctive benefits to both mentor and protégé. Unity and acceptance between a mentor and protégé increases awareness of different backgrounds, broadens perspectives, and leads to emotional satisfaction, increased creativity and productivity (Brinson \& Kottler, 1993). A harmonious, crosscultural mentoring relationship achieved through mutuality within common interests, can enhance a protégés academic, personal and professional success (Levinson, Darrow, Klein, Levinson, \& McKee, 1978). Cross-cultural mentoring can also promote an understanding and appreciation of multicultural differences (Galbraith \& Cohen, 1995) however, we should not assume that members of all ethnic groups can integrate into and embrace the cultures of the majority (Cox, 1993).

Cross-cultural understanding and interaction allows mentors and protégés to share and understand each other's cultural backgrounds, and to understand the different types of conflict that can arise (Crutcher, 2007). As a learning relationship, mentoring requires a lens that can be adjusted to various relational dynamics, an understanding and ability to compromise without being patronizing, and an appreciation of another's beliefs, identity and culture (Zachary, 2000). Through a strongly developmental relationship (Galbraith \& Cohen, 1995) mentor and protégé can explore cultural experiences from each other's point of view, and can develop a stronger understanding of each other's needs and 
expectations by appreciating differences in values, beliefs, norms, or attitudes. Empathy “characterized by mutuality" (Jordan, 1997, p. 20) enables mentors and protégées to become more trusting and supportive of each other.

Perceptions. Through sociohistorical circumstances society has allowed monolithic groups to rule, manage and practice "self-constituting acts which produce history" (Ratner, 1991, p. 45). Dominant cultures presently establish norms, expectations and values, and determine which practices are unsuitable or inferior (Amstutz, 1999). Perceptions of inferiority causes those in minority cultures to develop resistance to, and to require additional time to adjust to dominant cultures, while simultaneously allowing their own cultural identity to become submerged (Amstutz, 1999; Vickers, 2002). A homogenous approach to mentorship which assumes that the dominant culture has the upper hand and is capable of being the better mentor cannot sufficiently support all protégées (Johnson-Bailey \& Cervero, 2002). By encouraging mentorships with a dominating influence from one ethnic group over others we may unintentionally propagate inequalities.

In cross-cultural mentoring relationships the structure of our social lives cannot be left at the classroom door (Johnson-Bailey \& Cervero, 2002). However, bringing our social lives into the classroom increases the potential for culture clash. This can arise when socialization within another culture does not occur, and individuals' thinking, behaviors and beliefs collide with those whose views, beliefs and expectations remain constrained (Cleminson \& Bradford 1996). Unfortunately, cultural pluralism maintains that individuals can remain effective when they adapt to the dominant culture (Hraba \& 
Hoiberg, 1983). Such a perception can create biased assumptions on either side of the mentoring relationship.

Mentors benefit from understanding of their own personal prejudices and attitudes towards other cultures, and an awareness of their protégés' perspectives as well. Prejudice is defined as an aversive or hostile view of persons who simply belong to a group, and are presumed to have the objectionable qualities of that group (Allport, 1954). Prejudicial feelings rooted in bigotry, discrimination, narrow-mindedness, injustice and historical biases of either the mentor or protégé can evoke feelings of mistrust, and so can undermine the mentoring relationship. Knowledge of existing prejudices among cultural groups can help the mentor differentiate between honest and prejudicial actions, reactions or comments. Mentors need to be particularly sensitive where a lack of knowledge about the protégé's cultural experiences in the formal educational setting may be perceived as the protégé's indifference or stereotypical behavior toward the mentor.

Events in society, publicized via the media and events on college campuses exacerbate the connection (or lack there of) between mentors and their respective protégés (Beyene, et. al., 2002) and can create biased assumptions from either side of the mentoring relationship. Empathy, through mutuality enables mentors and protégés to become more trusting and supportive (Jordan, 1997). Deeper dialogues and further exploration into specific cultural perspectives could derive more valuable and meaningful mentorships. Mentorship is not necessarily about matching races or social standing, but finding individuals willing to establish trust, advise, challenge, motivate and encourage collaboration and initiative. 
Although the concept of mentoring is reflected in early Greek mythology, the body of research took root around 1958 when Carl Jung described the archetype, function and presence of a mentor (Daloz, 1999). Initial studies focused on mentoring in teacher preparation, leadership development, and nursing, however since the early 1990s peerreviewed studies have grown exponentially. Researchers have now explored gender differences, challenges, reflection, dialogue, values, attitudes, social justice, engagement, environment, identity, participant efficacy, motivation, perceptions, sexuality, and culture using various methodological formats to capture deeper meaning within mentoring contexts.

\section{Culture in Mentoring Relationships}

Cultural sensitivity builds cultural competence, a level of awareness, knowledge and skills based on congruent behaviors and attitudes that enable mutually effective cross-cultural interaction (Cross, Bazron, Dennis, \& Isaacs, 1989). Cultural competence enables integration, understanding and reframing of knowledge regarding individual and group cultures that can be used in a variety of settings and cultural contexts. A lack of understanding can negatively impact the mentoring relationship (Kim, 2007). Cultural competence enables definition of values and principles that support effective crosscultural relationships.

To further develop cultural competence, mentors and protégés should learn about diversity, dynamics of difference, cultural knowledge, and the need for assessment and measurement of cultural understanding (Kim, 2007). Understanding the need for intercultural competence is a reasonable starting point from which to develop cultural sensitive practices including approachability, receptivity, positive orientation, social 
openness, respect, cultural perspectives and flexibility among other factors (Elmer, 1986). Understanding the contexts, situations and worldviews that affect critical reflection, dialogue, behaviors, interactions, responses and praxis is enhanced when protégés are in cross-cultural relationships with culturally competent mentors (Rose, 2000).

The concept of relationship moves away from instrumental activities that support notions of an isolated individual self, toward interactional, emotional connections with others (Beyene, Anglin, Sanchez, \& Ballou, 2002). Relationships vary by culture, cultural settings and according to who is the minority in the mentoring relationship (Ragins, Cotton, \& Miller, 2000). The minority culture changes for instance when there is one or a few males in a female-dominated environment, or vice versa. Understanding the experiences of minority cultures and subcultures within cross-cultural mentoring dyads is critical.

\section{Minority Groups in the United States}

To date research surrounding culture as it relates to mentoring has explored attitudes, behaviors, knowledge, linguistics and motivation from a multitude of cultural perspectives (Elmer, 1986, Golde, 2005; Kim, 1997; Taylor, 1995; Ulmer, 2008). Researchers have also explored perspectives of local and minority cultures with a significant focus on African Americans (Carter, 2000; Chan, 2008; Dickey, 1996; Roeder, 2006; Taylor, 2000; White, 2006; Wilson, 1998). Researchers have examined subcultures of Latin America (Bernard \& Gravlee, 2005; Holst, 2006; Irvin, 2007; Wong, 2001), and the Caribbean at large (Glasgow, 1996; Hanson, 1990; Mckenzie, 1984). Further studies were based on Asian participants (Bauer, 1999; Brown, 1995; Lowe, 
2005; Ramaswami, 2009; Samuel, 1993), as well as the indigenous Native-American population (Hektner \& DeJong 2007; Horwedel, 2005; Portman, 2005).

As demographics and migration patterns changed in the U.S., mentoring research expanded into cross-cultural aspects. Cross-cultural mentoring studies focus largely on the African American race, while significantly fewer studies explore relationships with Latin Americans, Asian Americans, Native Americans and other ethnicities present in the U.S. today. The section that follows provides a brief review of empirical studies on cross-cultural mentoring relationships of Africa Americans, Latin Americans, Asian Americans, and Native Americans. The section ends with a discussion of the literature surrounding Caribbean immigrants in the United States.

African Americans. African American mentoring studies to date have focused on the mentoring process, experience, perceptions and expectations in relationships between Euro-Centric, Euro-American or White as mentors, with minority protégés (Barker, 2007; Brown, 1988; Chan, 2008; Dickey, 1996; Wilson, 1999). African American students confront a legacy of societal racism that for African American males especially challenges social and academic mobility, deterring transition to a predominantly White college or university, and reducing national attendance and graduation from college (Brathwaithe-Gardner, 2006; Cole, 2001; Freeman, 1999; Wilson, 2000). Mentoring is the first step in achieving the urgency needed to reach younger Black students and reverse the trend of a questionable future for the Black males' persistence in higher education (Reddick, 2006; Roach, 2001; Wilson, 2000). Mentor support leads to increased self- efficacy, resilience, and an enhanced perception of education and the long-term benefits (Jackson \& Harris, 2007; Rushton, 
2003; Schilling, 2008). Campus climate, race relations, cultural acceptance, increased minority recruitment, socialization and relationship building, are areas where mentors could lend support to enhance the learning environment for African American learners. Mentors' cultural knowledge, understanding of students' backgrounds, use of multicultural teaching materials, mutual collaboration, confidential dialogue and sensitivity were reflective of their cultural competence (Brathwaithe-Gardner, 2006; Carter, 2000; Taylor, 1995; White, 2006).

First generation African Americans and female African Americans leaders found that mentors' recognition of barriers, and strategies to increase their visibility were assistive (Ishiyama, 2007; Jackson \& Harris, 2007). African American women in particular experience additional discriminatory challenges in higher education, and to a greater extent in the workplace (Blake-Beard, 1999; Holmes, Land, \& Hinton-Hudson, 2007). Due to the White male patriarchal systems, Black women were traditionally denied educational opportunities, and consequently, few gained senior positions (Brubacher \& Rudy, 1997). Although women today still face some level of resistance, significant progress has been made regarding fairness, gender bias and career development (Bauer, 1999; Hansman, 2003; Hughes, 1999). Status reversal, where the mentor is African American and the protégé is White, lead to an understanding of shared values, appreciation of the learner's role, respectfulness and recognition (Roeder, 2006).

Latin Americans. Although Latin Americans have encountered xenophobia, inequality and oppression they have successfully broken barriers allowing them to become more visible, and their voices to be heard in academic, organizational and political spaces (Bernal, Alemn, \& Carmona, 2008; Holst, 2006; Jeria, 2002; Stanley, 
2006; Vassoler, 2008). Latin American students believe that mentors could be helpful in furthering their college self-efficacy, academic goal definition, career and personal development and program satisfaction (Bond, Gray, Baxley, Cason, \& Denke, 2008; Okawa, 2002; Roland, 2008; Staikidis, 2006). Advisors and mentors are able to provide the nurturing, emotionally supportive, encouraging relationships that help Latin American students overcome isolation and build the self-confidence required to become a scholar and life-long learner (Okawa, 2002; Shultz, 2001). There remains a need to prepare teachers, mentors and leaders so they may better assist Latin Americans overcome the systematic challenges, stigmas, sacrifices and conflicts that confront them (Bond, Gray, Baxley, Cason, \& Denke, 2008; Cavazos \& Cavazos, 2010; Gravlee, 2005; Munguia, 2001; Roland, 2008).

Native Americans. Mentoring within Native American cultures requires respect and special attention to tribal culture and customs. Mentoring programs typically focus on trust building, communication, exploration of cultural differences and sensitivity, respect for and dedication to family and tribal beliefs (Anderson, Belcourt, \& Langwell, 2005; Waterman, 2007). Mentors should understand their own cultural biases and influences (Salzman, 2000), lend support in building community and social partnerships (De Lapp, Hautman \& Anderson, 2008), and foster collectivistic relations toward building natural, collegial, respectful and socially integrative learning environments that support Native-Americans (Branley, 2008; Portman \& Garrett, 2005; Waterman, 2007). In efforts to build leadership development among women, mentoring relationships should include shared vision, recognition and nurturing that builds upon traditional Native- 
American worldviews of "collectivism, collaboration, compassion and courage" (Portman \& Garrett, 2005, p. 6).

Asian Americans. There has been little research on mentorships of Asian Americans possibly because they are considered a model minority due to high rates of academic and economic success (Gloria \& Ho, 2003). The Asian American population however consists of over 25 racial and ethnic groups, which vary by education levels, history, acculturation, socioeconomic and class status, religious and ethnic beliefs (Henderson \& Chan, 2005; Lew, Chang \& Wang, 2005). This heterogeneity leads to stereotyped assumptions that can negatively affect them during college and their careers. Asian American students experience difficulty connecting with mentors because of conflicting cultural expectations, specifically because they are socialized to wait until acknowledged or asked to participate by an authoritative figure (Henderson \& Chan, 2005). Faculty or administrators may often consider this as the student being withdrawn or apathetic. They also face challenges from unrealistic personal and familial expectations which stem from high standards of excellence and environmental pressures, yet few seek or admit they need assistance (Gloria \& Ho, 2003; Lew et al, 2005).

These students are also confronted with language barriers, cultural misunderstanding, social isolation, racism and subtle discrimination (Lew et al, 2005; Lowe, 2005) that further increase their sense of isolation. The resulting emotional and social distance serves as a barrier which keeps their cultural differences submerged within American cultural contexts (Brown, 1995; Liang et al, 2006). Similarly, humility and modesty may discourage them from seeking out promotions and advancement later on when they begin their careers (Henderson \& Chan, 2005). 
Some students are able to seek faculty and staff as vocational counselors, guides and mentors (Liang, Tracy, Kauh, Taylor, \& Williams, 2006) from among faculty or staff who recognize that Asian culture values happiness, harmony, and positive environmental and psychological forces, and typically display deference to authority and respect (Gloria \& Ho, 2003; Henderson \& Chan, 2005; Liang et al, 2006). For other Asian Americans, peer-mentors who share similar values and interests can be intentionally placed in their environments to help them connect and build relationships (Yeh, Ching, Okubo, \& Lutha, 2007).

These studies showed how various cultures adjusted and progressed in spite of challenges within higher education, and the workplace. Some studies focused primarily on challenges participants encountered as immigrants in academe. More recently researchers have delved a bit further and explored cross-cultural, inter-cultural and multicultural competence (Chan, 2008; Deardoff, 2004; Gay, 2000; Pollock, 2008; Salzman, 2000; Schriner, 2004; Stanley, 2005). These studies examined participants' understandings of culture, behaviors among different cultures, and how multiple cultures interact in various academic spaces. None of these studies examined cultural perspectives of Indo-Caribbean immigrants in the United States. The Indo-Caribbean subculture in the U.S. is presently embedded among research on African Americans, and the Afro-Centric or Black community (Henke, 2001).

\section{Caribbean Immigrants in the United States}

Caribbean immigrants in the U.S. face many of the same obstacles that other immigrant groups encounter including communication barriers, stereotypes and racism (Barrett, 2010; Feldman-Abe, 2002; McKenzie, 1984). Barrett's (2010) study further 
showed that in some instances West-Indian women who sought professional and social relationships with non-West Indians were rebuffed. Further studies explored immigrants' acculturation, adjustment in light of social and economic hardship, and social and cultural perceptions (Albertini, 2001; Johnson, 1993) to understand their adjustment patterns and social mobility.

To date, only a few researchers have explored the experiences of Caribbean immigrants in the United States. In existing studies participants are primarily identified as Black, African American, Afro-Caribbean, Caribbean-American, West Indian or Jamaican who migrated from, or whose parents were from the English speaking Caribbean (Barrett, 2010; Feldman-Abe, 2002; McKenzie, 1984). Researchers acknowledge that cultural, social, political and historical contexts of mentors and protégés contain useful information to engender support, community, understanding, socialization and development of Caribbean immigrants to the United States.

There is a single study performed in the U.S. that references the existence of the Indo-Caribbean subculture, however the study explores Indo-Caribbeans' religiosity following migration to Queens, New York from various Caribbean islands (Verma, 2008). The purpose was to understand the strategies and practices they employed to retain Hindu cultural authenticity in a "third" space outside of India. Although this study provided insights on the cultural underpinnings of Hindus from the Caribbean, it does not explore cross-cultural mentoring. Further, all Indo-Caribbeans are not Hindus, and this particular study is limited to only Hindus, whereas Indo-Caribbeans may hold a multitude of religious beliefs and practices based upon personal preference. 
There is one mentoring study which compares mentoring relationships of IndoCaribbeans and Afro-Caribbeans, however it is situated in the Caribbean and therefore does not hold the same significance as a study placed in the U.S., where protégés would be a diasporic minority subculture (Glasgow, 2006). This study explored the communication styles and expectations of East Indian and African cultural groups regarding mentor preferences in response to Hofstede's cultural dimensions. Mentors were from similar cultural backgrounds in Trinidad. In this study East Indians and Africans are actually the descendants of Indians and Africans who served as indentured laborers and slaves respectively. This study showed differences between both ethnic groups in that Africans preferred encouragement, nurturing and supervision while East Indians preferred indirect more passive interactions.

Although Caribbean immigrants are somewhat represented in the mentoring literature, participants are generally categorized Black, Afro-Caribbean, or even African American, with no indication or references that Indo-Caribbeans have been considered or even exist. Other studies that reference Indians in the U.S. speak to Native-American Indians (Andersen, Belcourt \& Langwell, 2005; Portman \& Garret, 2005) or East-Indians who migrated from the continent of India directly to the United States (Ghosh, 2008; Ramaswami, 2009). Neither of these groups shares the same history or culture of IndoCaribbeans. No studies have focused on the mentoring relationships of Indo-Caribbean immigrants in the United States. This implies that Indo-Caribbeans have succumbed to cultural syncretism, whereby researchers have allowed socio-cultural characteristics to appear melded, as though a single Caribbean subculture exists in the United States. 


\section{Understanding Indo-Caribbeans}

This section describes Indo-Caribbean history beginning with events that led to their arrival in the Caribbean, adaptation to Caribbean life, and heritage and values within the Caribbean. The second section provides insight on Caribbeans' migration and adaptation to the United States. The section concludes with a discussion on the community and culture among Caribbean migrants in the U.S., stereotypes, and cultural misrepresentation of Indo-Caribbeans.

Indo-Caribbean is the primary term used within this study to describe descendants of indentured laborers who were brought to the Caribbean from India, many of whom have now migrated to other countries. East-Indians are those who were never indentured but may have migrated directly from India to the U.S. or elsewhere, and West-Indians or Afro-Caribbeans are those not of Indian ancestry who were born in the Anglophone or English speaking Caribbean.

\section{History}

Following Columbus's discovery of the Caribbean in 1492 the Europeans, British, French, Dutch and Spanish laid claims to the new lands and began work. European arrival exposed the Caribbean natives, the Caribs and Arawaks to diseases such as measles and smallpox which combined with criminal acts, slavery and cruelty, soon fraught one of the earliest and massive genocides in history (Floyd, 1973; Stannard, 1992). By the end of the $17^{\text {th }}$ century during which were a number of wars, most Caribbean islands were divided between France and Britain, the latter owning most of the sugar producing islands (Craton, 1997). Needing laborers for their sugar plantations they turned to Africa and began the infamous slave trade. 
In 1833 the British government passed the Act of Emancipation that freed over 600,000 African slaves in the British Caribbean (Tinker, 1974). Slavery was further abolished in the French and Danish Caribbean in 1848, and in the Dutch Caribbean in 1863. The abolition of slavery lead to a crisis within the highly labor intensive sugar plantations. Planters attempted to rehire ex-slaves but were unsuccessful primarily because resistance served as a protest against the inequalities they suffered as slaves. Efforts to obtain labor from other continents proved futile because of the intense heat and hard work required in the agriculture industry.

This began the first of three waves of the East-Indian diaspora; the first becoming the indentured laborers, the second, those who moved to the Indian Gulf and neighboring areas and the third and present wave of professionals and educated elite seeking economic development (Ministry of External Affairs, 2000). The first wave encountered possibly the greatest challenge among the three waves because of the difficulties during and after crossing the "kala pani" or big water. In 1838 Indian labor import began, and continued through 1917, during which time over half a million laborers were brought to the Caribbean (Tinker, 1974). At the time East-Indian peasants faced famines which destroyed traditional industries and therefore served as 'push factors' leading many Indian emigrants into the indentured labor system.

Under indenture contracts East-Indians migrated to Mauritius, Guyana, Suriname, Trinidad, Jamaica, other British and French West Indian islands, South and East Africa, Fiji, Burma and Malaysia (Tinker, 1974). As indentured laborers they were to serve out labor contracts ranging from 3 to 5 years (Tinker, 1974). These contracts, being temporary, made the lives of indentured laborers different from those of slaves who were 
in life-long bondage. The indentured laborers received minimum wage, housing accommodations and health care from their employers. They were to be well treated, although this did not always occur (Ministry of External Affairs, 2000). By 1917 the system of indentured labor was officially terminated. By then East Indian immigrants already owned a significant amount of land. They began building family businesses and working to improve their economy. Following indentureship many were also offered land to encourage them to stay and so help to develop the local economy.

Within the indentured migrant groups were those known as Kalkatiyas from Calcutta, versus South Indians called Madrasis from Madras, and Jangalis or hill coolies from the more tribal areas such as Bihar and Bengal (Ministry of External Affairs, 2000). The majority of East-Indian migrants however were from western Bihar and eastern Uttar Pradesh, because even within India, planters were prejudiced against southern Indians. Regardless, a range of social, religious and caste backgrounds were brought to the Caribbean to serve as indentured laborers. The brotherhood or kinship that developed during these extensive 3 to 4 month long voyages lead to solidarity among the travelers. It also helped to diminish some elements of the caste system, a social system of hierarchical lineage associated with "occupations, ritual duties and roles...essential attributes surrounding degrees of purity/pollution" (Vertovec, 2000, p. 240).

In total over 500, 000 indentured laborers were brought to the Caribbean from India. The largest numbers on record were taken to Guyana $(238,909)$, Trinidad (143, 939), Guadeloupe $(42,326)$, Jamaica $(36,420)$, Suriname $(34,304)$ and Martinique $(25$, 509) (Roberts \& Byrne, 1966; Singaravelou, 1990; Tinker, 1974). The other islands of French Guiana, Saint Lucia, Grenada, Saint Vincent, Saint Kits, and Saint Croix received 
a combined total of approximately 17,000 laborers. The descendants of these immigrants today remain in many of these islands, although many have since migrated to the United States. In Guyana, Trinidad and Suriname approximately $50 \%, 40 \%$ and $37 \%$ of the existing population is of Indian descent (The CIA World Factbook, 2009). In Guadeloupe, Martinique, Saint Vincent and Grenada approximately 5\% are of Indian descent, while in Jamaica, Saint Lucia, French Guiana, and Saint Croix there are approximately $1 \%$ to $3 \%$ of Indian descent, and none on record in Saint Kitts. Other than Indian descendants, there are also those of African, Chinese, British, Portuguese, Lebanese, Asian, and native Amerindian descent, together with some Creole or mulatto (mixed races) inhabiting the Caribbean islands.

\section{Adaptation: Becoming Indo-Caribbean}

The British colonials remained distant from the East-Indians following indentureship, treated them as outsiders, described as heathens or barbarians and ridiculed their "language, dress, food, religion, and value systems" (Henke, 2001, p. 12). Confronted with these attitudes migrants from various castes, regional and linguistic backgrounds grouped together in their new homelands where they formed homogenized cultural and social networks (Vertovec, 2000). Others later settled in the areas where inhabitants with regional and religious origins similar to their own were already established. The caste system soon dissipated as a result of the low male to female ratio leading to marriages across castes, which soon became the norm, whereas it had been taboo in India. Further the custom of providing a dowry to the husband's family also was reversed because there were so few females. 
They made various other changes in lifestyle, and adapted to their new roots, where they began rebuilding a new history for themselves. They relied on their native skills and crafts, and brotherly cooperative efforts to make life more comfortable (Ministry of External Affairs, 2002). Being determined to succeed and to function within a new environment they adapted their social, cultural and religious patterns due to external forces including demography and political economy (Vertovec, 2000). In efforts to shape society, the planters in Guyana (formerly British Guiana) attempted to create a white middle class, to serve as a buffer between the more affluent Whites and the Black and creole inhabitants. This polarization lead to the first threads of racialized and politicized behaviors which soon became rampant in the Caribbean (Vertovec, 2000). Polarization within the Caribbean made social order and development more challenging. During the 1950s and 60s Indo-Caribbeans struggled with poverty and underemployment. They were discriminated against in the civil service and many other sectors primarily because of political practices which increased polarization between the Afro-Caribbeans and Indo-Caribbeans. These struggles engendered "a strong sense of ethnic identity, a powerful commitment to upward mobility, and a perceived experience of socio-economic and political exclusion and oppression" (Vertovec, 2000, p. 112).

Ethnic and political struggles became more prevalent in Guyana and Trinidad since there were larger numbers of East Indians in these countries (Allahar, 2005; Henke, 2000, Ramdin, 1999). In efforts to overcome the exploitation and blocked achievement that resulted from these pressures Indo-Caribbeans developed a sense of adaptation and a "stubborn vision of renewal" (Vertovec, 2000, p. 147). These visions and attitudes have 
brought Indo-Caribbeans to their present position in the upper middle classes of many Caribbean nations.

Prominent Caribbean author V. S. Naipaul's writing characterized by immigrant struggles speaks to his life among colonial transplants, the indentured, and to the physical alienation they felt after being removed from their homelands in India (Singh, 1988). Their emigration to him suggests they never really took root in any society and therefore attempted to "escape" so as to build their own sense of place, purpose and identity. Himself, Naipaul found life in Trinidad to be "suffocating, confining, and restricting" (Singh, 1988, p. 7). He stated in many instances that he never developed a sense of belonging or the ability to establish roots and to confirm his cultural identity, and as such still lives in England, rather than Trinidad, the home of his indentured ancestors. He further stated that the socio-political strife and failure to build a unified, synthesized hybrid Caribbean culture, because of strong racial conservatism increased his sense of being an invisible minority, an outcast without a community, causing him to migrate.

\section{Heritage and Values in the Caribbean}

Although the older generations of East-Indian descendants are still emotionally attached to India, they now consider their homelands to be the Caribbean nations, whether Trinidad, Guyana, Suriname or other island where they settled (Ministry of External Affairs, 2002). On their own plantations they grew rice, sugar, cocoa and other vegetables and over time they gradually accumulated more land and possessions to draw themselves and their children out of poverty. Many became wealthy and well established, and strongly supported education or vidya through arts, sciences, and other 
skills. They consider education as the key to human development, materially and spiritually in the form of liberation or moksha, the freedom from earthly existence. Indo-Caribbean cultural heritage is included in the legacy presently used to maintain their cultural identity (Vertovec, 1992). They established parochial educational systems for the younger generations so as to regenerate cultural traditions, while instilling value in the need for quality education. They reestablished their religious institutions where both the Hindu and Muslim religions were practiced (Ministry of External Affairs, 2002). Commitment to their cultural identity is reflected among ethnic, linguistic and religious groups, where customs, practices, values and beliefs continue.

Social segmentation based on caste, sub-caste and sect, language origins, regional histories, and provincial customs blended together built hybridized cultural understandings and practices among the Indo-Caribbeans (Vertovec, 2000). One particular Indo-Caribbean preference that has changed somewhat within recent decades is that married sons and their wives live with the paternal family (Vertovec, 2000), and that wives serve as homemakers while the husbands develop their social standings through education, employment and income. This ideology is still ingrained in the Indo-Caribbean mindset, especially older generations to a large extent.

Women born in the Caribbean islands as a whole were traditionally expected to be submissive while in their parents' homes (Butterfield, 2004). Indo-Caribbean women are presently expected to complete their education, become employed, then raise a family (Butterfield, 2004). Nonetheless, East Indians, both males and females, are presently in the upper middle classes within many Caribbean nations, and hold professional positions as doctors or lawyers, or are business owners or civil servants. 


\section{Caribbean Migration to the United States}

When Caribbeans initially migrated to the U.S. they worked for a specified amount of time after which many returned to their Caribbean homes to invest their earnings. By the early 1900s roughly 100,000 Caribbean residents had migrated to the U.S. (U.S. Department of Homeland Security, 2010). Then during World War I (1914 to 1919) and World War II (1939 to 1945) because of reduced employment opportunities in the United States many migrants returned to their homelands. In addition, in 1924 the U.S. immigration law established national quotas that further restricted Caribbean immigration (Henke, 2001).

The 1965 Immigration and Nationality Act also known as the Hart-Cellar Act abolished the national origins quota system that was in place since the 1920s (Henke, 2001). With this, preference was given to skilled immigrants or those with familial relations within the U.S., and visa restrictions were set at 170,000 per year, not including immediate relatives of citizens or special immigrants. Special immigrants were those from independent nations in the Western hemisphere, former citizens, ministers, employees of the U.S. government who were living abroad.

As a result of the Hart-Cellar Act many women took advantage of the family preference allowance to gain employment in the U.S., by filling positions recently vacated by American middle-class women (Henke, 2001). Women in the U.S. had moved to positions previously considered a male domain during World War II, hence they worked in factories and other industries. This increased the need for domestic help, caregivers and nannies, positions quickly filled by migrant women. 
During the first half of the 1900s most migrants were from the middle and upper classes, but by the end of the 1990s this was no longer the case (Henke, 2001). Further, from 1900 to $1965,75 \%$ of all immigrants to the U.S. were European, by 1968, 62\% were Asian and Latin American, although by 1978 this figure increased to 82\%. Caribbean immigrants were among the lowest entrant group to the U.S. at this time. Before the end of the 1950s up to 51\% of English speaking Caribbean immigrants were mostly single women (Henke, 2001).

An increased demand for labor in the U.S. domestic market required skilled labor in areas including health and education which lead to active recruitment of nurses as early as the 1960s and 70s (United Nations Secretariat, 2006). This resulted in the loss of skills and people power (brain drain), mostly from Jamaica and Trinidad. Around the mid1960s there was a greater emphasis on middle class and professionals, and the reunification of families; however by the 1970s through the 1980s the Caribbean migrant community was younger, from rural areas, and less educated, hence changing the profile of Caribbean migrants overall (Henke, 2001). By 1980 over $85 \%$ of Caribbean immigrants were women.

The Immigration Act of 1990 was intended to enhance the domestic labor market however admissions from the Caribbean during this time was still marginal. The U.S. further issued 120,000 employment visas as a part of the Immigration Act of 1990, although the quantity that was issued to the English-speaking Caribbean is not specified. Nonetheless, over three million Caribbean nationals migrated to the U.S. during the 1900s (U.S. Department of Homeland Security, 2010). According to the DHS the Caribbean includes Anguilla, Antigua and Barbuda, Aruba, Bahamas, Barbados, 
Bermuda, British Virgin Islands, Cayman Islands, Cuba, Dominica, Dominican Republic, Grenada, Guadeloupe, Haiti, Jamaica, Martinique, Montserrat, Netherlands Antilles, Puerto Rico, Saint Kitts and Nevis, Saint Lucia, Saint Vincent and the Grenadines, Trinidad and Tobago, Turks and Caicos Islands, and the U.S. Virgin Islands. Data for individual islands was not reliably recorded until the year 2000 .

Caribbean life held various shortcomings, whereas life in the U.S. promised far more opportunities for achievement through professional development (United Nations Secretariat, 2006). As such, there are both push and pull factors that lead Caribbeans away from their second homeland, to the U.S. as a third. The main push factor was the poor system of health care which lead people to leave as early as the 1970s. Additional push factors that increased emigration included low wages, unfavorable working conditions, weak leadership and management, few opportunities for professional growth, and lack of recognition.

Pull factors that drew Caribbeans to the U.S. on the other hand stemmed from attractive employment opportunities including better wages and career development, well-designed management systems and work environments and availability of resources, support from family and friends already in the U.S., and an anticipation of an overall improvement in the quality of life (United Nations Secretariat, 2006). Additional pull factors included the value placed on family ties, geographic closeness to the Caribbean for ease of access, and use of a common language making the U.S. a preferred destination for Caribbean migrants. Caribbean migration rates for Guyana, Suriname, and Jamaica are presently among the highest worldwide as these voluntary immigrants leave the 
Caribbean in search of personal and economic achievement and political freedom (Mehta, 2004; Ogbu, 1983, 1990).

From 2000 to 2009 over 4,000, 000 Caribbean immigrants became legal permanent residents, and over 300,000 became naturalized citizens of the United States yet there is no actual data to show how many of these immigrants are Indo-Caribbean (U.S. Department of Homeland Security, 2010). Further, there are approximately 10, 000, 000 non-immigrants from the Caribbean who enter the United States as tourists or business travelers, or to work, study, or engage in cultural exchange programs (U.S. Department of Homeland Security, 2010). We can only infer that since Caribbean migrants are among those from countries which house as many as 30 to $50 \%$ IndoCaribbeans, or as little as 1 to $5 \%$, that among the millions of Caribbean migrants presently in the U.S., there is indeed an Indo-Caribbean population.

Although the Indo-Caribbean population may seem arguably irrelevant in comparison to the multitude of migrant populations in the U.S., education and other literary documents have misrepresented them among studies of African Americans, Latin Americans and Asians (Allahar, 2005; Henke, 2001; Krase \& Hutchinson, 2004; Vertovec, 2000). Indo-Caribbeans do not possess the same history or cultural underpinnings as African Americans or Blacks, nor are they the same as other groups such as Afro-Caribbeans, Asians, Creoles, West-Indians or even East Indians with whom they are often confused.

Caribbean people who migrated to the U.S. are typically referred to as Black or West-Indian, and sometimes Latin American within U.S. research and literature. This stems in part to the classifications established by the U.S. Census Bureau to "generally 
reflect a social definition of race recognized in this country, and are not an attempt to define race biologically, anthropologically or genetically" (U.S. Census Bureau, 2010, p. 4) as approved for data collection by the U.S. Office of Management and the Budget (OMB).

The OMB Standards for the Classification of Federal Data on Face and Ethnicity under Federal Register Notice adopted May 12, 1977, and since revised October 30, 1997 recognizes five categories for data on race which includes American-Indian or Alaskan Native, Asian, Black or African American, Native Hawaiian or Other Pacific Islander, and White, and 2 categories for data on ethnicity, Hispanic Origin, or Not of Hispanic Origin. They state that categories of race include racial and national origin or sociocultural groups, however within their descriptions, there is no clear classification for Indo-Caribbeans. As a result the Indo-Caribbean Task Force for Census 2000 believes that Indo-Caribbeans were misclassified within the 1990 census, as they are convinced this population should be over 100, 000 (Hum, 2004). The Task Force further advised that in the future Indo-Caribbeans should check "Asian", and "Asian Other", and pencil in "Indo-Caribbean" in the space provided, so that they are counted.

Indo-Caribbeans in the United States. East-Indians and their descendants around the world vary in their beliefs, practices, identities and social formations owing to their various historical trajectories. These trajectories have changed their national loyalty, conceptual maps, and ethnic relations, so much that Indians who "landed" in the Caribbean, differ from Indians who migrate directly from India. Socio-cultural transformation within the Indo-Caribbean diaspora should not be measured against the traditional Indian archetypes, but rather considered innovative, and dynamic because of 
the tremendous changes that have taken place since the end of indentured labor (Vertovec, 2000). The present day concept of diaspora considers heterogeneity, diversity, and the concept of identity that exists despite differences and hybridity that stem from identities constantly being reproduced and transformed.

The cultural identity of Indo-Caribbeans has further evolved within an ethnically plural society that includes a largely Afro-Centric influence allowing Indo-Caribbeans to be referred to as West-Indians by those familiar with the Caribbean and its history, especially in New York or Canada (Allahar, 2005). The term West Indian however is typically associated with those of African descent, or Afro-Caribbean. Further, West Indian is described as Black within U.S. society, and remains a much argued and subjective term among Caribbean nationals (Allahar, 2005). This association is frowned upon by some Indo-Caribbeans because of the inequities they faced during racialized political struggles that were extensive throughout the Caribbean since the early 1950 s (Vertovec, 2000).

Caribbean nationals are often referred to as West Indian, East Indian, Black, or Caribbean (Allahar, 2005). The term East Indian was coined to differentiate them from indigenous or Native-American, or Amerindians (natives) from the West Indies. To Americans, Caribbean nationals may be West-Indian, Caribbean, Black, East-Indian, Indian, Hindu, or a national of their Caribbean island being Jamaican, Trinidadian, Guyanese, Surinamese, Vincentian or the like. Ironically, individuals may at times possess more than one racial, ethnic or national identity because of the many connections formulated through the diaspora, for example East Indian, Hindu, Trinidadian, and U.S. Citizen, which can all still refer to an Indo-Caribbean. 
Race as opposed to ethnicity dictated where Indo-Caribbean immigrants settled, especially at the beginning of the $1800 \mathrm{~s}$, however closer to the $20^{\text {th }}$ century they began moving into the Black areas in the U.S. (Henke, 2001). Primary cities with concentrations of Indo-Caribbeans include New York City, and Schenectady in New York; Washington, D.C.; and Orlando, Miami, Fort Lauderdale and Hollywood, in Florida (Gosine, 1999). Indo-Caribbeans now residing in the U.S. have maintained their collective identity, created a sense of community, and retain implicit ties to their homeland, while also assimilating into mainstream U.S. society. They have been accepted into the U.S. society, however as a people, they are not recognized as an ethnic culture (Vertovec, 2000). In this sense they remain among those referred to as "other" in this society.

While diasporic individuals may experience a sense of duality resulting from attachments to more than one background or environment (Vertovec, 2000), they also develop a sense of multi-locality as they draw upon collective memory and create new maps of attachment. These new maps evolve through adaptation within complex social relationships to create fluid identities that represent both native and host societies (Schiller, Basch, \& Blanc-Szanton, 1992). As such, some migrants identify with one culture more than the other, while others maintain several identities linked to more than one nation. Multiple racial, national or ethnic identities enable migrants to distance themselves from political and economic issues, often to accommodate to living conditions and other vulnerabilities (Schiller, Basch, \& Blanc-Szanton, 1992). Because of these vulnerabilities migrants tend to support civic causes, human rights and social justice, ethnic mobility and identity issues (Vertovec, 2000). 
Although religion itself is not considered diasporic, religious tenets form the foundation which supports diasporic consciousness (Vertovec, 2000). A significant basis of Indo-Caribbean belief is built upon Sanatan Dharma, meaning eternal cosmic order, or sacred duty. Religious practices are maintained by many within the U.S. owing to the heavy emphasis placed on traditional Indian lore although they are subject to selfquestioning resulting from their disconnect with routine religious practice and habits, rote learning and "blind faith." In many areas including Florida and New York, Indo Caribbeans have built temples as an avenue to maintain their culture -and even though not largely religious themselves prior to migration, hold on to spiritual life in the U.S. as a way to retain the traditions, and lifestyles through religious symbols, fasting, praying, music, dance and food (Henke, 2001).

Use of the traditional Indian language, Hindi, is rarely used or even known to many Indo-Caribbeans (Vertovec, 2000), although it is used during religious ceremonies and practices. Temples and religious community life is used to engender cultural practices and cultural preservation in the younger generations, as well as to help them maintain their identity. As a result of discrete cultural practices and beliefs among the various Indo-Caribbean nationals, there are some descendants whose culture has become diluted in that they may know "little or nothing about their past which has gone into making who they are" (Ramdin, 1999, p. 329). While there are many present day IndoCaribbeans who no longer actively participate, or have changed their religious beliefs, their respect for religious beliefs and its sanctity remains (Vertovec, 2000).

Community and culture. Skin color has not affected Caribbeans' selfconfidence or self-worth when confronted with White or light-skinned society as they 
traditionally experienced less racial tension coming from societies where the majority of the population was dark-skinned (Allahar, 2005). They were willing to do whatever was necessary to progress in the United States. Many West Indians, both Indo-Caribbean and Afro-Caribbean have experienced downward mobility in the U.S., and worked beneath their skill levels, whereas they may have had their own employees whilst "back home".

As immigrants they have worked in menial jobs as service workers, operators or manual operators, porters, waiters or elevator operators. Their attitude to work as gainful employment and a means to success allowed them to accept lowly positions, wages and status, and lower working conditions than other nationals. To outsiders however this made Caribbeans appear unenthusiastic or nonchalant about progression and may have led to negative stereotypes.

The goal of Caribbean immigrants was to become economically independent, therefore even those with existing degrees, diplomas or trade certifications chose to further their studies in the U.S. (Henke, 2001). Caribbean cultures are viewed as individualistic cultures (Allahar, 2005; Glasgow, 1996; Henke, 2001), characterized by independence, directness or honesty, task and goal orientation and self-expression (Hofstede, 1997). Overall Caribbean societies place emphasis on "hard work, delayed gratification, or personal austerity" (Henke, 2001, p. 52). They emphasize the value of a good education, earning scholarships, and academic achievement because they view education as source of economic strength or social capital.

Caribbean flexibility, adaptation and problem solving efforts are reflected in their will to survive, preparedness to migrate or to return home, coping in a new environment and adaptation to the sense of displacement (Taylor, 2001). Their struggles are evident in 
their creativity in theatre and annual Carnival festivals. These celebrations are characterized by Caribbean polyrhythmics which reflect multicultural wholeness manifested in fully involved dances integrating both Afrocentric and Indocentric rhythms, for example chutney-soca. As oppressed peoples their dance demonstrates complexity, rhythmic movements depicted in absorbing, redirecting, reworking, surviving, thriving, exemplified figuratively through dodging, shifting, changing beats, and creating new beats (Taylor, 2001).

Caribbean people enjoy active social life and interpersonal relationships within the community. They attempt to maintain country traditions within their social systems, e.g., dropping in, liming which slang for socializing, and ole talk, or extensive conversations with no specific basis other than to maintain conversation (Henke, 2001). In some instances, particularly when they socialize together some aspects of their speech may be difficult to understand as many speak using Creole grammar and pronunciation although most now use standard English.

Stereotypes regarding Caribbeans. Although Caribbeans are proud of their heritage, they are "still stereotyped, and their history and culture are largely misunderstood" (Ramdin, 1999, p. 330) within the Caribbean and worldwide. In many cases Caribbeans themselves are unaware of their rich history and culture and may appear confused about their identity, making them more vulnerable to stereotypes. Education systems in the Caribbean remain Eurocentric because of British rule and development, and as such, this population has remained on the periphery of Caribbean, African or Indian historical and cultural studies, both locally and internationally. 
Being dark-skinned, many Caribbean natives are considered Black, and ascribed the prejudice and stigma attached to the African American ethnicity or the Black race in the U.S. (Henke, 2001). Descendants of indigenous peoples, indentured laborers and enslaved Africans may appear to be passive learners, or even apathetic in the classroom or learning relationships. During British rule Caribbeans were exposed to the banking system of education which was initially used to "adjust these 'incompetent and lazy' folk to its own patterns by changing their mentality" (Freire, 2006, p 74). East-Indians from India on the other hand consider themselves pure in comparison to their Indo-Caribbean counterparts who have been polluted in the Caribbean (Vertovec, 1994). Caribbeans typically do not attribute problems, difficulty or successes to racism or racial solidarity since they were raised in a multicultural environment, which causes even further conflict with Blacks (Henke, 2001; Vertovec, 1994). As a result some African Americans consider Caribbeans to be over accommodating to the rules, regulations and values imposed by Whites.

Education practices throughout the Caribbean subscribed to the banking model, the Eurocentric school of thought which ignores knowledge developed outside the context of "whiteness" (Johnson-Bailey \& Cervero, 2000). Europeans, mainly the British, White males who were actively involved in developing the education systems in the Caribbean used the banking system to reinforce stereotypes and to maintain social order and cultural hierarchy (Freire, 2006). The banking model denied the historical being of learners by transforming them into passive if not necrophilic objects in an attempt to control their thinking and behaviors (Freire, 2006). Learners received knowledge only as passive entities, which allowed them to be easily oppressed, so that 
they fit into the oppressors' worlds without objections. Educators filled regulatory roles, deposited information they considered true, mythicized reality by concealing specific facts, resisted dialogue, inhibited creativity, and isolated learner consciousness.

Caribbeans possess good command of the English language, are regarded as "less demanding, more docile, and easier to satisfy" (Henke, 2001, p. 43). English speaking Caribbean immigrants are also considered a model minority because of their good work ethic, intent to succeed economically, employment flexibility, kinship and familial regard, and respect for formal education through academic and professional development (Henke, 2001). These stereotypes have at times made them more vulnerable to discrimination, and often made it difficult for them to find and keep jobs, or to gain promotions since they are willing to make sacrifices to meet their goals (Henke, 2001).

Cultural misrepresentation of Indo-Caribbeans. Indo-Caribbeans have been misrepresented within studies of African Americans, Asians and other ethnicities associated with the Caribbean even though they do not possess the same history or cultural backgrounds (Allahar, 2005; Henke, 2001; Krase \& Hutchinson, 2004; Vertovec, 2000). The Indo-Caribbean emergence as a diasporic, transnational, ethnic culture in itself is unique, and incorporates fragments of a rich history that is not represented in the mentoring research. Although Indo-Caribbeans may have departed from their indigenous cultural identity, it is valuable to examine their perceptions of mentoring relationships in spite of diasporic transnational migration. The Indo-Caribbean subculture should be clearly represented in the body of mentoring literature so that its cultural contexts are not "erased from the 'story of mankind' [nor] from the records of those who control access to 
public memory, oral and written [potentially] distorting our self-perceptions" (Munich, 2005, p. 49].

It is critical to understand what occurs within cross-cultural mentor-protégé relationships rather than to generalize existing cross-cultural dynamics to all mentoring relationships. Cross-cultural mentoring as way of systems thinking (Hargreaves \& Fullan, 2000) should seek to build greater levels of success in education and society, representative of all cultures, to diminish isolation through "collaboration, exploration and inquiry" (Mullen, 2005, p. 7). Learning about immigrant island societies (Henke, 2001) is essential to improving learner-oriented relationships.

\section{Summary}

In this chapter, conceptual and empirical literature related to identity, culture, mentoring and cross cultural mentoring, was discussed, along with relevant literature related to Indo-Caribbeans and their migration to the United States. In Chapter 3 the phenomenological research method used in this study is explained. Chapter 4 includes the findings of the study. Chapter 5 includes discussion, implications, and recommendations for further research. 


\section{CHAPTER III}

\section{METHOD}

This chapter begins with the purpose of the study and the research questions. The phenomenological framework is then discussed, followed by my autobiography, assumptions related to the study, and research journal. Procedures for data collection, data management and data analysis are then described, followed by a discussion of integrity measures and study limitations.

\section{Purpose of the Study}

The purpose of this phenomenological study was to explore the perceptions of Indo-Caribbean protégés regarding the effects of their cross-cultural mentoring experiences in the United States.

\section{Research Questions}

The phenomenon of interest is the cross-cultural mentoring experience of IndoCaribbean protégés presently living in the United States, to understand their perceptions regarding the effects of their cross-cultural mentoring experiences. The primary research question is: How do Indo-Caribbean protégés in the U.S. perceive the effects of their cross-cultural mentoring experiences? Secondary research questions are:

1. What factors do Indo-Caribbean protégés report that facilitate their successful cross-cultural mentoring relationships?

2. What challenges do Indo-Caribbean protégés encounter within their cross-cultural mentoring relationships?

4. What mentoring strategies and practices do Indo-Caribbean protégés believe will help to enhance their professional development? 


\section{Phenomenological Framework}

The phenomenological research approach is used to explore the lived experiences of participants, regarding a specific concept or phenomenon (Creswell, 1998). It is "the systematic attempt to uncover and describe...the internal meaning structures, of lived experience [by studying the] particulars or instances as they are encountered" (Van Manen, 1990, p. 10). The researcher examines the meaning of participants' lived experiences surrounding a concept or phenomenon "as they present themselves to consciousness" (Van Manen, 1990, p. 9), "the study of essences" (p. 10), and the "attentive practice of thoughtfulness" (p. 12). This approach allows participants to articulate their experiences so that the researcher can uncover underlying essences and meanings, so as to interpret and arrive at his or her own understandings of the phenomenological interaction being studied (Bogdan \& Biklen, 1992; Creswell, 1998).

Using the phenomenological approach was ideal for this study as it supported indepth data collection, using multiple sources, about the phenomenon of cross-cultural mentoring, to explore "the structures of consciousness in [protégés'] human experiences" (Creswell, 1998, p. 51). This method allowed exploration and understanding of IndoCaribbeans' perceptions and perspectives within cross-cultural mentoring experiences. The phenomenological framework was used to explore the essence of protégés' mentoring experiences with mentors from cultures that differ from their own.

\section{Researcher's Autobiography, Assumptions, and Journaling Process}

Since phenomenological research relies on interpretation (Creswell, 1998), the challenge to the researcher is to allow participants' subjectivity to emerge authentically. Bracketing of the researcher's assumptions, a phase in the research referred to as epoché, 
allows the researcher to give pause to, suspend, or set aside any personal assumptions so as to identify and gain clarity in the research, distinct from personal preconceptions (Patton, 1990). Bracketing entails recognizing the essence of meaning ascribed by the researcher, to the phenomenon under scrutiny (Moustakas, 1994). To bracket my assumptions I wrote a descriptive autobiography, listed my assumptions regarding crosscultural mentoring relationships, and kept a journal to promote reflection and observation of my personal ideas and feelings as they related to the research.

\section{Researcher's Autobiography}

The idea of a mentor, coach or guide strikes me as a truly meaningful way of lending support to another. I know that a mentor would have been useful to me during my undergraduate and graduate programs, to help me think through my next steps, or even earlier when I chose my degree programs. I really feel that my degrees in business administration were not helping my career as I had hoped. My perception was because I did not have a mentor, I never gained a strong sense of direction.

Mentoring to me, is really a deeply meaningful way to serve others. Similarly, I feel enriched and supported, as though I matter, when others take the time to coach or mentor me. Learning to meaningfully serve others is closely connected to my memories of my mother's involvement with her own students during my childhood. While her

actions were not mentoring per se, they were built upon a deep, genuine interest and care for her students. I recalled her high school student whose home was destroyed in a fire.

I was with my mom one day when she brought food and clothes to her student's family, a single mom and her six children of various ages. They were still living in the burned out shell of a home with grey smoke covered walls, and almost no furniture. My 
mom served many of her students as so much more than just their art teacher. She was their counselor, their friend, their refuge, their protector often from abusive parents and still so much more. I sometimes thought "well, I don't need her to do anything for me so she might as well help them." Of course, now that I think about it, she still found time to teach, support and guide my three brothers and me without fail. My dad similarly stood behind us every step of the way, chauffeuring us around, preparing and bringing us meals fastidiously before all of our extra lessons, coaching us through studies beyond our class curriculum so that we were prepared for high school entrance exams. Yet still finding the time to nurse a broken wrist or to teach us how to fish. A more diligent and caring father I could not imagine. Indeed, parents are our first mentors.

My parents' actions strongly influenced my life and the person I am today as a result of how deeply they cared for us, and for others. Through their strict yet loving guidance we learned to respect others, to show deference to teachers and leaders, to our family, and to elders. Their support of their own siblings through school, family crises and financial hardship showed us the value of commitment to others, and the responsibility that we had to help each other. My parents' and also my grandparents' fervent goals were always to support the achievement and progress of the family, so much that often their Hindu religious prayer sessions to the various deities sought blessings in the form of guidance, educational "wealth", and prosperity. Simply knowing that guidance, educational "wealth" and prosperity were so important and valued that they were prayed for, has built in me tremendous regard for the teachers, leaders, family and elders who guide and assist me toward my personal and professional goals. I recall that even on a religious pilgrimage to India at the age of 12 , when considering what I 
myself would seek as a blessing, I knew that I would ask for "knowledge". Because knowledge means so much to me, the teachers and mentors I have met along the way, regardless of their race or ethnicity have had a tremendous impact on my life and my actions toward other learners.

Fast forward to when I started college in Miami at the age of 17. At college there were no other Indo-Caribbeans like me. I felt like an outsider in an overcrowded, competitive and overwhelmingly White learning environment. I struggled for the first 2 years until I ended up on academic probation and dropped out. I sometimes think that perhaps my personality and upbringing led me to feel like an outsider at that college, especially when active participation in class projects or group work was required. At times I thought my academic adviser led me to fail by placing me in too many difficult classes all at once. Regardless, I now think the failure was entirely mine.

Almost 10 years later, I started college again here in the U.S., but this time as the mother of a young child. Motivated to provide for him, I became a full-time employee and a full-time student. I completed both a bachelor's and a master's degree and later began the doctoral program in Adult Education and Human Resources Development. My achievements so far have affirmed that I am able to succeed as a student.

During one of my first doctoral classes, I noticed approximately five students from one particular ethnicity struggling with the class. They would miss classes, not participate, and appeared apathetic during class projects, and eventually they stopped attending the class. It appeared that they did not discuss any problems or concerns they had about the course with the instructor, but instead simply stopped attending. I became 
curious as to why they were so demotivated, since they were a tightly knit group, and appeared to collaborate well with each other.

Ironically, my experiences in the class were the complete opposite. I worked with peers to develop a lesson plan for presentation to the class, on various group assignments and also on a research paper that we were going to publish. My co-authors on the paper were from different cultures, and the purpose of our research was to explore how our lives shaped our development as learners and as educators. Our writing explored multiple layers of our consciousness and helped us connect our personal feelings to our cultures. This research lead me to think about the complex nature of culture and how we were each shaped by our life experiences and upbringing even though we were of different races and ethnicities. I began thinking about the aspects of culture that affect our relationships with others.

Working together on the paper encouraged me to collaborate closely with colleagues who had more experience than myself, both as educators and as doctoral students. They served as my mentors in the sense that they helped guide my progress as a novice student. I was able to contribute to discussions and to the papers and presentations we prepared together. This collaborative experience led to my first publication, which was a great accomplishment for me since it was just my first semester as a doctoral student. I also realized that during my initial college experience as a teen I had missed out on a world of relationship building and networking - friendships, collegiality and support that I found at FIU.

As I continued with my program of study and attended various dissertation group meetings, I noticed that student participation and engagement varied, and I began to 
wonder why. Ironically, I met students who sometimes seemed indignant, unaccepting of feedback and constructive criticism, and challenging to work with. This surprised me as I assumed feedback and constructive criticism would help us achieve a common goal yet behaviors and responses toward faculty mentors and their support varied significantly. This surprised me since these students were individuals of racial and ethnic minorities just like myself. I became curious about the cultural differences that existed between mentors and their protégés.

My colleagues and I shared a number of faculty from various cultures who assumed mentoring roles, and would frequently go the extra mile it seemed to set up learning opportunities, collaborative experiences, and developmental challenges. They consistently encouraged us to publish, to attend conferences, and to seek out experiences that would help us meet our own personalized goals. I took advantage of the guidance I received and participated in writing groups, publishing and professional development activities. I also paid attention to colleagues' reactions, behaviors, and challenges. I assumed that our various ethnic cultures caused us to each react differently.

Personally, I have been overwhelmed by the quality and depth of interaction that I have found with some of the faculty here at FIU. To me, it feels as though they truly serve students above and beyond teaching, beyond coaching, and beyond mentoring. We have faculty who invest entire weekends focused solely on our success and who frequently help graduate students who have difficulty when members of their committees leave the university. They engage noteworthy guest speakers to enrich and expand our thinking, and bring social justice and the struggles of others into our classrooms. This is truly my vision of what mentoring means. 
I have also gained many friends, allies, co-travelers and peers from different racial and ethnic groups along my journey. Never before had I classmates who I could instant message (IM), email or call at any point in time, and just ask basically any school related question (even if I had the answer stored in an email or notes someplace). Never before had I access to colleagues' writing as samples or models. Never before had anyone shared the fears, challenges, heartbreaks and rigor of a journey with complete honesty. My peers were open, honest, curious, intelligent, and supportive. I could not hope for better peer-mentors.

In my professional life I have had managers and supervisors who served as mentors also. My most recent supervisor stands out as an ideal mentor, because, although his ethnicity differed from mine, I found him to be an exemplary mentor in that he took the time to discuss my academic and professional goals, and aligned my work projects to help me develop competencies and knowledge that would help me achieve these goals. We often discussed how projects unfolded, both in a critical and developmental manner so that all aspects could be understood. At times I felt almost incompetent, yet at other times I felt extremely knowledgeable and efficient. I was always eager to learn and explore new scenarios in collaboration with this particular supervisor even though ethnically and culturally, he was very different from me.

How and why does culture enter this equation? I often wonder whether having ancestors who originated in India, and served as indentured laborers building a new life in the Caribbean have shaped my own culture. I am curious about whether any aspects of my upbringing and culture influence my cross-cultural mentoring experiences now that I have migrated to the United States. I know that as a people Indo-Caribbeans have a rich 
cultural background. My life is built around a rich ethnic history, religious beliefs and practices, close knit family life, change, migration, educational and career aspirations, and a keen interest in serving others. My values, thinking, and goals have been shaped by my family life and upbringing, yet sadly, my ethnic identity remains designated as "other" here in the U.S., and even at this university which is a minority serving institute.

I seek growth, success, enrichment and consistent improvement, am fulfilled when I serve others, and deeply appreciative when others assist me along my journey. I aim to be successful, and am eager to give back to the community, to help others along their own journeys, and to serve. What I have experienced at the hands of those who care enough to light the way takes on new meanings for me especially since cultures differ in the many ways they do, here in the United States. Like so many others who have migrated to the U.S., I believe I have much to discover and to share.

\section{Researcher's Assumptions}

The following lists my assumptions as I entered this study:

1. Indo-Caribbean culture is so deeply ingrained that regardless of whether they have recently migrated, or are first or second generation U.S. born, their perceptions of mentoring experiences will be similar.

2. Indo-Caribbeans' ethnic culture impacts the relationships they have with mentors of different cultures.

3. The upbringing of Indo-Caribbeans influences their mentoring relationships in ways that may differ from other immigrant groups in the United States.

4. Individuals allow their perceptions about individuals from different ethnic cultures to affect their interaction with and behaviors toward them. 
5. Individuals may discount others' genuine interest in their success and achievement if their ethnic cultures are not the same.

\section{Researcher's Journaling Process}

I kept a journal to record my thoughts, feelings and observations during this study. This journal allowed me to self-reflect so that I could explore my own biases or assumptions that emerged as the study unfolded. Immediately after I conducted each interview, I recorded my observations of each, together with my reflections. I was able to capture my thoughts about each interview as it occurred.

\section{Sampling Methods}

In an effort to identify and select participants for this study both criteria and snowball sampling were used. Criteria sampling means selecting participants who meet specific, predetermined criteria (Patton, 2002). Initial participants for the study were selected using criteria sampling. In order to identify initial participants I emailed former classmates, friends, family, acquaintances, and Indo-Caribbean organizations in the United States, and requested their assistance in finding participants who met the criteria for the study.

Participants were required to meet the following criteria (a) be Indo-Caribbean, (b) have parents who are both Indo-Caribbean, (c) have ancestors who served as indentured laborers in the English-speaking Caribbean, (d) were born in the U.S. or have lived in the United States for 3 years or more, (e) have completed a baccalaureate degree or beyond in the United States, and (f) have had a mentor from a culture different from their own for a minimum of 1 year. There are presently no records that verify whether Caribbean immigrants or Caribbean-Americans are Indo-Caribbean therefore the specific 
criteria above related to participants' ancestry were used verify ethnic culture. It was necessary to verify participants' ancestry so that their ethnicity could be differentiated from other races and ethnicities from the Caribbean. Other criteria were related to participants' life and education in the U.S. as the context for their cross-cultural mentoring relationships.

Participants were Indo-Caribbeans who migrated from countries in the Caribbean, primarily Guyana, Jamaica and Trinidad (Vertovec, 2000), or were born in the United States to parents of East-Indian ancestry, who migrated from one or more of these countries. Guyana, Jamaica and Trinidad are among the Caribbean nations which house the greatest percentages of Indo-Caribbean descendants (The CIA World Factbook, 2009), therefore the study included immigrants or descendants of Indo-Caribbeans from these nations, although Indo-Caribbean immigrants from other Caribbean nations who met the criteria for this study were able participate.

Twelve participants were found using criteria sampling. The initial participants were then asked to recommend others who met the criteria for the study so as to increase the number of participants. Snowball sampling occurs when the initially identified participants, as well as other individuals are asked to recommend participants who meet the criteria for the study (Bogdan \& Biklen, 2006; Creswell, 2005; Patton, 2002). In doing so, three additional participants were identified by the initial participants.

In phenomenology, the goal is to obtain a detailed understanding of the essence of participants' experiences with a phenomenon (Moustakas, 1994). Morse (1994) recommends six participants, Creswell (1998) recommends up to 10, Guest, Bunce, and Johnson (2006) recommend six to 12, and Miller and Salkind (2002) recommend five to 
25 participants. My aim as a researcher was to have a minimum of 15 participants, that being a median sample size based on these ranges. In this study, a small sample size was useful in obtaining the perceptions of a relatively homogenous group, and to provide "reasonable coverage of the phenomenon" (Patton, 2002, p. 46).

Fifteen participants were selected to be interviewed in this study. Having 15 participants in the study allowed for in-depth and detailed exploration while accommodating schedule challenges, unexpected cancellations or other contingencies that may have otherwise hindered data collection.

Requests for participants were sought via email or online messaging systems that included the FIU information letter sent as an attachment (see Appendix A), or directly pasted into the body of the email, together with an explanation about the study, and why I needed their assistance. The information letter included the participant criteria. No members of my immediate or extended family participated in this study to avoid the possibility that similar and/or shared culture within the family might influence the study so that the data could remain neutral.

\section{Participant Demographics}

The sample for this study included 15 Indo-Caribbeans who were protégés in cross-cultural mentoring relationships. All participants self-identified as Indo-Caribbeans who either migrated from the Caribbean, or were born in the United States to parents who were both Indo-Caribbean and had ancestors who served as indentured laborers in the English-speaking Caribbean. All participants obtained at least a bachelor's degree or further from the United States, and were protégés within dyadic mentoring relationships with a mentor from a culture different than their own for a minimum of 1 year. 
Participant demographics include: (a) gender, age range, place of origin, and (b) educational attainment, and profession during mentorship. Participant demographics are discussed in the following section.

\section{Gender, Age, and Place of Origin}

Of the 15 Indo-Caribbean protégés in the study, 13 were women and 2 were men. The participants ranged in age from 20 to 60 years old. With regard to their Caribbean origins, two participants were from Guyana, 10 participants were from Trinidad, one participant's parents were from Trinidad and Jamaica, and two participants' parents were from Trinidad and Guyana. Only one participant was born in the U.S., the other 14 migrated to the U.S. with their families or for the purposes of education. This information is summarized in Table 3.

Table 3

Summary of Participant Age, Sex and Caribbean Origin

\begin{tabular}{lll}
\hline Category & Description & Frequency \\
\hline Age & $20-29$ & 4 \\
& $30-39$ & 4 \\
& $40-49$ & 5 \\
50 and over & 2 \\
Sex & Male & 2 \\
& Female & 13 \\
Caribbean Origin & Guyana & 2 \\
& Trinidad \\
& Trinidad/Jamaica* & 10 \\
& Trinidad/Guyana & 1 \\
& & 2 \\
\hline
\end{tabular}

* Participant born in the U.S. 


\section{Educational Attainment and Profession during Mentorship}

All participants obtained a bachelor's degree or further in the United States. At the time of the study five participants had terminal degrees, five had Master's degrees, and five had bachelors degrees. Fields of study included podiatry (2), business (2), psychology (3), social work (1), Russian studies (1), technology (2), international relations (1), biology (2), and K-12 education (1). During their mentoring relationships participants were either students or working professionals. Three participants were postdoctoral students, four were undergraduate students, seven were employed full-time and one worked full-time while attending school to obtain her teacher certification. Protégés' educational attainment and profession during mentorships are summarized in Table 4.

Table 4

Summary of Educational Attainment and Profession during Mentorship

\begin{tabular}{lll}
\hline Category & Description & Frequency \\
\hline Degree Earned & Doctoral & 5 \\
& Masters & 5 \\
& Bachelors & 5 \\
Post-doctoral Students & Podiatry & 2 \\
& Psychology & 1 \\
& Biology & \\
Undergraduate Students & International Relations & 1 \\
& Russian Studies & 1 \\
& Technology & 1 \\
& Business (HRM \& Real Estate) & 1 \\
Working Professionals & Counseling Psychology* & 2 \\
& Education Administration & 1 \\
& Education (K-12) & 1 \\
& Scientific Research* & 1 \\
& Social Work & 1 \\
& Technology & 1 \\
\hline
\end{tabular}

* Participants held terminal degrees 


\section{Reported Sex, Race/Ethnicity and Professional Relationship with Mentors}

Although mentors did not participate in this study, participants reported on the gender, race/ethnicity and professional relationships with mentors. Ten participants spoke of one mentor, while five participants spoke of two mentors. Eight mentors were male, 12 were female. Twelve mentors were White, two were African Americans or Black, two were Black-Jamaican, one was Black Cherokee, one Hispanic, and two were East Indians who migrated directly from India to the U.S., therefore not Indo-Caribbean. This information is summarized in Table 5 along with protégés' pseudonyms and sex.

Table 5

Reported Sex, Race/Ethnicity and Professional Relationship with Mentors

\begin{tabular}{|c|c|c|c|}
\hline Protégé & Mentor & Mentor & Professional \\
\hline Pseudonym & Sex & Race/Ethnicity & Relationship \\
\hline Kara (female) & Male & White & Supervisor \\
\hline Suren (male) & Male & White & College Advisor \\
\hline Bela (female) & Male (2) & White & Faculty Advisors (2) \\
\hline Prad (male) & Male (2) & White (Jewish) & Supervisors (2) \\
\hline Aalia (female) & Male & White (Jewish) & Faculty Advisor \\
\hline Sita (female) & Female & White & Faculty Advisor \\
\hline Arti (female) & Female & White & Residency Director \\
\hline Rani (female) & Female & White & Supervisor \\
\hline Prema (female) & Female (2) & Black/White & Principal/Supervisor \\
\hline Nira (female) & Female (2) & Black-Jamaican*/White & Faculty Advisors (2) \\
\hline Keya (female) & Female & Black-Jamaican* & Supervisor \\
\hline Kavi (female) & Female & Black & Supervisor \\
\hline Mrita (female) & Female & Black Cherokee & Supervisor \\
\hline Anu (female) & Female & East Indian^ & Supervisor \\
\hline Bina (female) & Female/Male & Hispanic/East Indian^ & $\begin{array}{l}\text { Principal/Spiritual } \\
\text { Leader }\end{array}$ \\
\hline
\end{tabular}

* Mentors were of African descent who migrated from Jamaica

$\wedge$ Mentors were East-Indian, of Indian descent, directly from India 


\section{Protection of Participants}

Protecting the privacy and anonymity of research participants through ethical reviews and procedures is important (Creswell, 2005; Dresser, 1998). Participants' rights include being informed about the study, not being harmed by the study, and freely deciding to participate and to withdraw without penalty. Kvale (1996) further adds that informed consent requires a balance between over-informing and under-informing as trust between researcher and participant is negotiated.

Participants who agreed to be in this study were asked to sign a Florida International University Institutional Review Board informed consent release form to acknowledge their voluntary participation in the study (see Appendix B). This form explained the purpose of the study, expectations, data reporting, and expected use of the research and resulting publications. In the form, participants were informed that they could choose to withdraw participation at any point in the study.

Participants were informed that interviews would be private, confidential and uninterrupted. Since interviews were estimated to last approximately 60 to 90 minutes, a quiet and comfortable environment was selected to conduct the interviews so that there were no distractions or disruptions. Pseudonyms were selected by participants and were used to reference them in the study to provide anonymity. Demographic information regarding participants was be referenced. No uniquely identifying information such as mentors', universities' or employers' names were used in the study. In instances when mentors', universities' or employers' names were used, they were replaced with pseudonyms. 


\section{Data Collection}

Data collection took place via a semi-structured interview guide. Qualitative interviews may vary in their degree of structure (Bogdan \& Biklen, 2006). Interviews were performed to enable the researcher to obtain participants' descriptions and interpretations of the described phenomenon through both structured and purposeful dialogue (Kvale, 1996), so that participants were able to expand upon their experiences.

\section{Interview Guide Construction}

The semi-structured interview guide (see Appendix C) contained questions to help the researcher learn more about participants, their ethnicity, and their perceptions regarding previous cross-cultural mentoring experiences. The interview questions encouraged participants to speak at length and to provide in-depth details about their experiences of cross-cultural mentoring relationships in their own words rather than in brief responses (Patton, 2002; Rubin \& Rubin, 1995). Answers to open-ended questions provided extensive details that addressed the research questions in this study. The researcher was flexible enough so as to understand the complete depth of each participant's experience (Rubin \& Rubin, 1995). These questions sought (a) background information of participants, and (b) participants' perceptions regarding their crosscultural mentoring experiences.

The section of the interview protocol that asked about participants' perceptions regarding their cross-cultural mentoring experiences contained main questions and probing questions (Rubin \& Rubin, 1995). Main questions were used to elicit more lengthy responses as they encouraged participants to tell me about their experiences. For instance, participants were asked, "Tell me about challenges in your mentoring 
relationship". Probing questions sought clarity on items raised from participants' answers to main questions, for instance, when participants reported receiving feedback, they were requested to, "Give me an example of how your mentor provided feedback."

The phenomenological interview tends to be informal, conversational, and interactive (Rubin \& Rubin). To help participants speak more freely about their experiences, particularly regarding situations when they experienced difficulty, I was patient and attempted to put them at ease by being open, encouraging and flexible. This helped participants describe their experiences as fully as possible so that I could explore and understand each experience.

The semi-structured interview guide was reviewed by two colleagues in the researcher's dissertation peer-group, my dissertation committee and the Office of Graduate Studies so that could provide feedback on any necessary revisions. Further revisions were made to the research questions in collaboration with the Chair of my dissertation committee, and two colleagues from my program. In addition, an IndoCaribbean medical researcher was contacted through friends in Miami, and was asked to pilot the interview guide.

\section{The Pilot Interview}

The pilot was designed to provide feedback on whether questions were understandable, and would elicit responses with sufficient richness, detail and nuance needed to answer the research questions in this study. To pilot the interview guide the same protocols the researcher planned to use to interview participants in the study were applied. The pilot study however, was not included among the 15 interviews in this study as it was designed to serve as a tool to help me as the researcher refine the interview 
guide so as to elicit meaningful data for the study. Piloting the interview guide also helped the researcher become more familiar with using the guide during an interview. No revisions were made to the interview guide following the pilot since all questions were understandable, and with probing questions and follow up questions, elicited responses with sufficient richness, detail and nuance to answer the research questions.

\section{Interview Administration}

Prospective participants who met the criteria for the study were recruited via phone or email with an invitation that described the study, and listed the criteria to participate. Prospective participants, friends and formal classmates were also asked to identify additional interview prospects, and to provide those prospects' contact information including name, phone, and email address. All prospective participants were contacted by phone to confirm that they met the criteria to participate in the study, and that they were free to be interviewed regarding their cross-cultural mentoring experiences. Individuals who met the criteria of the study and could speak to their experiences were asked to participate.

Mutually convenient dates, times, and communication formats for interviews, either in person, via Skype, or phone, were scheduled based on what each participant was most comfortable with. Eight interviews were conducted in person, five were via Skype and two were by phone. Skype, a computer aided communication programs, was used when participants lived in other states, so this enabled the researcher to see and be seen, and to communicate with participants. Mutually convenient dates and times together with locations that were quiet, comfortable, and private were selected for the in person interviews (Glesne, 1999). Locations included (a) workplaces, (b) participants' homes, 
and (c) study rooms at local libraries. The interviews all lasted approximately 60 to 90 minutes and were digitally recorded on two separate devices for the full duration of each interview in case one malfunctioned. All interviews were audio-recorded regardless of the communication system or format used during the interview.

\section{Informed Consent}

All participants were asked to sign duplicate copies of an approved Florida International University Institutional Review Board informed consent release form to acknowledge their voluntary participation in the study (see Appendix B). In addition to consenting to participate in the study, this form served as an agreement of anonymity and confidentiality of the participants' interview responses. Participants were provided with the forms, they retained one copy for their records, and provided a copy to the researcher prior to the interview, or returned a signed copy as a scanned attachment via email.

\section{Field Notes and Journal}

I recorded typed field notes following each interview to maintain a record of participants' behaviors and the researcher's own observations. By doing this I immediately captured my thoughts and ideas, so that they were more detailed and accurate (Patton, 2002). My field notes included basic information such as date, interview location, participant information and other facts about the interview in a sequential format (Patton, 2002).

I kept a typed journal of my thoughts, feelings and immediately following each interview, and throughout the study to further examine assumptions as they arose during the research process and interviews, and to record participants' nonverbal behaviors during interviews. 


\section{Data Management}

Data management must "enable the researcher to organize and make data easily retrievable and manipulable" (Marshall \& Rossman, 2006, p. 153). Data for this study included the interview guide used to conduct interviews, audio-recordings of each interview, transcripts of complete interviews, researcher journal, field notes, copies of email correspondence, and data analysis files.

All interviews were transcribed verbatim by a transcriptionist. The transcriptionist was asked to prepare verbatim, fully typed versions of each interview, including the notations of "unintelligible" phrases or words that she could not decipher from the audio recordings. The interviews were provided to her on the researcher's iPod and were transcribed directly off this instrument. Completed transcripts were also stored on the iPod and returned to the researcher. The transcriptionist did not retain any audio or typed records, and further, she was instructed to delete any temporary files that may have been created on her computer during the transcribing process. Her computer was also inspected by an Information Technology professional to verify that all records were removed from any traceable sources and completely deleted.

All files were transferred to my computer and deleted from the iPod upon receipt. I transcribed two of the interviews that were performed via Skype so that I was able to use audio enhancing software to assure accuracy of the transcripts, and also to expedite completion of the transcribing. All transcripts were verified for accuracy by the researcher. This process entailed listening to the audio recording while reading the transcript. During this process I corrected and clarified any unclear or incorrect notations that were on the transcripts. 
Electronic data in this study was managed and will continue to be protected according to the FIU IRB Data Management/Security Guidelines. Sub-folders were created on the researcher's computer to contain records including questionnaires, transcripts, journals, field-notes, audio-recordings and copies of email correspondence from this study. Electronic records were backed up to an external drive and are stored in a safe. All printed records and documentation that are not electronic are stored in a locked file cabinet to which the key is secured. These records will be kept for 3 years following the study after which they will be destroyed. Electronic files will be kept secured indefinitely.

\section{Data Analysis}

Data analysis includes data organization, thematic analysis and interpretation, and report writing (Marshall \& Rossman, 2006). Data analysis requires breaking data into "manageable units, synthesizing it, searching for patterns, discovering what is important and what is to be learned, and deciding what you will tell others" (Bogdan \& Biklen, 1982, p. 145). A computer software package was used to assist with the data analysis process, and Microsoft Excel was used to organize the analyzed data.

The purpose of the data analysis via transcribed interviews and field notes was to analyze Indo-Caribbean protégés' accounts of their perceptions regarding their crosscultural mentoring experiences in the United States. The analysis aimed to obtain "a universal description of the experience representing the group as a whole" (Creswell, 1998, p. 122).

Creswell's (2007) simplified version of Moustakas's (1994) Stevick-ColaizziKeen Method of Analysis of Phenomenological Data was used as it provided "the most 
practical, useful approach" (Creswell, 2007, p. 159). The analysis of the data was conducted in two phases, the individual phase, and the composite phase.

\section{Individual phase}

In the individual phase transcripts were read and re-read to determine their significance to the phenomenon. Next statements were coded according to what was explained in the content or contexts of each experience. This was done using AtlasTi. All statements were then imported into MS Excel, from where they were sorted to identify relevant/non-repetitive statements, or meaning units of experience. Each meaning unit was placed on a separate tab in the Excel workbook. These meaning units were grouped into categories which were clustered into themes and color-coded in the Excel workbook. The meaning units of experience and themes were synthesized into textural descriptions of what was experienced, for example, feelings, challenges, and beliefs, and illustrated with verbatim excerpts from each transcript.

\section{Composite phase}

In the composite phase, textural descriptions were combined to build composite textural descriptions to describe how participants collectively experienced the phenomenon. For example, a composite textural description of sources of wisdom described participants' mentoring experiences in this study. Three themes emerged that describe participants' collective experience with the phenomenon.

I then created a codebook to define the overarching themes, and to cluster and describe the sub-themes that emerged under each theme. Using the codebook helped me organize the supporting categories within each sub-theme, and how each subtheme related to the overarching theme. 


\section{Integrity Measures}

The integrity of qualitative research is reflected in its trustworthiness and rigor (Lincoln \& Guba, 1985). Credibility, transferability, dependability and confirmability are four criteria used to 'formalize rigour' $[\mathrm{sic}]$ or product and process in the social sciences. This serves to show that findings are "worth paying attention to, [and] worth taking account of (Lincoln \& Guba, 1985, p. 290). The strategies that were used to enhance trustworthiness and rigor of this study follow.

\section{Credibility}

Credibility refers to the degree to which findings makes sense and are believable (Lincoln \& Guba, 1985). Strategies to enhance the credibility of this study included (a) member checking, (b) including quotes from participants' interviews (c) peer reviews, (d) engaging in epoché, and (e) maintaining a researcher journal.

To perform member checking I emailed transcripts of participants' interviews to them and they verified that they were correct according to what they previously shared (Lincoln \& Guba, 1985). None of the participants reported any incorrect information, however one participant, Nira emailed me some additional information to lend clarity to one aspect of her interview that I inquired about as it was unclear. This information was noted and added to the end of her interview transcript, and was used in the data analysis.

When I presented the research findings I provided quotes from participants in the study so that readers and other researchers could read actual participants' responses as evidence regarding their cross-cultural mentoring experiences. By presenting accurate representations of participants' experiences readers who have shared a similar experience may recognize the realities that have taken place (Sandelowski, 1986). 
Peer review requires having one's peers review the research methods, meanings and interpretations for methodological coherence and congruency (Corbin \& Strauss, 2008; Creswell, 2007). To perform peer review my dissertation peer group engaged in review and discussion of the research methods, interview guide, data collection, and data analysis prior to proposing the study. Revisions were made based on feedback. The data analysis containing textural and structural descriptions and composite textural-structural description of meanings and essences were also reviewed by my peer group and classmates who agreed to assist with this aspect of the study. During the peer review that took place following the initial thematic analysis it was suggested that the cross-cultural aspects of the study were not evident hence significant revisions were made so that findings pertaining to participants' and mentors' cross-cultural mentoring relationships were more evident.

To maintain the research journal I recorded my thoughts, feelings and reflections of my experiences immediately following each interview, and throughout the study so that I could further examine my assumptions as they surfaced during the research process and interviews. I also recorded participants' nonverbal behaviors.

To engage in epoché I also clarified my experiences with the phenomenon by setting aside or bracketing my preconceptions, assumptions and biases (Moustakas, 1994) within the research journal. I also answered the interview questions myself and transcribed the answers before beginning the interview process.

\section{Transferability}

Transferability requires describing the phenomenon with enough thick, rich detail that readers can evaluate and determine whether findings from this study can be 
transferred to their own or other settings (Lincoln \& Guba, 1985). I provided rich, thick descriptions, and textural and structural descriptions of participants' perceptions and experiences with the phenomenon to help readers determine whether the findings can be transferred to their settings.

\section{Dependability}

Dependability refers to the consistent application of data analysis procedures so that the research process is replicable (Lincoln \& Guba, 1985; Miles \& Huberman, 1994). I created an audit trail containing detailed descriptions of the research process including data collection, data analysis and synthesis, and related decision-making. The reflective journal described under the data collection section was used to maintain the audit trail. The peer review process as described previously also served to enhance consistency, consensus and any assumptive representations.

\section{Confirmability}

Confirmability refers to how the researcher demonstrates neutrality in interpretation of the data and serves to authenticate the results of the study (Lincoln \& Guba, 1985). A peer group external auditor assisted with confirmability of this study. The auditor reviewed the research process, interview transcripts, textural/structural and composite descriptions, the researcher's journal, and the data collection instruments and found that they documented the research appropriately.

\section{Limitations}

Participants' experiences of difficulties or challenges within their cross-cultural mentoring relationships were subjective, and therefore some participants were somewhat cautious as they divulged details regarding difficulties within their mentoring 
relationships. Further, since 13 of the 15 participants were female, and 13 of the 15 also had one parent of Trinidadian origin, this study is not generalizable to all IndoCaribbeans who have experienced cross-cultural mentoring relationships in the United States. This study also collected data from participants in various industries, and professions, with different levels of education, the findings therefore may not be extended to every cross-cultural mentoring relationship.

\section{Summary}

In this chapter the phenomenological framework used for the study was explained. The researcher's autobiography, assumptions, and journal, research procedures, and strategies used to select participants were also presented. Data collection, data management, and data analysis using the modified Stevick-Colaizzi-Keen Method of Analysis of Phenomenological Data were detailed. Measures taken to protect participants in the study, integrity measures and limitations of the study were also provided. Chapter 4 includes the findings of the study, and Chapter 5 includes discussion, implications, and recommendations for further research. 


\section{CHAPTER IV}

\section{FINDINGS}

In this chapter, the findings of the phenomenological study on the perceptions of Indo-Caribbean protégés regarding the effects of their cross-cultural mentoring experiences in the United States are presented. Protégés in this section are referred to as participants to reflect their connection to the data. The findings in this chapter emerged from the inductive analysis of data collected from participants' interviews. When quotes from participants' transcripts are used to support the findings, pseudonyms and line numbers from transcriptions are provided (e.g., Ashti, lines 110-112). An eclipses is used when words are omitted within a quote.

Participants in this study were Indo-Caribbeans, that is, of Indian ancestry, who migrated from, or were born to Indian parents from Trinidad, Guyana, and Jamaica in the Caribbean. The 15 participants reported on their perceptions as protégés in dyadic crosscultural mentoring relationships with mentors who were European American, African American, and East Indian directly from India, Black Cherokee, and Hispanic. They chose these mentors primarily because their race or ethnicity was different from their own, and because these mentoring experiences stood out within their academic and professional careers. Protégés' perceptions were shaped by East Indian traditional practices that influenced their approach to learning and education. Mentor influences were primarily shaped by ethno-cultural factors developed within the U.S., or in their native homelands.

The initial findings of this study reflect how participants were influenced by familial and cultural aspects of their East-Indian heritage as well as influences from being 
raised in the Caribbean and in the United States. Participants' perceptions of their crosscultural mentoring relationships as a result of the differences between their IndoCaribbean culture and the racial and ethnic cultures of their mentors are also included in this section to reflect the cross-cultural aspect of these mentoring relationships.

According to traditional East Indian philosophy the guidance of a mentor or guru stems from early East-Indian theology representing a relationship where a disciple or protégé seeks to advance his knowledge through guru-shishya (R. Persaud, personal communication, February, 19, 2012). This is a relationship through which the learner gains scriptural knowledge of the Upanishads or holy texts as a means to achieving atmajnana or self-realization at the feet of the master (Gosvāmī, 1977). Although participants in this study may not be aware of these historical East Indian contexts, they form the foundations for how East Indians traditionally approached learning and education.

This underlying concept of guru-shishya holds true for participants' in this study regarding their cross-cultural mentoring relationships although learning and guidance was specific to participants' needs within academic and professional spaces in the United States. The goal of the mentor/protégé relationship follows the same guru-shishya principle; the protégé obtains subtle or advanced guidance and may eventually master the knowledge embodied by the guru (Vaswani, 2008). Themes are contextualized within East Indian tradition to reflect the foundations of guru-shishya, the guru/disciple relationship.

First "sitting at the feet" of gurus within participants' personal lives taught them bhakti or devotion and surrender to others. This shaped participants' attitudes toward academic achievement and obtaining new knowledge from mentors whose cultures were 
different from their own. Second, guru-shishya, the path to learning and discipleship reflects ways that protégés perceived mentors' guidance related to work, skill acquisition, and social or emotional support. This influenced participants' acceptance and appreciation of mentors, and what they learned within their cross-cultural mentoring relationships. Third, samavartan sanskar or the sense of coherence that protégés and mentees' attained which helped them understand, manage and find meaning in their lives, academically and professionally. The sections that follow provide details on the three themes: (a) "Sitting at the feet" of gurus, (b) Guru-shishya: Learning and discipleship and (c) Samavartan sanskar: Building coherence.

\section{"Sitting at the Feet of Gurus"}

"Sitting at the feet of gurus" within participants' personal spaces helped them learn bhakti or devotion and surrender to others. Historically, learning at the feet of a guru was a privilege afforded only to the Brahmin castes in India. Following indentureship, when Indians migrated to the West the caste system was no longer practiced, family members assumed a primary role in ensuring that all children were taught. In doing so, their children could become educated, would not be viewed as subordinate or inferior. "Sitting at the feet" of gurus or teachers within the secular world could provide the opportunity for higher inquiry through education, and allow learners to become successful professionals, beyond what they could accomplish in India.

Within this study, "sitting at the feet of gurus," informs ways that participants" families and Indo-Caribbean heritage shaped their attitudes toward academic achievement and obtaining new knowledge, making them more accepting of guidance from others. Gurus or mentors in participants' early lives included parents and family 
members who instilled the importance of higher inquiry through learning and educational achievement. Understanding the benefits of educational achievement influenced participants' attitudes toward gurus or mentors outside of the home, who were from Eurocentric, Afrocentric, Indocentric, Hispanic-centric and Native-American backgrounds. Mentors' included faculty, advisors and supervisors whose knowledge became sources of wisdom for participants in this study. "Sitting at the feet of gurus" shaped participants' attitudes toward academic achievement symbolized by: (a) indebtedness to parents and family (b) sampradāya or East Indian traditions, and (c) sources of wisdom.

\section{Indebtedness to Parents and Family}

Indebtedness to parents and family refers to the learning and guidance that participants obtained from their relatives, both immediate and extended. Traditionally, Indo-Caribbeans focus on educating their children so that as adults, they are able to care for their parents and elders when they are no longer able to work. As such, the child has the opportunity to repay his debt to his parents and family for their efforts and support during his childhood. Symbolically, indebtedness to parents and family represents a sacred thread of debt to one's parents and ancestors as those who caused the individual's existence and first nurtured him. In this study parents and family shaped participants attitudes toward knowledge acquisition.

Acquiring knowledge fulfilled two roles, firstly, it was a means of retaining cultural traditions and secondly, it provided financial stability and a successful life (Crowley, 1990; Shyam, 2008). Retaining cultural traditions, while adapting to new social conditions became deeply embedded following indentureship. In an effort to 
preserve cultural traditions, the family became the individual's first learning environment, such that parents, grandparents and relatives focused on teaching Indian cultural practices, ideals and symbolic systems to their children. Focusing on education offered an opportunity to become prosperous by purchasing land, and attaining professional status, traditionally as doctors, lawyers and politicians.

Although participants belonged to a range of fields, and also departed from cultural traditions following their migration to the U.S., they all reported on how the support and actions of their families shaped their views regarding education and toward those who support their educational and professional goals. Prad, Bina, Rani, Nira, Bela, Aalia and Sita reported that their families influenced (a) learning and educational achievement, (b) sacrifices toward educational goals, and (c) discipline and respect.

Learning and educational achievement. Learning and educational achievement refers to the academic goals that participants developed. Seeking learning and educational achievement through knowledge acquisition is rooted in the Eastern belief that the holistic development of wisdom connects the mind, body and spirit to the universe (Thaker, 2007). Although most participants in this study may not necessarily be aware of this cultural truth, their parents, grand parents and older relatives retained the significance and meaning of knowledge as the means to uphold dharma. Dharma being the duty to seek liberation, or self-actualization through one's profession, religion and life in accord with good and decent conduct. In this sense, participants' parents, grandparents and relatives assumed the responsibility for guiding their learning, and were influential in building their value for learning and educational achievement, and their regard toward those who influenced their academic and professional development. 
Prad shared that elders within his home were his first mentors who guided him since early childhood, "We start from a very young age to be mentored. Fast forward to my professional mentoring story is that I was already at home, working with all these different types of people" (lines 657-560). As a child and young adult, his maternal uncles and grandmother served as his mentors and even teachers when they guided his spiritual knowledge, and his academic work and conduct. In the Indo-Caribbean home, elders were well respected and held the right to teach, guide, influence or discipline the younger generations. Elders frequently served as teachers, role models and mentors.

For Prad this was significant because the comfort and acceptance he felt when being mentored by his family was distinct and different from the judgment and prejudice he felt after migrating to the United States, and learning to work with others in his field. Although his mentors were not prejudiced, many authorities within his field whom he expected to be supportive allies, in fact were prejudiced against him because of his dark complexion, his Caribbean accent, and his extensive knowledge in the field.

Aalia contended that the value and importance she placed on education was instilled in her as a child, and came from her Indian heritage, "Education is always the way to get you forward so I think from my Indo-Caribbeanness...that's what sorta stands out for me" (lines 65-70). Aalia felt that her grandmother's struggles to educate her daughters in spite of neighbors' criticisms was inspirational to her:

What she did which is quite unusual at that time was to send all her daughters to school when everybody in the village sorta frowned upon that and said "well why are you wasting money to send your daughters to school, that doesn't make sense", but...because of that my aunts sorta became like teachers, or nurses, you know worked their way up. Then that gave my generation, so my cousins and I the opportunity...to do great things... and really sorta move up the ladder, whether class, economic, social. (Lines 49-61) 
Aalia, like Prad and Sita felt privileged to have the opportunity to gain an education in the U.S., compared to their ancestors who struggled to earn a living, and often never attended even elementary school. Sita's family was impoverished just as Aalia's and so she came to value the academic opportunities she gained when her family emigrated.

Participants' respect for education and learning was strongly influenced by their parents and ancestors, leading to the indebtedness described here. Mentors' views, based on what emerged from interviews with participants, and based on existing research are presented below to describe ways that mentors of various races and ethnicities appeared to view learning and education. Mentors' views were similar to participants' views in some ways, yet at times they differed.

Mentors who were East Indian and migrated to the U.S. directly from India demonstrated understanding and appreciation of participants' orientation toward learning and achievement and the challenges they encountered, particularly because of their shared Eastern value of knowledge and enlightenment. Anu and Bina both had mentors who were East-Indians, and both mentors were enthusiastic and assistive in providing experiential opportunities, training, and guidance that exceeded their expectations. Anu in fact was overwhelmed by the guidance she received.

Mentors who were Black, Black-Jamaican, and Hispanic by virtue of being minority cultures in the United States shared an appreciation for cultural acceptance, visibility, increased achievement, socialization, trust and relationship building, consistent with existing research (Brathwaithe-Gardner, 2006; Carter, 2000; Jeria, 2002; Taylor, 1995; Waterman, 2007; White, 2006). These factors became tools mentors used to 
enhance participants' learning. For instance Kavi and Mrita both had Black female mentors, who while they appeared to be more rigid with rules and procedures, would always safeguard and protect their protégés. Bina's and Keya's mentors, Hispanic and Black-Jamaican females respectively, assumed strongly developmental roles in that they personally trained or selected the training protégés needed in the field. Minority mentors appeared more empathetic and sensitive to challenges that participants experienced.

In contrast, mentors who were White males or females were raised and educated in the United States where they experienced the privilege of public schooling with organized support systems that collectively empowered those who had access (Young, 1990). For White mentors, learning and educational achievement were centered on institutionalized Western ideals, focused on providing recognition and validation of cognitive achievements. Western knowledge is defined by rigor and purpose, and the value that it brings to roles in society through balance and fulfillment (Merriam, 2007). Consequently learning and educational achievement reflects individualized success. Bela's mentors for instance, were White males, and very often focused on commending or praising her work and achievements.

White mentors also focused on guiding participants toward achieving the objectives of their academic or professional roles centered on participants' acquisition of work-related competencies, achieving good grades, and completing required internships or practicums. White mentors who were Jewish, however displayed more empathy and community toward participants. They exhibited interest in participants' well being, care toward their families, and sought to build more collegial relationships with them. For instance Aalia's mentor, a White Jewish-American male, often invited her to his home to 
spend time with his family, particularly because they shared a mutual enjoyment for discussing international politics.

Sacrifices towards educational goals. Sacrifices refer to activities or benefits that participants and their families gave up so that they could redirect resources toward educational goals. Sacrifices toward educational goals constitute a significant focus of the Indo-Caribbean family and individual, and while they may not be directly related to mentoring relationships, sacrifices are endured by many immigrants who attempt to have their children educated in the U.S. so that they may build better lives for themselves. Based on this study, participants pushed themselves to succeed in part, because of sacrifices made on their behalf. Makin g sacrifices for one's family stemmed from migrations at the time of indentureship when Indians gave up their material possessions including their castes or social stratifications, to seek a better life in the West Indies (Shyam, 2008).

As immigrants, participants in this study felt that their family's sacrifices helped to shape their views on educational achievement. This is an important foundational element that characterizes the Indo-Caribbean individual living in the United States. In the new environment, caste was no longer relevant, instead, the successes and achievements one earned through hard work and perseverance determined one's standing. Indo-Caribbean parents were and are determined to take any means necessary so that their children would progress and become successful in their careers.

While enlightenment is the goal of education in the traditional Eastern perspective, becoming successful for participants in this study meant they were able to understand, manage and find meaning in their lives, academically and professionally. 
Education is viewed by older adults as the route to independence so they make all necessary sacrifices for their children to be well educated. Educational goals were foremost in the Indo-Caribbean home and achievement of one's goals is a mark of success and worth for the entire family. Bina and Bela reported on the sacrifices their families made for their education. Bina's family was intent on their children being educated abroad even though it was very costly:

My dad wanted all of us to have an education abroad, working both of them in school didn't earn that much [making teachers' wages], plus my dad's brother was studying in England, so my dad and mom had to sacrifice a lot to send all of us abroad to study as well as support his brother who was studying medicine in England. (Lines 32-35)

Even though many families did not earn high incomes, they made the necessary sacrifices so that children could be well educated.

Bela's parents also made sacrifices so they could afford a private education for their two children from elementary school through to college. They viewed private schooling as a superior quality of education than public schooling:

We had a one-bedroom apartment even though there were four of us, because my dad always wanted my brother and I to be in private school. He worked at a marketing company, but at the time it's not a lot of money. So he sacrificed but my mom sacrificed too even though she didn't work, but we lived in a smaller place. So he could pay for both of us to go to private school. And I went all the way through high school to private school....He always tried to put us in the best education system. (Lines 35-43)

It took most of her father's earnings to put Bela and her brother through school. Her parents in return expected the children to excel in their fields, particularly since such tremendous sacrifices were made on their behalf.

The idea of making sacrifices for one's education is clouded by the Western view that education is one's entitlement. For mentors who were born or became naturalized 
citizens in the U.S., education had been paid for by the government or via scholarships, fellowships, and other funding available only to U.S. citizens and hence they were eligible for such funds. In the U.S. free education and training are enforced through equal opportunity legislation, to increase employability and to reduce discrimination (Young, 1990). Increased diversity has created opportunities for and increased the visibility of Black, Hispanic and Native American populations, many of whom may be cognizant and empathetic to those who are not afforded similar opportunities as themselves.

Discipline and respect. Discipline refers to the strictness that was practiced within the home, and respect refers to the regard and deference toward teachers and older adults, instilled both at home and at school. Discipline and respect toward teachers and older adults formed an integral part of participants' upbringing, which transcended into their regard and respect for mentors as wiser, more learned adults. Discipline in the typical Indo-Caribbean home stemmed from the practice of living among extended families, such that anyone in the home had the right to enforce discipline, whether corporally or through less authoritative means. At school in the Caribbean, discipline stemmed from practices within the traditional banking system of education (Freire, 1993). Respect for teachers was enforced as a remnant of the banking system of education formerly used to reinforce stereotypes and to maintain social order and cultural hierarchy (Freire, 2006).

Respect stemmed from the practice of bowing at the feet of elders, gurus and Hindu priests to obtain blessings by virtue of their age and wisdom, and is a historical cultural practice encouraged by Indo-Caribbeans (Ranmath, 2010). Respecting elders 
and teachers was paramount within the home, and parents encouraged both teachers and family members to assume responsibility for guiding and enforcing rules primarily so that children would focus on their studies, and do what was expected at home and at school.

Bela and Bina reported on their parents' beliefs regarding discipline. Bela grew up with a lot of discipline, with parents who were both very strict, and united in the way they enforced discipline, especially regarding education, which was a priority in her home. She shared: “One person tells you what to do and you do it. You don't ask questions" (line 288). Typically, in East Indian households, the expectations are to focus on getting an education, finding a job, getting married and settling down to raise a family in that order. Obtaining an education represents the tenth samskara or right of passage in Hindu philosophy, and parents, especially those who adhered to tradition were very strict about studying and completing one's education. For instance, Bela learned how unacceptable it was for her to break this format when she had her daughter, was later divorced, and then chose to go back to school. Her mother was in disbelief:

She's like, "I can't believe you would do that." When I quit my job, I was working full-time, to go back to school. My family sat me down, they're like "are you crazy? You quit your full-time, you decided to leave this guy and have this kid, and now you're quitting your job to go to school?" (Lines 566-570)

As far as Bela's parents were concerned she achieved a graduate level education and left college behind so she should now be married and raise a family. They were upset that she broke this tradition and became divorced, even though she had a child, then chose to return to school. To confound this even further was the stigma attached to being divorced since women were expected to conform to their roles in the family and not to question or challenge oppression within their marriages (Shiw-Parsad, 1999). 
Bela was fortunate that her mentor at the time, a White male, was far more understanding than her parents. Within the U.S. women had already entered the field of medicine to some extent so navigating around childcare needs was not a new phenomenon--it simply meant making different decisions. Bela's mentor counseled her on planning a career and academic pursuits that would accommodate the needs of her daughter:

As far as the career path goes, he spoke to me about the fact that I had my daughter and... where I was going. Because originally I said I wanted to be a neurologist. And he said, "Really?" I mean like the hours, and what's gonna to happen to... One thing he always took into consideration was my daughter. So he said what about how much you're dropping her off now, and leaving her with your mom now. And when we talked, when I shadowed this doctor I realized what he was saying. (Lines 100-107).

Bela was originally planning to study neurology, and her mentor suggested she focus on a field that would require less academic involvement so that she could be available to spend time raising her daughter. Her mentor also had her shadow a surgeon so she could see first hand how demanding a career in neurology would be.

Bina's family was also disciplined about education. Her parents were very strict, especially since her dad was a school principal and her mom was a teacher. This meant their children needed to live up to even higher standards reflective of their parents' roles as educators. Bina described the differences she saw growing up in Trinidad, versus how kids in the U.S. are raised, "It was so different growing up in Trinidad...I had rules, my parents always took the side of the teacher, my teachers they always expected...the highest academics from me" (lines 82-85). Indo-Caribbean parents always insisted that their children display respect and obedience to teachers. Disobeying or disrespecting teachers in any form meant you would be punished. 
Kavi, Bina and Arti observed how little respect is shown to teachers and elders in the United States. Kavi shared, "My culture has taught me [about] respecting my elders, respecting my mother and father....Dealing with children today, I see a lot of disrespect compared to when I was growing up" (lines 64-70). Kavi was raised by her grandparents, and so being older and more set in their ways, were even more insistent that Kavi was respectful to everyone.

Bina, because of how she was raised assumed that her students' parents would teach them to be respectful. She learned however that in the U.S., little value was placed on respecting teachers or elders, in fact, in U.S. society, teachers and elders are devalued and disrespected (Seepersad \& Bailey-Watson, 2007; Sultana, 1996). Bina shared:

You almost have to teach them that you as the teacher, require and expect respect, in Trinidad it was very different....I have to get used to the parents not always having the kind of respect that...you would expect as somebody working in education....I work hard at you know raising those standards. (Lines 87-98)

Bina was surprised to see young children being disrespectful to their parents here in the United States, and that parents would allow such behaviors. Like Bina, Arti expected that teachers would be shown a certain level of respect.

Arti explained how teachers in Trinidad always seemed a little distant, somewhat apart from students in that they never fraternized or became involved with their students on a personal level, and so she developed a certain level of regard for them. She shared, "I grew up treating and seeing teachers and mentors... a little distance apart from ourselves and just treating them with a certain respect that was different from everyone else... and it has stuck with me up until this point" (lines 137- 140). 
Arti contrasted the deference and respect that students in the Caribbean showed to teachers, to the lack of respect shown to teachers, mentors and professors here, "I really see a big difference between the way that they're treated...I've seen the lack of respect and just marveled and how absolutely different it is here" (lines 137-150). In U.S. society discipline and respect are enforced only when written rules or policies are broken, otherwise, learners appear to assume free reign and behave in ways that are often viewed as discourteous and disrespectful by those from other cultures (Lew, Chang, \& Wang, 2005).

Because protégés in this study were always respectful of mentors, they were perceived at times to be too passive. As such, mentors frequently encouraged them to stand up for themselves, to contest grades, or to advocate more for themselves, rather than accept the status quo, and at times even felt the need to protect them.

In one particular instance, Mrita's mentor, a Black-Cherokee woman felt the need to be protective. She saw that Mrita was being treated disrespectfully by a male employee who sought her assistance. Mrita explained:

I remember specifically this one time where this older gentleman, he was just having a ridiculous problem with his computer. He came barging into my office, and he started cursing at me. And this was my first encounter with him. She came out her office, she heard him, and she dealt with him head-on. First of all she made him literally turn his head, and not look at me but face her. So she stood in the way so he was facing her and not me. So right there I felt protected. (Lines 224-230).

Her mentor was direct and confrontational both verbally and physically, and stood between Mrita and the employee in a protective stance, while insisting that if he had further problems, he should direct his inquiries to her, and not be rude or disrespectful toward her staff. By doing so, the mentor showed Mrita an example of how she too could 
protect her own employees. This Native American mentor recognized the value of respect, and saw how the passivity of her employee was being abused. This mentor was both sensitive and nurturing as she defended her protégé, consistent with existing research on Black Cherokee women (Portman \& Garrett, 2005).

Participants in this study were raised within East Indian traditions that required respectfulness, obedience, humility and submission to others. Participants maintained a high level of respect for mentors and recognized that their years of experience, expertise in their fields, and establishment in their careers were to be valued. Learning and educational achievement, making sacrifices toward educational goals, and discipline and respect toward others were taught to participants by their families. Value of learning and educational achievement, making sacrifices toward educational goals, and discipline and respect toward others influenced participants' cross-cultural mentoring relationships, and ultimately what they achieved through those relationships.

\section{Sampradāya}

Sampradāya refers to the East Indian traditional and religious practices which form the foundation for how participants live their lives, approach, perceive and experience meaning. Within U.S. society, culture and education are distinct entities. In spite of the myriad of races and cultures in the U.S., making connections within the education system have traditionally been discouraged. Instead adult learning in the U.S. focuses on self-directed learning, independence, rational discourse, and reflection centered around the individual learner (Merriam, 2007). Within recent decades has there been discourse that places value on the multi-cultural, multi-ethnic capital that can be harnessed to advance connections and relationship with the learner and his environment. 
Cross-cultural mentoring relationships in this study exposed participants to cultures from various races and ethnicities. Participants' emotional and motivational responses within their relationships appeared to be guided by certain traditional and religious practices within their own lives, that also cemented their connections to the Indo-Caribbean ethnic identity. In addition, the ethno-cultural aspects of Indo-Caribbean culture are included to differentiate this group from other Caribbean immigrant groups in the United States. This is significant since other mentoring studies have not clearly described Caribbean racial and ethnic groups within mentoring literature (Barrett, 2010).

Symbolically sampradāya represents the respect and power wielded by spiritual masters that lends stability to religious identity. This stability generates the formation, transmission and perpetuation of truth through learned practices, views and attitudes (Gupta, 2005). In this study, the respect that participants extended to their mentors is largely shaped by their traditional and religious practices. Sampradāya or East Indian schools of thought are manifested as (a) East Indian cultural practices, (b) Eastern vs. Western religion, and (c) adaptation and flexibility.

East Indian cultural practices. Cultural practices refer to the deeply ingrained, traditional, East Indian cultural practices that participants maintained. East Indian culture served as a connection to participants' heritage and a source of pride, and helped them to remain focused on their own values within the U.S. environment. The primary school of thought that stems from East Indian culture is the focus on learning and studentship - a tenet that undergirds the mentoring relationship. It dictates that within the Hindu lifespan the first 20 years should be dedicated to bramhacharya-ashrama or the student phase 
(Venugopal, 1998). This reiterates the value placed on obtaining an education, whether academic and secular like in this study, or ascetic and scriptural as historically practiced. Cultural practices were represented in East Indian songs, scripture, practices, and family participation in East Indian events and ceremonies. Arti, Sita, Prema and Prad reported that they retained East Indian practices of attending temple, playing Indian music, and participating and attending Indian ceremonies and events after migrating to the U.S., so they felt connected with their heritage. Prad in particular shared many highlights that explained how deeply his Indo-Caribbean culture was embedded in his heart. One item he mentioned was the 16 samskaras or rites of passage that make meaning of events during a person's lifetime:

One particular samskara...would be the time when you get married or when your children are born, you invoke certain 'situational' songs or participation from different people... so over... we approach the issues of marriage, the issues of childbirth, the issues of child, children growing, up for example. (Lines 53-59)

Within East Indian culture, samskaras mark turning points in an individual's life. There are 16 samskaras in total all dedicated to guiding the individual toward learning truth and righteousness. The tenth samskara focuses on education, studying the Vedas or religious texts that begins at age 8 . Upon completion of this samskara this one pays homage to the guru, and departs from the guru-shishya relationship to return home and raise a family.

Retaining East Indian cultural connections served as a tool to help Prad find meaning in his life despite changes in his U.S. environment. He frequently discussed these practices and traditions with his mentors and peers to draw connections with his culture and his experiences in the U.S. workplace. 
For participants in this study, being raised as Indo-Caribbeans meant they were guided by both East Indian and Caribbean practices. As such, the value of education from their East Indian roots combined with tenets from within the banking system of education. The banking system of education is still practiced in the Caribbean and has influenced how participants in this study approach learning and respond to those who teach and guide them. As such, participants view learning and the acquisition of knowledge a required aspect of their life, causing them to be humble and accepting of others' guidance, yet given to passivity, hard work and diligence.

Eastern versus Western religion. Eastern religious practices and beliefs from Hinduism helped to strengthen participants' tolerance, humility and acceptance within their cross-cultural mentoring relationships. The Hindu religion focuses on attaining Brahman or release from the eternal cycle of birth and death. Although many East Indian participants retained Hindu religious practices and beliefs, others lost touch with it, and accepted new religions that were taught to their ancestors by missionaries in the West. In some instances, religious differences between protégés and mentors caused difficulty for some participants, yet for others religious differences strengthened their relationships with mentors. Aalia for instance found that her practice of Islam or the Muslim religion intrigued her Jewish-American mentor particularly because of his interest in international relations. They often discussed her religious and political views. Arti, Sita, Prema and Bina also spoke of how religion influenced their mentoring relationships.

Arti spoke about religious practices within her home: "I come from a deeply seated religious family, immediate family of Hindus...going to our local temple or mandir every Sunday...very immersed" (lines 9-11). Arti adheres to her East Indian 
religion and continues to instill these practices in her children, even though they live in the U.S., and attend Christian schools, hence she continues to propagate East Indian traditions and beliefs. She shared, "[It is] important to be able to be tolerant with everyone else's beliefs [since their] beliefs encompass their cultures and their backgrounds and their likes and everything" (lines 206-210). Raising her family as East Indian within a Christian environment reflects Arti's tolerance and acceptance of others' beliefs, while propagating her ancestral religious practices. Arti however still had difficulty accepting all of her mentor's suggestions.

Arti's mentor, her resident director was a White female who Arti described as very rigid and overbearing with her expectations of protégés. She practiced Scientology, and felt that Arti and another surgical resident needed to adopt some of its principles related to communication, to the point that she could be viewed as a religious bully to some extent. Arti reported:

(Scientology) it's a very very intense, straight on the path sort of sort of religion. You don't veer here or there. It's very black and white. And they have certain beliefs and they're very strong in it. I think a lot of it had to do with the way that she viewed people and she viewed life because of the background of Scientology and that came out and had effect on us and on me. (Lines 157-163).

The mentor's concerns were specifically related to her protégés' communication skills as she did not attempt to impose any other aspect of her religion. At one point this mentor insisted Arti and a colleague attend a Scientology communication training session so that they could learn of what was acceptable within the Scientology paradigm. Arti considered this one of her mentor's weaknesses:

(She was not) able to listen, and to take any feedback from anyone else. Her thoughts and her beliefs were so strong that she believed that it was always 
correct... and not just correct for her but was you know $100 \%$ correct for everyone else too. So I don't think she was open to listen to anyone else. (Lines 198-202).

The ideal being that the surgical residents should accept all they were being told by their resident director, and become more acquiescent to the mentor.

Sita felt deeply about her religion and her East Indian identity, particularly because of the alienation she sometimes felt, "You're born into the culture, you can't really shake it off... I feel like it's my every being" (lines 27-30). She frequently attended temple in the U.S., and felt that maintaining her religious and cultural beliefs taught her to be "tolerant of each other's differences, religions and colors" (lines 46-48) particularly because she was made to feel like an outsider in Texas because of her religion and East Indian appearance. Migrating to Texas was a challenge for Sita since her appearance and religious practices were alien to Texans. She chose not to be prejudiced against others so that she would not inflict on others the alienation that she experienced, even at the hands of her mentor at times.

Prema's religious practices included bhajans (religious chants), and transcendental meditation which she began at 8 years old. She has been on multiple pilgrimages to India to visit Sai Baba, an Indian guru, known by his devotees for his adherence to and message of unitary faith, spiritual principles, and love. She explained what spirituality meant to her: "When you're on a spiritual path...[it] is really about opening your heart. I always remember Sai Baba saying, 'I've come for the transformation of your heart'” (lines 367-371). For Prema, religious awakening and progression through meditation became a critical aspect of her life which she integrated into her professional practice as a clinical psychologist to help her connect and empathize 
with her clients. Because of the love and devotion she learned through her religion, she was able to harness these as tools within her personal life and her mentoring relationship, especially at times of difficulty.

Bina's religious background helped her build a strong connection with her East Indian mentor because of their shared spiritual values and backgrounds. She believed that the spiritual forces in her life led her to him, a priest who had worked with Mother Theresa, "I feel God gives you these opportunities and it's up to you whether you take them or not" (lines 791-792). Bina's family accepted Christianity, so based on this they continued to instill in her the importance of serving others. For Bina her religious beliefs were instrumental in the role she assumed at her church where she ministered to the terminally ill. As a Christian, she accepted the teachings of her mentor, who was in fact a Hindu priest, raised in India, who accepted Christianity, and served as a minister at her church. His care and interest in serving others formed an enduring connection between them both.

While most Indo-Caribbean families have retained Hindu religious practices, many older Hindus have developed an aversion to all things European or Westernized. They viewed religious conversion as a tool used by others to control and manipulate the slaves and indentured laborers. Missionaries sought to convert East Indians to Christianity however, despite efforts by Wesleyans, Anglicans, Lutherans and Roman Catholics, only a few East Indians converted (Ramdin, 2000). This reflects East Indians' adherence to tradition, religious practice, conservatism and ethnic cohesiveness, which remains ingrained in many East Indians today, forming an aversion against non-Indian religions. 
In the past, some East Indians accepted teachings from missionaries in an effort to be accepted, and consequently, their families were raised to follow new religious practices causing them to depart from East Indian religious beliefs, however they retained the cultural practices and conservatism which shaped dedication and commitment to East Indian ideals (Roopnarine, 2007). Parents in the Caribbean are also known to convert to various Christian based religions so that their children may be accepted into parochial schools to attain a higher quality of education than in public schools. This increased the prevalence of multiple religions throughout the Caribbean.

Some participants in this study chose to accept Christian religions because of the truths, values and beliefs that it represented to them. Being raised within one religion, within a society that contained multiple religions increased participants acceptance of others truths, values, and beliefs, preparing them to be adaptable and flexible here in the United States. Participants in this study who migrated for the purposes of education and professional achievement in the U.S., are accepting of different religions and religious persuasions as they recognize the diversity inherent within U.S. society, just as they did in the Caribbean.

Adaptation and flexibility. Adaptation and flexibility refers to cultural shifts in behaviors or thinking that participants made prior to, and following their migration to the United States. Being raised within ethnically heterogeneous societies as in the Caribbean, Indo-Caribbeans were accustomed to multiple racial and ethnic persuasions, and could easily adapt to various cross-cultural interactions. Adaptation typically meant changing communication styles or religious views, or adopting a more creolized or panethnic identity. 
Adapting for Suren meant speaking differently, "When I am in Trinidad I speak with the Trinidadian accent and not so much when I'm on campus" (lines 195-196). He added, "But then there are more deeper meaningful ways that I adapted to culture here" (lines 197). Following his migration to the U.S., Suren accepted Christianity, and for him, Christianity formed a meaningful foundation for how he lived his life, his responsibility to others, and the basis of his mentoring relationship. To him, Christianity was one of the ways that he adapted to live in the U.S. and for him it meant being, "Open minded towards each other and the ability for each other to grow and change...that's something that definitely developed" (lines 320-322). Suren found that being openminded and flexible helped his mentoring relationship in that he shared many of the spiritual beliefs of his White male mentor and was able to discuss areas of conflict more openly.

For Anu and Aalia, adaptation meant accommodating a more Westernized and a more multi-cultural Caribbean outlook respectively. Anu shared:

I feel like I moved away from more traditional Indian things. I really didn't grow up in it. My parents are really traditional, but I'm not. I've become more Western in my ways. I would say the Indian part of me of my heritage I really kind of lost touch with. (Lines 35-42)

Although Anu identified with being Indo-Caribbean, she no longer practiced the Hindu religion, which surprised her East Indian mentor, especially when Anu declined her invitation to attend temple with her. This however did not cause conflict, as her mentor accepted that Anu no longer practiced Hinduism.

Aalia explained that growing up in an integrated and interracial Caribbean environment made her feel both an Afro (African influence) and Indo (Indian influence), 
since those are the predominant cultures in Trinidad. She held a panethnic or unified view of her ethnicity, "Being a dougla which means you're half Indian half African...I've always thought that's what I most identified with" (lines 20-22). Aalia's family lineage is entirely Indian, however she believes the extensive Afro-centric influence that she experienced growing up made her feel "mixed," which positively influenced her acceptance of others, her ability to interact with mentors from different races and ethnicities, and enhanced her effectiveness in the field of International Relations.

Adaptation and flexibility served as a common bond between participants and mentors who were also immigrants. Although most mentors were born and raised in the U.S., at least five mentors migrated from India (2), Jamaica (2), and Germany (1). Anu shared that because her mentor was Indian, she assumed a motherly role with her, and tried to include her in family or religious celebrations. Keya and Nira shared that because their mentors were Black-Jamaican women, they bonded because of their island heritage and their zeal to excel professionally. As Caribbean immigrant women, they shared the drive "to have success with what they're doing" (Keya: lines 101-102). Prad's mentor migrated to the U.S. at the end of the Second World War. He shared that "as a German, as a Jew, [his mentor] had to navigate his own problems, or issues" (line 160). As a result he was able to help Prad acculturate or meld culturally in the United States.

Mentors who were themselves immigrants appeared to have a more caring and empathetic bond with their protégés. In these relationships, participants felt that mentors spent more time discussing their needs, and trying to help them personally. For instance Anu's mentor helped her furnish her home, and Nira's mentor encouraged her to continue attending school during an unexpected pregnancy. Keya's mentor often sat beside her to 
coach her in communicating with students, and Prad's mentor helped him overcome prejudicial feelings against him within the workplace.

\section{Sources of Wisdom-Western Experiences}

Sources of wisdom refer to the social supports, assistance, guidance and interactions with faculty, advisors, supervisors and peers that lead to higher inquiry, or enhanced learning and understanding. In this study, sources of wisdom included faculty, advisors, supervisors and peers within participants' classroom and professional interactions. Symbolically, seeking higher inquiry or Vedanta recognizes the master or guru as the source and giver of wisdom. Sources of wisdom that emerged were (a) discipleship and (b) gendered differences.

Discipleship. Discipleship speaks to participants' initial relationships with mentors in the U.S. who invested time and effort in the transference of knowledge either at college, or in the workplace leading to learning and professional development. While most participants knew of the role of mentors, two participants reported on their initial mentoring experiences, distinguished here because for these participants, mentoring relationship formed a new source of wisdom.

In the Caribbean teachers provided knowledge and guidance geared toward passing exams, and supervisors provided supervision and direction toward doing the job - there was no developmental component. Mentoring as a developmental exercise was not traditionally practiced in the Caribbean until well into the $20^{\text {th }}$ century when leaders realized that success in the workplace required everyone to be knowledgeable, and not merely competitors seeking promotion or higher salaries. 
Anu and Suren held a somewhat different understanding of mentoring as it was a new experience for them. Anu in particular experienced greater difficulties in accepting guidance. Anu explained that she did not have a mentor before. She shared, "I didn't realize the importance of having (a mentor) ...to just have someone take on that role (lines 106-110). She further added:

I never really understood the concept of mentorship until coming to the Untied States.... She took me under her wings, and she really helped from my first year at grad school. She really helped lay out a path for me. She connected me to researchers...helped guide me in terms of things that would really enhance my skills and...build my CV. (Lines 72-78)

Anu's mentor was an East Indian woman who came to the U.S. directly from India, and this possibly caused her to feel kinship or responsibility toward her. Anu had recently been employed when her supervisor took it upon herself to provide guidance regarding her research, practicum sites and internships, and other suggestions. She assumed the role of mentor even though she was Anu's supervisor in a role unrelated to her academic program. Anu accepted her guidance and found it to be very helpful and rewarding. Suren as well felt that mentoring was not a common practice in Trinidad where he was raised. His college had a faith-based organization focused on helping students transition from college to professional lives, and his mentor was a White male. Suren shared, "What was unique about my relationship with him was that I had a lot of insight into his family life at a time when I didn't necessarily have a lot of insight into family life...in the U.S." (lines 70-72). Since Suren accepted Christianity earlier on he felt that what he learned from his mentor formed an ideal that he could aspire toward in his own life. Suren and his mom migrated first to Canada and later to the U.S., and so learned from his mentor what his role as a breadwinner and parent required. For Suren, having a 
mentor was pivotal in his life since he worked in the field of IT, which tends to be extremely demanding, and hence the knowledge he gained regarding balancing his work life, spirituality, and family life was very influential.

Although Prema had prior mentoring experiences, her feelings toward her mentors exemplified how deeply she connected with them, and how accepting she was of being guided by them. She shared, "People pick up energy...these women...can feel my energies...that has really developed the relationship" (lines 386-389). Prema felt that her mentors were extremely brilliant, articulate and generous women who helped her become more confident. Her mentors were both women, one White, the other Black; both were impressed by Prema's knowledge and humility, and encouraged her to take risks and to stand up for herself. The moral for Prema was, "Go study with the best if you wanna learn...find the best, and seek the best" (lines 487-488). Because of the confidence she learned Prema was able to open her own clinical counseling service.

Mentoring as a form of discipleship taught participants many things about themselves. Aalia for instance learned to accept challenges. She shared about her mentor, "We very rarely agree, but he is open to different ideas and concepts and I am open to hearing his suggestions and it's like having best of both worlds, because I challenge him, he challenges me" (lines 147-149). Her Jewish-American mentor was firm and idealistic; characteristics which helped Aalia excel academically.

Keya's mentor helped her learn more about college administration and counseling. She shared, "[My mentor]...helped me to discover a different side of me" (lines 43-48). College administration is a career niche that Karen still enjoys today. 
Mentors were more than just teachers or guides; they were influential forces that elevated participants' learning, conceptualization, growth and progress.

Participants' relationships with mentors occurred through formal and informal mentoring relationships. Formal relationships meant that for a specific duration protégés would work under the supervision or direction of a faculty member or advisor so they could learn competencies related to specialized knowledge in fields such as medicine, science, technology or degree requirements. Protégés in formal mentoring relationships knew going into the relationship that mentors would be directing their learning and experiences. Informal relationships were typically initiated by mentors, occurred within no defined timeframe, and provided guidance related to skills and functions related to protégés' jobs as they arose, or that mentors felt they needed to experience.

Gendered differences. In this study, gendered differences refer to insights that female participants gained regarding more equitable standing of females in U.S. society. Within ancient East Indian tradition only males were qualified to study under the auspices of a guru. Indo-Caribbean society traditionally placed priority on the male child being socialized to dominate over his wife and children, to be educated to earn a living, become recognized, and own property, while females became equipped to raise children and manage the home (Kanhai, 2011; Lowenthal, 1972). During recent decades less traditional Indo-Caribbean families became proponents of equitable female proficiency, encouraging females to pursue academic and professional achievement.

Female participants in this study were raised in homes where they had the opportunity to seek an education abroad and to specialize in fields generally known to be male dominated, such as information technology (IT) and medicine. Female participants 
in fields of IT, hotel administration, and medicine were the only participants who explicitly reported on gender related issues. Rani and Arti both spoke of mentors who were White women, Mrita spoke of a Black Cherokee woman, and Bela spoke of White mentors who were both men. Those with the White women mentors and the Black Cherokee mentor experienced gendered challenges in the field, while the participant with White mentors reported that although her mentors were men, they were very supportive of her role as a woman in medicine.

Mrita, Rani and Arti reported how mentors helped them to thrive despite pressures that stemmed from being in male-dominated fields and how they learned about gendered challenges. Mrita spoke of her experience in IT:

When I started [in the field of IT] I was only surrounded by guys. [My supervisor] was the only female around...[otherwise] it was only gentlemen that I had to deal with, and they were not always the best communicators. And so I had to go to her for advice all the time too about that. (Lines 201-207)

Mrita shared that her mentor, a Black Cherokee woman became more comfortable over time in the male-dominated field of IT and eventually became a manager herself. She shared that men in the field actually encouraged her mentor and helped her get into the field. The mentor's work environment, Mrita's present environment, provided an opportunity for the mentor to practice patience, listening, and developing innovative systems with her staff. Mrita spoke of two situations when her mentor's communication and negotiation skills, diplomacy and tact helped her resolve problems with irate or uncooperative male employees and leadership where they worked. In the situation with the angry male employee described earlier, the man may have assumed that because Mrita was a woman that she was inept, since technology is considered a man's domain. 
Mrita's mentor, a Black Cherokee woman, instead defended Mrita from becoming the object of his frustration.

Black Cherokee women are in fact socialized to hold leadership positions, often able to make decisions that would affect an entire tribe (Portman \& Garrett, 2005). Cherokee men respect women as bearers of children, who are strong and capable contributory models in society. In Cherokee tradition, mentoring is a nurturing relationship in which the mentor is to "visualize, understand, and enter the world in which the individual being mentored lives and interacts" (p. 6). With this foundation, Mrita's mentor purposefully protected her as the less experienced person, and assisted the angry male employee.

Rani worked in human resources at a hotel in the U.S., where she too encountered challenges. She felt even though her mentor was a White female, the mentor strove to surpass the proverbial glass ceiling that allowed only White males to become top-level managers. Rani shared her view of being a woman in the hotel industry:

It's hard for women to succeed in our field. It's very hard for a woman to be a director. It's very hard for a woman to be a VP of human resources. It's very hard for a woman to be on a strategic committee of a hotel. (Lines 72-75)

Seeing that her mentor was able to become a manager encouraged Rani to persist in the industry, so that she could learn and progress as far as she was able during the time she worked at that company. Unfortunately after some time Rani's White female mentor developed a closer, more supportive mentoring relationship with a White male employee and so Rani felt that her mentor no longer taught or guided her, and could not help her progress further within that company, and so Rani resigned. 
Arti's mentor was a White female who advocated for equality among female podiatrists in the medical field. Medicine has traditionally been another male dominated field, so for women to become recognized as equally proficient, they needed to contribute to research and achievement in the field. Arti shared about her mentor:

She would push for equality in podiatrist among the medical field. She would push for females among the males in medicine. And she would also push for all cutting edge things trying to get forward with whatever we might be doing medical-wise. (Lines 180-183)

Ironically, this mentor became almost obsessive in her goal to be recognized in the field, and so her female protégés frequently felt pressured by her as a result. This mentor's enthusiasm according to Arti was driven by the poor representation of females in medicine, hence she felt added pressure for her female protégés to excel.

In U.S. medical schools participation by women has traditionally been significantly lower than men. In 1970-71 female participation was at $9 \%$, increasing to 43\% by 1998 (Bowman, Frank \& Allen, 2002). By 2010, there were over 30\% female practitioners, whereas there were only $7 \%$ in 1970 . Representation was similarly poor in academic medicine where women were both outranked and undercompensated in comparison to their male counterparts (Ash, Carr, Goldstein, \& Friedman, 2004).

Bela's experience in the medical field was the opposite of Arti's even though they were in the same specialty—podiatry. Bela's White male mentors were always encouraging and supportive of her, at times they appeared to be greater allies than her parents. She shared of her mentors, "It's their culture, their openness and allowing me to speak, and allowing me to be a young lady who's trying to compete in a workforce which in the sciences it's usually a lot of men" (lines 547-550). Bela's mentors did not appear 
to struggle like Arti's female mentor, instead they focused on supporting their protégés, and were not appear distracted by inequalities, or being recognized. Potentially because of the privileged positions the male mentors hold in society, they were better able to not pass on their pressure to their protégés. These male mentors encouraged Bela to be creative so she could become recognized and rewarded on her own merit.

The theme of "sitting at the feet of gurus" informed how protégés became empowered "intellectually, socially, [and] emotionally" within the family structure (Ladson-Billings, 1994, p. 18). Table 6 includes a summary of the findings that emerged within the theme of "sitting at the feet of gurus."

Table 6

Summary of "Sitting at the Feet of Gurus"

\begin{tabular}{ll}
\hline Theme & Description \\
\hline "Sitting at the & "Sitting at the feet of gurus" within participants' personal spaces \\
feet of gurus" & $\begin{array}{l}\text { helped them learn bhakti or devotion and surrender to others. This } \\
\text { theme informs ways that their families and heritage shaped attitudes } \\
\text { toward academic achievement and new knowledge. }\end{array}$
\end{tabular}

Subthemes

Indebtedness Indebtedness to parents and family - learning and guidance to parents and participants obtained within the family that shaped their attitude family toward knowledge acquisition as a means of retaining cultural traditions and to build financial stability and a successful life.

Sampradāya Sampradāya - the East Indian traditional and religious practices which form the foundation for how participants live their lives, approach, perceive and experience meaning--shaping participants emotional and motivational responses, and cementing their IndoCaribbean ethnic identity.

Sources of Sources of wisdom-Western experiences - the social supports, wisdom assistance, guidance and interactions with faculty, advisors, supervisors and peers that lead to higher inquiry. 


\section{Guru-Shishya: Learning and Discipleship}

Guru-shishya refers to the path of learning and discipleship as the prevalent theme that emerged reflecting the manner in which protégés perceived the mentors' guidance related to work, skill acquisition, and social or emotional support. Symbolically the gurushishya relationship reflects a succession of teachers within Indian culture and religion, the guru being the giver of knowledge, and the learner being the recipient of knowledge through commitment, devotion and obedience. In this study, interactions with mentors influenced professional competence, shared values, and sociability through social and cultural interactions. Mentors belonged to various racial and ethnic cultures, and were from a range of academic and professional environments.

Cross-cultural mentoring requires enhanced flexibility, adaptability, unity and acceptance, awareness of differences, broader perspectives, and emotional understanding (Battaglia, 1994; Brinson \& Kottler, 1993; Kochan \& Pascarelli, 2003). Good crosscultural mentoring relationships however require participants' willingness to acknowledge and understand the experiences of those from diverse racial or ethnic backgrounds (Davidson \& Foster-Johnson, 2001; Wright-Harp \& Cole, 2008).

Mentors were supervisors, faculty advisors, residency directors, school principals and spiritual leaders. The faculty advisors, and residency directors were White or Black men or women, and the school principals, supervisors and spiritual leaders were White, Black, Black Cherokee, Indian and Hispanic men or women. From experiencing gurushishya within their cross-cultural mentoring relationships protégés experienced: (a) anugraha--mentors' dispositions and (b) leaving in tears. 


\section{Anugraha--Mentors' Dispositions}

Anugraha or mentors' dispositions refer to mentors' attitudes within their crosscultural mentoring relationships and how they influenced protégés. Anugraha informs how mentors behaved toward protégés as they imparted developmental types of guidance that ideally contributed to sustainable relationships and outcomes. Anugraha also informs the negative energies that were transmitted. Symbolically, anugraha represents the grace with which sacred knowledge is transmitted by the guru, enabling the recipient to be open and accepting of new knowledge, versus it being forced or imposed.

Anugraha was represented as (a) conferring positive energy, and (b) increasing visibility.

Conferring positive energy. Conferring positive energy refers to the psychosocial support that participants gained through interactions with mentors during their tenure as undergraduate, graduate and doctoral students, and also professionally in the fields of social services, science and technology. Symbolically, positive energy represents mentors' advocacy, attitudes and dispositions that influence how knowledge was received. Participants described gaining knowledge in terms of: (a) building foundations, (b) encouragement and support, (c) care and nurturance, and (d) trust/mistrust.

Building foundations. Building foundations refer to the actions of mentors that helped participants succeed in college and later in their chosen professions. Nira, Aalia and Suren were undergraduates when they met their mentors, and they expressed that their mentors taught them foundational lessons that shaped their involvement at school, and their approach to professional work. These mentors were White, and just like White mentors who were supervisors, these focused on the concrete and measurable aspects of 
their protégés' learning. The skills they taught were more focused on building organizational and management competencies that served protégés through school. Since Nira and Suren were raised in the U.S. where the focus on education was not as rigid as it was in the Caribbean, their mentors were particularly instrumental in building the lifeskills they needed to succeed in school and as they began their careers.

Nira's mentor encouraged her to plan ahead, to be more self-sufficient as she prepared for graduate school, and to be a better leader within her student organization:

You really had to start thinking seriously about your future...building your foundation and making sure that you're focused and that you have that work ethic, that self-discipline that you need to make it....I was challenged to do more than the required...really push myself to be the greatest I can be. (Lines 126-134)

Nira also reported developing organizational skills, self-discipline, and leadership skills when her mentor pushed her to delegate work to members of her student organization rather than carrying the load by herself. Her mentor was a White female who was also among senior administration at her university, and was well published in her field. She recognized the need to be objective, results-oriented and proactive so that one could succeed both academically and professionally. Nira shared:

[My mentor] had an open door policy with me where I could come in and discuss with her issues that I was having with the board members, and help me develop my leadership qualities and how to do conflict management within the organization, and that was something that extremely important for me....But often times is [means] working with your e-board and learning how to be a team player and I think that is something that she definitely helped me to do. (Lines 102-110)

Nira's mentor helped her meet the challenges of managing the student organization and helped her to excel as their leader.

Aalia's mentor, a White male, was fully involved and successful in his work as a researcher; he was equally immersed in planning her entire academic career by personally 
selecting all of her classes, study abroad programs, professional experiences and internships. Aalia fully appreciated that he was fastidious about student development, planful, honest, diligent and attentive, as he guided her toward the activities and relationships that could enhance her professional growth. In order for her to be efficient and competent in her field her mentor generously did all he could to help her learn the right protocols and practices, specifically because in her field of international relations, something as seemingly insignificant as "a comma could make another country not agree to your proposed resolution" (lines 655-657).

Suren explained that his mentor, a White male, taught him how to prioritize and balance his life, so he could discern when "to charge ahead and work, work, work, and when it might make sense to have academics not be first priority so that something else can be first priority" (lines 294-297). Suren respected his mentor's holistic success which he generously shared with others, "He has a healthy functional family life... and meaningful spiritual life, and he has a healthy and successful professional life" (lines 208-210). He contended that his mentor's character and integrity was derived from his spiritual success. His mentor's guidance was both influential and informational, and helped Suren build the work/life/spiritual balance he wanted.

This was helpful to Suren since IT is constantly progressing, with frequent new developments that require professionals to be immersed in their specializations so that they master new developments as they arise, frequently neglecting their personal lives. For Suren, it was important that he balanced work/life/spirituality as those were driving forces in his life. White males predominate in science and technology so learning 
strategies to manage the challenges that lay ahead helped Suren prepare for the life he wanted both as a successful professional and as a homemaker.

Encouragement and support. Encouragement and support refers to positive attributions that participants reported receiving from mentors. Mentors' encouragement and support helped participants build the confidence and connections that impelled their progress. Protégés felt they could discern when mentors genuinely cared for them from the mannerisms and attitudes mentors displayed toward them.

Coming from Indo-Caribbean homes, parents generally expected high performance and academic excellence, so consistent progress was considered the norm. Parents generally assumed that students were applying their best efforts, and in many cases were simply proud that their kids were "studying abroad"--a prestigious accomplishment in itself. While parents did commend or reward academic achievement, they were not knowledgeable enough to provide details on opportunities and involvements that could help students navigate through complex U.S. academic systems. Mentors filled this role by providing expert guidance, encouragement and support.

Aalia had a White male mentor during her undergraduate tenure who she described as extremely nurturing and supportive throughout her program, when she began applying for highly recognized graduate programs, and later when she sought employment. She reported that his encouragement and commendations also empowered her, "I really think he just saw something special in me... and...was able to nurture that by placing a huge amount of pressure on me to live up to his standards" (line 104-106). His knowledge and reassurance helped her through the revisions to her dissertation that she described as a painstaking process since a dissenting faculty member tore it to pieces. 
Aalia's mentor reassured her by explaining the committee voting process which instilled confidence and determination. She recounted what he shared in his effort to assuage her fears, “'Listen there are three professors on this committee, there's me, there's Dr. Dissention, and there's Dr. Fair. Dr. Fair is objective and unbiased...I just want you to know that you only need [our] two votes to get your thesis passed"' (lines 439-443). By explaining the process to her, and candidly stating the potential outcome, Aalia was confident to go into her defense knowing that she would pass.

As a White male her mentor was quite likely socially privileged within the university setting, and welcome into the so-called "good ole boy" system frequently referenced in the U.S. workplace. This network is able to define and establish societal norms, and command power and stature (Delgado \& Stefancic, 1997). Aalia's mentor was knowledgeable of the system and the political forces that he as the dissertation chair would counteract to help his student succeed. He was not at all intimidated by the concerns and opposition from the White male faculty member who expressed dissention toward Aalia's research. As a White male in academia, he was familiar with the trials involved in preparing and defending a dissertation, and he quickly advised Aalia on what changes she needed to make to appease the dissenting faculty member.

Bela reported unwavering support and encouragement from her White male mentors during her medical school residency, especially when she encountered challenges. Because she returned to school as an adult learner, she felt she was too old to retake courses, and became dejected when she had difficult exams or failed a course. Her mentor encouraged her to persist, "If it wasn't for him, I don't think I would have gone 
down this path, and been this successful as I am now....It's like they carry you" (lines

111-122). She spoke of how they responded to her self-doubt:

They never lost faith in me, even in the times when I wasn't even sure...there are times where you stop and you're like, "Why am I taking out all these loans? Am I gonna make it? Am I going to pass this exam? Am I gonna get there?" They're like, "What's the big deal? You're still going to get the degree, and you're still gonna get where you're going. Why do you keep shooting yourself in the foot?" (Lines 603-609)

Her mentors' recognition and pride in her accomplishments showed when they helped her gain entry into the right scientific clubs, win the right awards, and guest lecture whenever possible. For Bela however, this felt like emotional support reflecting that they cared about her as a person, and wanted to lessen the anxiety and insecurities she experienced.

Anu, also a doctoral student, reported that her mentor helped her build connections and advocated for her early on in the mentoring relationship. Her mentor was an East Indian woman, who emigrated directly from India. She respected that Anu was studious, knowledgeable, disciplined, obedient, humble and even-tempered, valued traits within Hindu tradition, and so she openly spoke of her to others. Anu spoke of how positively her mentor regarded her:

In the faculty meetings she would really talk me up...like my "work-study is such a good hard-working person". I can tell, because when I met other faculty members even if they didn't know who I was, when they heard my name they're like, "I heard about you." I mean the entire faculty knew me... she always talked about me in a really positive light. (Lines 392-402)

The mentor seemed to recognize that by telling others about Anu's positive attitude and work ethic would help Anu become well known around the department, while also affirming her strengths as a worker. In another instance, when Anu received a poor grade, her mentor advised her to meet her instructor and dispute the grade, "get more 
information...from a stand point of wanting to learn more and...correct this" (lines 128130). She taught Anu how to self-advocate, and not allow the particular instructor to intimidate her. She felt that because she was a naturally passive person, she would rarely stand up or question teachers or leaders. Anu learned to be a bit more rigid, which was an Americanized trait that her mentor had mastered.

Care and nurturance. Care and nurturance refers to mentors' propensities to emotionally nourish and care for participants beyond their professional development needs. Care and nurturance extended into participants' personal lives and the challenges they faced. Because of the care and nurturance that mentors exhibited toward protégés, many protégés reported feeling compelled to mentor others in a similar manner. Anu, Bina and Kavi spoke of how involved and immersed their mentors became.

Anu reported, "she was motherly in some ways... very parental... and so that was really kind of cool to have that when I just moved to the U.S." (lines 481-482). She felt that her mentor was interested, involved, and generous toward her. Knowing that Anu had recently migrated to the U.S. and may have needed help settling in, she helped to furnish her home, took her to lunches and shared dinners at home with her own family. To Anu this was both comforting and meaningful particularly since Anu was new to the area and did not know anyone else. Looking back, Anu shared, "She kinda took me under her wing, and nurtured me, and taught me these things, and guided me, and provided advice and everything" (lines 488-490). This sentiment reflects the depth of care and gratitude Anu felt toward her mentor. 
Bina explained that her Hispanic mentor was empathetic and supportive. When she recognized Bina's work ethic, she encouraged her to become certified, then promoted her to the highest level at their school supporting Bina's progress in her career:

My principal saw my whole work ethic, she started encouraging me to take more and more classes and telling me she would come to see the day care which was a lot more unstructured than a classroom, she would come in the day care and then tell me afterwards, 'you really need to do this class and this class so I could give you your own class.' (lines $613-617$ )

She also demonstrated care and concern when Bina's husband lost his job. Bina

shared how she felt:

I've never worked with somebody who was as supportive as my school mentor here, I didn't really think it was possible and in this country the opportunity is there much more so than any other country I've ever lived in...because whatever you want to do, I believe there is something called the American Dream. (lines 772-776).

The mentor immediately created a summer job for her to help offset their financial needs, demonstrating to Bina how much she was valued and cared for.

Kavi's Black mentor, although strong minded, was very soft hearted—which according to Kavi, "She never showed anybody" (lines 231-234). Her mentor's display of emotion on rare occasions helped Kavi realize that although her mentor was tough on the outside, she was warm and caring on the inside, especially toward staff she cared about, and the people they helped in social services. She was accommodating and protective when Kavi needed time off to care for a sick relative and in another instance when Kavi was summoned to court:

The judge called me, chewed me out said she wanted to see my supervisor...I though that was it, she's gonna give me 50 hours community service...my supervisor went to court .... and went to bat for me... and before I had a chance to respond, my supervisor just took over that courtroom and made that judge feel smaller than I did. (Lines 406-420) 
Kavi came to respect and appreciate her mentor very highly, and built a strong sense of security through her support and excellent leadership. Kavi shared, "[You] feel safe in knowing her review, her directions, you can go to sleep at night” (lines 92-95). Her mentor served as a guardian and protector when difficult situations arose.

Kavi's mentor, a Black woman, appeared compelled to protect Kavi in court, because she knew of Kavi's diligence and commitment—well respected traits within a stressful work environment. The mentor was also empathetic to Kavi's feelings as a minority facing accusatory judgment in court, in a scenario where she had done nothing to generate guilt or mistrust. Kavi's mentor became someone significant in her life who chose to advocate for and defend her protégé.

For Mrita, the sense of family at work made her feel cared for. Mrita thought of her mentor more like a mother because of her protectiveness within the work environment:

She still calls us her children. She would protect us...[as] a contracted department...we were viewed as outsiders...[so staff at] the university...would always look down on us... She would step in, and say "talk to me if you have a problem". (Lines 117-124).

According to the literature, Black Cherokee women can be caring and nurturing without feeling like their strength is being compromised as such traits are encouraged by tribal leaders (Portman \& Garrett, 2005).

Trust. Trust refers to feelings of reliability and dependency that participants felt toward their mentors that encouraged them to accept and follow their mentors' advice and guidance. Within mentoring relationships trust is viewed as a necessary ingredient for collaborative success, particularly among African American protégés, women, 
organizational leaders, and intergenerational groups (Bailey \& Cervero, 2002; Dyal, 1984; Salkind, 2004). Although the element of trust is implied within every mentoring relationship, three participants specifically addressed trust within their relationships. In this study, trust became a scaffold that encouraged protégés to lean on mentors who were Indian, Hispanic, and White for Bina, Kara and Suren respectively.

Bina described how she felt toward the East Indian priest and her Hispanic school principal, "I've selected to listen to the ones who I feel truly care about my growth...those are the ones that I really trust and the ones that I really think that they want my well being" (lines 276-279). She further shared, "I trust their opinion...it really makes for a brilliant working experience" (lines 608-609). She held them in high esteem because of the courtesy, respect, interest and care they extended to her, and because of their integrity and leadership in their respective domains. Mentors' professional roles rather than their ethnicities more likely conveyed trustworthiness since as a priest and a principal their roles require that they maintain ethical standards and practices.

Kara, because she deeply trusted her mentor's knowledge, guidance and experience, was able to learn from him, build a successful career and start her own business. She shared:

The most important aspect was definitely the bond I formed with him, it was one of pure trust. He had this incredible...knowledge of real estate... I bonded with him, and just learned from him as much as I could, I devoured him. (Lines 119123)

Kara's mentor was a White male retired army officer, who she described as extremely knowledgeable, candid, and supportive. As his protégé, Kara learned everything he could possibly teach her and made lucrative investments based on his guidance, never did he 
abuse her trust even though he spoke of how attractive she was. This is uncharacteristic of older White males, many of whom have historically treated female protégés as muses, lovers, mistresses, brainchildren and sirens (Rushing, 2005). Within Eastern cultures, mentors or gurus were men, and they rarely taught or discipled female students, consequently the element of trust does not arise in a male/female mentoring relationship. Since no similar studies were located regarding Indo-Caribbean experiences, this implies the need for further inquiry.

Suren's relationship with his mentor grew from trust and mutuality regarding what he described as spiritual truth. He shared:

I think one thing that was helpful for him and I was the spiritual truth, a lot of spiritual truths that we believe are the same and so we're able to use those as guiding principles and apply them to real life so to speak. (Lines 173-175)

Suren was confident that shared spiritual truths grounded in Christianity built a foundation of trust between them. Suren viewed his mentor's key strength as his holistic success--he had a healthy, functional family life, a meaningful spiritual life, and a successful professional life. Suren explained, "he is the kind of guy that I see the more I have of him in my life the better off it is" (line 396). He believed in his mentor's character and integrity, based on shared religious foundations.

Mistrust. Mistrust refers to a sense doubt or caution that arose within mentoring relationships. Mistrust can be interpreted as a teachable moment-wherein one learns what actions cause mistrust, how to avoid it arising, and whether it is actually unfounded. In the instances below mentors were both White, and clearly driven to progress and become recognized as leaders in their fields of science and hospitality management. They often solicited protégés' thoughts, opinions or expertise, without rationalizing or 
justifying why they needed such information. This was the root cause of protégés' mistrust since they were cautious that their developing expertise could be usurped.

Prad preferred to be cautious when divulging his own expertise. As a scientist he trusted his mentor's experience and respect for intellectual property as it enabled them to work well and publish together, "You feel a mutual kind of respect, or mutual kind of benefit" (lines 120-122). Nonetheless he remained wary of disclosing his own proficiency to other scientific authorities, including his mentor, and those seeking patents in his field. Patents, authored works, and research are vulnerable to being misappropriated regardless of authors' or researchers' races or ethnicities.

Feelings of mistrust also negatively influenced Rani's mentoring relationship. Rani reported that when she became a more proficient manager her mentor became competitive, and she felt that the mentor stopped teaching her new things. Rani shared, "She stopped teaching me...that allowed me not to learn as much as I could've learned about the hospitality industry. Especially since she has 25 plus years in this" (lines $457-$ 462). Rani was hurt and disappointed that her relationship with her mentor and her opportunity to learn was curtailed because she became a potential threat to her mentor, despite their friendship.

In both situations above mentors' race/ethnicity may have been inconsequential. Feelings of doubt, suspicion, or lack of confidence in the other can negatively influence the cross-cultural mentoring relationship regardless of participants' races or ethnicities. Numerous circumstances arise daily that create misunderstanding, misinterpretation, and possibilities of offending others based on potentially false assumptions (Seepersad, Hagood-Elliott, Lewis, \& Strickland, 2007). Emotions stemming from trust or mistrust 
require that mentors, protégés seek common ground where cultural similarities and differences, and the proximal causes of those differences may be established (Dyal, 1984). Doing so will reduce doubts and suspicions, and build the foundation for more trusting relationships.

Increasing visibility. Increasing visibility refers to mentors actions that engendered a sense of safety and competence in protégés so they gained confidence in their roles as professionals. Gaining confidence allowed protégés to become more involved and influential, hence making them more visible in their respective fields and workplaces. Being new to the U.S. workforce, some participants were not equipped to manage the personal or professional situations they encountered here, so the impetus they obtained from mentors was beneficial.

In the Caribbean academic and professional competence meant simply having a job, and fulfilling what was on your prospectus or job outline, there were no cultural adjustments to be made. In the U.S. the individual needs to be far more "assertive, inquisitive...enthusiastic, inventive and independent of thought" than in the Caribbean (Thaker, 2007, p. 66). Mentors who were from Western cultures demonstrated how being visible impelled success and accomplishment within the U.S. workplace and so they strove to inculcate visibility in their protégés by building: (a) functional and professional competence, (b) cultural competence, and (c) interpersonal competence.

Functional and professional competence. Functional and professional competence refers to mentor influences that helped participants to be more effective and competent in their jobs within the U.S. work environment. Mentors were also focused 
and committed to building the proficiencies and field specific knowledge and practices that enabled participants' progression and capacity for growth within their fields.

Arti, Bela and Kavi reported on practices that supported professional development within the United States. Arti credited her residency director for building her competence as a surgeon. She explained:

[My mentor] had almost everything to do with my professional development, and my growth.... When it comes to my actual skills, my hands on skills at being a surgeon, and also my medical knowledge and intuition on learning how to treat a patient. Both medically and otherwise...she had really good ethics as well...I saw and appreciated that. (Lines 320-328).

Her mentor helped her develop her surgical skills, medical knowledge, learning how to treat a patient, and also encouraged cohesion, professional unity, active engagement, and good medical ethics. The mentor was consumed with cutting edge trends and technologies, professional prominence in the field, gender equality and good medical ethics. She was also very involved, held tight reign in the operating room, provided good instruction and guidance, and was highly competent. Arti reported that because of her mentor's support she became a competent and gainfully employed surgeon.

Bela's mentor also prepared her to excel in her medical career by being honest and responsive toward her. She shared, "He was a great advisor in understanding each student's needs" (line 294) and strengths so that he could provide targeted career advice which always seemed to garner positive and enduring results. For instance, he suggested she specialize in podiatry since it was an area he felt she would excel in, and would also have the time she needed as a single mom. He consistently nominated her first for cases or to design treatment protocols that augmented her experiential learning. Typically, her 
mentors would assign her surgeries to challenge her thinking. Bela provided an example about a case where the patient was too poor to afford the surgery he needed:

[My mentor] gave me a budget for a case... a really small amount....This person's poor, and this is all they can afford...they have this broken bone, and how are you going to fix it? I had to figure out everything, and have it ready for the case. (Lines 316-321)

He always pushed Bela to do better, "If you don't have all the materials [for a surgery], come up with something. You're smarter than that. Challenge yourself, and bring yourself to the next level" (lines 314-315). Bela's mentor encouraged her to think beyond what she learned about performing surgeries, and to be creative so that she could design a viable solution for her patient.

In the U.S., practicing medicine now means treating the whole person, not simply resolving their ailment. As such, being perceptive of patient needs, whether financially, familial, social or psychological; a medical practitioner has to be aware of all risks inherent to treating the individual (Passarelli, 2008). In addition, because of legislation in the U.S., medical personnel need to be aware of laws, rules and medical ethics governing patient care, far more rigid than in the Caribbean. Further, maintaining memberships within the right professional organizations, and participating in supportive networks among one's peers creates team driven organizations, characteristic of the U.S. workplace (Marquardt, 2002). Collegial professional relationships served as cohesive networks of support, whether for comparing ideas, treatments, or collective challenges within the field. Because health care is primarily government owned and managed in the Caribbean, the quality of treatment, patient service, and professional collegiality is less significant than in the United States. In fact, those who can afford to, typically travel to 
the U.S. for medical care. In addition, Caribbean education is not recognized in the U.S., and as such any training or education completed there requires recertification before practice in the U.S. may occur.

Kavi's mentor was instrumental in helping her overcome fears about making a critical mistake in the field of social services. A single error or oversight could prove fatal; and Kavi was always concerned about making wrong or potentially damaging decisions or untimely and inadequate documentation. When Kavi began working in social services, her mentor walked her through each process, helped her make crucial decisions, and actively reviewed her work so that she could fulfill the mandatory requirements of her job. Kavi believed that although her mentor was extremely rigid regarding rules and procedures, her guidance was always correct and formed a protective barrier shielding Kavi from making harmful mistakes.

She also helped Kavi learn about socially acceptable U.S. parenting practices that related to her functions as a caseworker. For instance, certain disciplinary actions of parents that were acceptable in the Caribbean were considered actionable in the United States. Whereas one could spank a child in the Caribbean, punishment in the U.S. more typically involves time-outs or positive discipline (Bridging Refugee Youth and Children's Services, 2005). Learning about acceptable U.S. cultural practices gave Kavi the confidence to make stronger, more suitable work-related decisions.

Kavi shared, "I strongly believe she had given me her all, and given me all the tools I needed and all the advice, the directives, everything she could have given me as a supervisor" (lines 375-376). Even though Kavi's mentor was a Black woman who appeared overbearing and harsh at times, her attitude encouraged staff to perform 
appropriately. Kavi understood that their goal was to protect their charges, and so she accepted and valued her mentor's strictness and control.

Kavi's mentor was a Black woman, who worked in social services for many years. Kavi shared that her mentor was extremely engaged in her role but was blunt, always took charge, and focused primarily on her charges. Kavi shared:

[My mentor had a] strong mind, strong personality, strong minded, strong person generally, overpowering personality, take charge...truthfully her weakest was the soft heart she had that she never showed anybody because she was a drug addict herself....She's very soft when it comes to the children [we work with] and that was the weakest point I've seen her when she was dealing with a baby...you're actually looking at these things, you're seeing what happened - it was an 18 month old we were dealing with and her weakness came out as far as the tears -she would regain herself real fast. (lines 231-242)

Kavi's mentor struggled with drug addiction at one point in her life so she had first hand knowledge of traumas often encountered by families who needed social services. While her personality was the antithesis of Kavi's calm manner, it proved helpful in that the mentor provided her staff the support they needed to be successful, likely because of the lack of support she experienced as a Black woman. Kavi felt that she grew more competent and reliable because of her mentor.

Keya reported that her mentor provided direct, specific and personalized support to help Keya in her role as an academic adviser. Her mentor would typically sit beside her and take notes as Keya interacted with students, after which they would debrief and discuss strategies and recommendations so that Keya could improve her work. Her mentor was "up front [in saying] exactly what she's looking for" (line 53-55), allowed "space to figure out what you needed to do as an individual to help yourself grow" (lines 
116). She felt it was important that her protégé was equipped with the information she needed to interact confidently and competently with students and their families.

Her mentor was a Black-Jamaican female university administrator who took a personal interest in Keya's professional development. Keya felt that because they were both from the Caribbean, her mentor understood her drive to be successful as professionals, and to consistently do better.

Cultural competence. Cultural competence for participants refers to new capabilities that they as protégés developed which helped them to negotiate, manage conflict, become confident, and interact in a manner that is respected and recognized in the U.S. workplace. While participants may have been equipped to thrive in the Caribbean workplace they needed to develop the competence and in some cases the selfassurance so they could reduce anxiety, take risks, handle inequalities, and be more resilient. How participants "think, feel, and act" (p. 395) in these circumstances are reflected in Hofstede's (2010) cultural dimensions of uncertainty avoidance, and power distance which differs among the U.S. and countries in the Caribbean. Prema, Prad and Mrita reported on how mentors helped reshape their subjective and attitudinal outlooks to be more congruent with cultural practices in the U.S. work environment.

Prema had been extremely introverted and shy and as a result she had difficulty within public forums, making presentations and interacting with clients. She believes her difficulties stemmed from her Caribbean background. She explained: "Growing up in Trinidad it was like you're seen and not heard. And so you're not encouraged to express your feelings or your thoughts and you're not encouraged to do critical thinking" (lines 203-205). Students sit silently, absorb information and regurgitate it back to their 
teachers. Consequently Prema became extremely nervous, experienced stomach upsets and sleeplessness at the prospect of making presentations, speaking publicly, engaging with others or even applying for jobs that required interaction.

Alternatively, she described her White mentor as very articulate and an "amazing public speaker...[who could] really connect with people" (line 546-547). Prema saw how her mentor prepared for each engagement, and would use her presence to command attention. Prema's mentor also helped her become more confident and self assured by engaging in conversations with her, confiding in her, and using her as a sounding board.

As a result, Prema became more empowered. She shared how she felt:

It's a feeling of being safe and...I can connect with them and I know that they're really listening to me and they have my best interests, and that they understand my limitations, but yet they're willing to say..."I really feel you can do this." And so I feel safe and I can open up, and I can just say what I have to say even though they kind of look at me and go, "What? What are you talking about? You know you can do this." And so it's just helping me get over my own my own blocks with myself. (Lines 273-281).

Prema overcame her initial feelings of stress, the emotions and anxiety attached to taking risks in any given scenario. She also became more participative and involved which gave her the confidence to engage as a public speaker and as a facilitator to conduct her own workshops.

Typically East Indians in the Caribbean are less direct and more submissive, an aspect of their cultural heritage acquired and learned from combined parental and academic influence (Glasgow, 2006; Hofstede, 2010). Uncertainty avoidance, reflective of Hofstede's cultural dimensions shows that feelings of uncertainty are reflective of Trinidad, Prema's homeland, at a higher rate than the U.S. according to Hofstede's (2011) comparisons of dimensions of national culture. 
Prema's mentor helped relieve her anxiety and uncertainty by reminding her that she was knowledgeable, and showing her that by preparing for presentation and interactions, she would know what to expect. When scenarios are clear and predictable, this reduces ambiguity and makes risk-taking less threatening.

Prad migrated to the U.S. decades before other participants in this study, and consequently he seemed to confront different levels of acculturation or cultural adjustments. Initially he felt that to be professionally accepted in the U.S., required sheer aggression, "You are required to be more aggressive towards getting a job, towards doing the job, towards completing a job, even towards getting your money from the job...Mentoring and coaching became very essential in moving up or moving anyhow" (lines 84-94). He felt that mentoring and coaching helped him progress.

His mentor later taught him meaningful information about group dynamics and conflict management to help him deal with how others perceived him. He shared:

The most important and most meaningful was dealing with the different cultural vicissitudes or resistance or ignorance that we do find in the U.S., so much so that when I walk into a room people are either at ease or uneasy... When we worked with conflict management and personality styles it was very important that I understood that I am dealing with people who are really truly ignorant of me, or where I come from--sometimes I would wear a beard, and having a longer than usual name...I would be easily perceived as a "Muslim" [My mentor] instilled resilience to educate people on who I am - not allowing them to define me. (Lines 185-196)

He was viewed as a Muslim because he was dark skinned, and wore a beard-both physical traits of Middle Eastern men, which in a post 9/11 world typically generated unease or fear. Prad's mentor helped him educate others about his culture, and helped him develop negotiation, listening, and communication skills. They employed 
conflict management principles that required understanding both sides of conflict through cooperative negotiation, to develop intelligible solutions (Ury, 2000).

Prad felt hurt that he was viewed as an outsider and as threat because of his appearance. By helping others become aware of his culture and beliefs, he made what was unfamiliar to them become less threatening. By demonstrating his expertise and competence in a collegial manner he built a sense of familiarity and connectedness within the workplace. In doing so he reduced the elements of uncertainty avoidance and the power distance that was evident within his workplace (Hofstede, 1997). He explained how his mentor's own experiences helped him:

[My mentor] came to this country at the end of the second world war, and as a German, as a Jew, he had to navigate his own problems, or issues, but he was successful, because he was trained at that time in Cambridge University in England and so he had a good perspective from being a German Jew in England, then came to America via Cuba. He worked with me personally to understand all those differences, that needs to be looked at in the perspective to get the job done... [the] need to focus on the tasks mostly, on getting the job done irrespective of what might be some of the 'apparent' challenges. (Lines 159-166).

Prad's perception was that his mentor's experiences with prejudice as a German Jew attending Cambridge University in England, then coming to the U.S. via Cuba influenced his empathy toward Prad and others. He also learned from him to focus on the tasks involved in his job, and not the personal challenges he encountered.

Mrita needed to build negotiation skills so she could obtain a better employment contract from university administration as an IT professional. Her mentor advised, "When the university offers you something, you make sure that offer is X amount over what you're getting right now. Or don't take the job. Go out there and look for something else" (lines 487-488). By bargaining, Mrita obtained the income she sought. 
Being Indo-Caribbean, Mrita tended to be indirect, passive and submissive and as such would not typically negotiate or bargain for a higher income. In the U.S. however women have to be more aggressive to be valued and respected. Women also have to be more individualistic in seeking out their own interests, a U.S. characteristic that helped Mrita earn the income she deserved as a knowledgeable and well trained professional.

In addition to building her negotiation skills, Mrita's mentor also helped her build confidence to make presentations, to train others with computer applications, to make learners feel comfortable during her training sessions, and to infuse humor in her presentations. Mrita realized that she was knowledgeable and competent to share her wisdom with others, and could earn respect as an educator, where initially she felt that she was not qualified. By learning to share her knowledge Mrita reduced the power distance gap between herself and employees she trained, and also overcame the fears that deterred her from progressing in her profession as an IT trainer (Hofstede, 1997).

Mentors helped participants develop the self-assurance and certainty that influenced how they interacted with others and performed at work. Participants explained how mentors enhanced their confidence by being role models who influenced their thinking, reasoning and problem solving abilities.

Kara explained how the directness she learned from her mentor helped, "I became more confident in knowing what real-estate is... what my clients wanted; I would be more direct" (lines 297-298). She could assist Indian clients because she understood what they valued when purchasing a home, and built the confidence to ask for the close, when suitable. She shared, "[My mentor] taught me to ask for something...that's not a cultural thing we learn in Trinidad" (lines 513-514). It was important to be able to ask a client if 
they were making a purchase or not. Kara's White male mentor was forthwith when dealing with clients, reflecting threads of the Eurocentric nature by exacting that a response was needed from clients (Brohman, 1995). In contrast, Kara had to learn to be direct, where she would typically display a more passive approach by establishing common ground with clients.

Kavi reported that she learned "just how to handle differences with people, and how to be able to evaluate anything...handle myself on any level, any character, any personality, and any challenges that could come at me" (lines 363-365). She also explained how her mentor taught her "to have a stronger backbone, [and to] make stronger decisions" (lines 430-431) which reportedly made her more effective in her field and in life generally.

Bina explained that she wanted to be professional in both her career and volunteerism in church. She reported on the actions her mentors took to help her build confidence, "my mentors realize I want to be an example to other people and so that has set the pace for how they relate to me, to be an example to others just like how they are an example" (lines 587-589). Her mentors modeled the practices and behaviors she needed to influence students and their families.

Interpersonal competence. Interpersonal competence refers primarily to verbal, interpersonal communication together with accompanying attitudes and accommodations or responses that participants experienced and learned about within their mentoring relationships. Interpersonal communication is taken for granted when one is within the native or local environment, the Caribbean in this case. For Indo-Caribbean participants, interacting in the U.S. required some adjustments. English is the first language for Indo- 
Caribbeans, as well, their ancestors originally learned English from the British colonists, hence the spoken word is typically clear and understandable. In the U.S. dimensions other than diction and grammatical accuracy are influential within cross-cultural communication. In this study, participants discussed interpersonal communication in terms of: (a) communication patterns (b) diplomacy (c) directness, and (d) feedback.

Communication patterns. Communication patterns refer to communication with mentors that participants felt they could emulate, or alternatively, could improve upon. Nira explained that her mentors all had an open door policy and so were accessible to her, "For me that was a great thing...because they hear within the tone of my voice or by looking at my face what's going on" (lines 259-261). She preferred in-person communication rather than electronic modes like email or phones which she found impersonal.

Nira leaned toward in person communication to avoid misunderstandings between herself and her mentors. She typically made appointments with them so they could sit in person and discuss her concerns. Nira communicated more comfortably and openly with her Black-Jamaican mentor because she felt that she understood her better because of their shared background. With her White mentor she always preferred to spend time sitting and discussing work related concerns. Her mentor was typically helpful and open to hearing what Nira had to say, and in turn provided reliable guidance to Nira.

In Suren's experience his mentor frequently used personal experiences, or examples when relevant to support his explanations or topics to help him better understand what they were discussing. Suren shared, "There was no topic that was pretty much off limits" (line 350). Similarly, Aalia's mentor frequently used analogies and 
metaphors to help others understand what was being discussed making information "become a lot more pertinent" (line 369); this helped her understand complex topics.

Both Suren and Aalia had White mentors who took the time to fully explain and provide examples to their protégés. Having clear explanations helped them understand better what mentors were trying to communicate. As well, this taught both Suren and Aalia a good communication practice that they could emulate. These White mentors had the confidence to openly provide personal examples, and the creativity to form connections between protégés' existing knowledge, and new knowledge.

Anu learned from her mentor how to be more collaborative. Anu reported, "I always felt like [my mentor] was just trying to be collaborative with me, but I just didn't have that confidence to be collaborative back with her...she's trying to treat me like a colleague, but I wasn't ready yet (lines 303-308). Anu's lack of confidence deterred her from asking questions, "I was very passive...without questioning" (line 299). She later learned to question and to evaluate information, which helped her during her internship. Anu's Indian mentor assumed the role of a guru or teacher, and as such she openly provided information and guidance. Unfortunately Anu could not be completely open and receptive to the knowledge and guidance in every instance.

Diplomacy. Diplomacy refers to participants' perceptions that mentors were tactful and considerate when communicating. Participants described how mentors' exhibited diplomacy when interacting and in creating connections.

Mrita reported that her mentor focused on getting her point across, then listening to the other person's point. Mrita shared, "[She would] always listen to your point... analyze and...compare the two and then she would come up with a 
recommendation...she was always a very good listener" (lines 341-344). Mrita learned from her mentor how to diffuse a situation, to keep people calm, to encourage them to provide more information, and to step back and sort through what she was going to say before speaking, all useful skills in the field of IT.

Based on existing research regarding American Indian (Black Cherokee) women, leadership skills meant practicing "patience, listening, contemplating the situation, and developing innovative strategies to accomplish the needed task" (Portman \& Garrett, 2005, p. 2). Traditionally these practices have encouraged independent thinking among American Indian female leaders.

Aalia reported that as a student, she was more of a talker; her mentor patiently listened to what she had to say, then he refuted her arguments or confounded her ideas with his deep, complex analyses which encouraged her to ponder her ideas more deeply. She further added, "In diplomacy [an integral aspect of international relations]...you focus a lot on things like body language ...you're taught to look out for different cues. In terms of his body language he would have always been quite open and very good at articulating specific point" (lines 372-375). She felt that her mentor prepared her well for a career in international relations.

Being Indo-Caribbean, Aalia's natural inclination was to be trusting and open when communicating. This approach is not suitable for a career in international relations - hence her mentor was very diligent about guiding her diplomacy, tact, and communication protocols to be congruent with her chosen career path.

Directness. Directness refers to mentors' reported candor within verbal exchanges, a pattern that participants emulated to enhance their communication. Indo- 
Caribbeans in this study typically were passive and less direct—idealized characteristics passed down generationally (Glasgow, 2006). Historically, indentured laborers did not have to struggle for their rights in the Caribbean, they simply worked and were paid, and so could progress. Compared to the African slaves brought to the Caribbean, the East Indians did not need to be aggressive in order to survive. In the Indo-Caribbean home children, regardless of age were to be quiet, and should never stand up against parents or elders, regardless of the situation. Life in the U.S. however seems to demand that IndoCaribbeans be more direct, and less passive, practices that Indo-Caribbean immigrants in this study needed to learn.

Arti's mentor always expressed what mattered most to her without compromising her own wants, beliefs, and interests. Arti realized this was her mentor's personal communication style, and that she had to accept it. Arti reported how her own uncharacteristically aggressive action gained her entry to her residency program with her particular mentor. After her scheduled interview she went unannounced to her mentor's office to advocate for herself:

It was that particular visit and not the actual interview is what got me into the program, because she really respected the fact that I came out and spoke with her about this actually unannounced and just made my wishes known....She actually thought that that I was much more aggressive than I really am. (Lines 269-277)

Arti later realized that her mentor was very aggressive possibly because of the rigidity of being a Scientologist, and being a White female in the medical field.

Suren and Kara both had White mentors who were very direct as well - they appreciated learning to be more direct as a result. Suren reported that directness was his mentor's strength. He explained that although his mentor being "very blunt or to the 
point" (line 219) was difficult for some, he was familiar enough with his mentor to accept it. At times, Suren felt that their directness resulted in conflict. He shared his view, "If we're gonna be successful and have meaningful results for anything you're gonna end up with conflict in there somewhere" (lines 364-366). It helped the mentoring relationship that they were both direct, and enjoyed the freedom to speak their minds although this sometimes resulted in disagreements and "bumpy communication" which they resolved by talking things through (line 305).

Kara, learned from her mentor when it was suitable to be more direct. For instance, in real estate, asking personal questions of clients could be considered discriminatory, however, being direct and asking customers for the close, or the sale, was crucial. She shared:

I have a tendency to ask very direct questions...I ask probably things that... appear to be inappropriate...I'll ask somebody, do you have kids, and in real estate you're not supposed to ask those questions, you're not supposed to stereotype. (Lines 257-262)

She felt that since many of her customers were of East Indian heritage, their shared culture enabled her to be more open with inquiries, and hence increased her sales. Being too direct in the field of real estate can be interpreted as discriminatory because of the anti-discrimination laws in the U.S. Kara's mentor, a White male, often cautioned her about this, as she tended to be too direct at times, but she felt justified making such inquiries of clients who shared her heritage.

Within cross-cultural communication misunderstandings occur frequently, because of simple misinterpretations. When discussing concerns in person both sides can see when facial expressions change, and consequently may be able to interpret whether 
there is confusion or concern. Approachability, receptivity, directness, respect, and adaptability are viewed as necessary characteristics of interpersonal competence that enhance understanding (Elmer, 1986). Indo-Caribbeans typically are indirect and passive, submissive in decision making, and prefer to avoid conflict (Glasgow, 2006). From this study, it is evident that the Indo-Caribbeans participants have learned to be more direct, less passive, willing and able to make timely and critical decisions in their own interests--academically, personally, and professionally.

Feedback. Feedback refers to the responses participants reported receiving from mentors regarding performance of work, or in response to questions. Although negative or insensitive feedback may be viewed as detrimental within cross-cultural mentoring relationships, constructive criticism was viewed by participants in this study as an opportunity for growth. In this section, participants' need for frequent feedback and their responses after receiving feedback are discussed.

Bina and Kavi reported that positive feedback regarding their good work was affirming and encouraging. Bina shared that her mentor consistently commended her work, and quickly shared positive feedback from the parents in response to her students' achievements. The feedback Kavi received, while being complimentary, also provided guidance on suitable actions, "listen to what I am telling you and you will never get yourself in trouble" (line 301-302).

Because their mentors Hispanic and Black respectively were forthcoming in providing feedback, Bina and Kavi were encouraged to work hard and to continue making progress in their fields. This serves as an example that affirming feedback from supervisors or bosses is appreciated by Indo-Caribbeans (Glasgow, 2006). 
Frequently participants needed to overcome challenges to achieve their professional goals. They spoke of constructive criticism, persistence, conflict, and personality differences and their thoughts when they encountered these challenges. Keya and Prad both felt that feedback was far too delayed for their needs. Unfortunately, in the U.S. workplace, supervisors and leaders are typically under pressure to perform and to continuously take on additional work. Hence, there is less time to provide feedback to colleagues and protégés.

Keya's main concern was that feedback was infrequent, sometimes after a couple of months. This alludes to a difference between Indo-Caribbeans' value for timeliness in contrast to what Keya experienced with her Afro-Caribbean mentor who was BlackJamaican. She shared however that when she obtained feedback, she used it to improve her work; she contrasted her outlook to others who viewed feedback negatively, "as bad criticism" (line 135). Keya knew that her mentor's feedback would help her improve as a professional. Aalia shared Keya's sentiment about receiving feedback on her thesis:

I was quite open to [my mentor's] constructive criticism, and I remember him saying to me...'that is quite a unique quality because very few people would change an entire dissertation or rework it based on findings'... I was open to that because I don't have any misconceptions that what I think is necessarily right. (Lines 231-235)

Aalia realized that if she was to succeed in international relations, being able to adjust her own ideas and thinking was necessary. Similarly, since she respected and valued her mentor's knowledge, she was open to accepting his feedback.

Prad main concern was that receiving timely feedback was necessary for his research protocols and various projects. He seemed to demand feedback, "I just walked into the door [and] said 'look where do we go from here', so I like feedback, I encourage 
it...it's one of my measures of getting things done" (lines 464-467). Prad at times aggressively pursued his mentor for feedback, "I would call him, and I will not stop calling...he was busy but I needed to get him...I got his fax number and faxed the questions to him. I got an instant response" (lines 432-435). Prad felt that his mentor should have been more accessible, however the mentor appreciated Prad's persistence to get the information he needed to move forward. In one instance Prad need some questions answered, so when his mentor had not responded to his calls, he faxed the questions over to him, and received an immediate response, "I found that style worked with him and he was very amused by what I did, but I had to get it done (lines 436-437). He felt that his White mentor recognized his persistence and aggression as necessary strengths within their work environment, and after many years in the U.S. learned he needed to be aggressive to succeed.

For some individuals, feedback is viewed as criticism regardless of the race or ethnicity of the person providing it, and may be rejected, or may incite feelings of defensiveness or rebellion. Within Black/White dyads particularly, racial dynamics increase communication barriers, and since Caribbeans as an ethnic minority in the U.S. are counted as Black, mentors may have expected protégés to be resistant or defensive to feedback (Brathwaite-Gardner, 2006). However, for Indo-Caribbeans in this study, feedback was well received and appreciated since they viewed mentors as role models, whose knowledge and guidance they respected—allowing them to accept feedback whether positive or negative. Over time, participants' communication skills improved in terms of their confidence, questioning abilities, attitude, and understanding. While they 
encountered challenges, most were able to reconcile why they experienced conflict when communicating with mentors, and to devise ways to improve communication.

Leaving in tears. Leaving in tears refers to the struggles and sense of opposition that arose within participants' mentoring relationships. Although in most cases mentors were agreeable, they at times were perceived as insensitive, overbearing or sometimes aggressive. Mentors unfortunately appeared oblivious to the struggles experienced by the participants' in this study, representing a cultural gap in understanding regarding Indo-Caribbean protégés. Such characteristics are the antithesis of Indo-Caribbeans' attitudes (Glasgow, 2006). Indo-Caribbeans tend to be non-confrontational, prefer to withdraw from opposition or conflict in favor of comfortable and amicable relationships, are co-operative, and conform to the status quo. As a result when mentors exhibited negative or opposing attitudes protégés felt: (a) imposed upon and embattled, and (b) disconnected and distanced.

Imposed upon and embattled. Being imposed upon and embattled refers to the forceful and unexpectedly aggressive natures exhibited by mentors. Being aggressive is not characteristic of Indo-Caribbeans as they are raised to be passive, reflected in the principle of ahimsa, which means practice kindness towards all. Participants therefore experienced difficulties interacting with mentors who were harsh or aggressive.

Arti shared that while she expected to be challenged during her medical residency, she got more than she bargained for. She reported, "throughout the 2 years [this experience] turned out to be probably one of the most difficult processes I ever went through largely because of my mentor" (lines 48-52). Arti felt like she was constantly battling with her mentor: 
She was a very aggressive person, and she wanted aggression on our parts as well, and she would say that. So if we were too passive in certain ways for instance if we were with the orthopedic residents and we didn't seem to measure up to them, in terms of their aggression...then we would have to suffer the consequences for that. And just generally speaking that was the way we had to live for those two years. (Lines 101-106)

Arti further shared that although she was enthusiastic to learn, and described her mentor as very belligerent at times, so she felt pushed, conflicted, and even somewhat antagonized during her residency, which made it very difficult.

I think if you're happy you learn better. It was a difficult program... when it came to our personalities and it clashed. So it was difficult on a daily basis... I had to struggle against that, whilst trying to learn. (Lines 333-337)

Arti felt strong opposition from her mentor, however looking back she rationalized, "at the end of it, [she did] make me into someone who I think is competent to do the job" (lines 57-58). Arti's mentor placed low emphasis on her manner when communicating to others, she remained extremely rigid regarding her expectations and demands of residents, and relationships among the residents needed to be mutually beneficial to her and to them; reflective of the highly individualistic U.S. society (Hofstede, 1997). All interactions appeared to be based on competence, skills and predetermined regulations, requiring task orientation, demonstrated in concern for productivity, versus concern for the individual (Blake \& Mouton, 1964).

Kavi reported that her mentor as well was a very strong minded and overpowering kind of person. Her job in social services required her to prepare a report immediately after dealing with each case. When presenting her work, she shared that her mentor was "a bullet headed lady that would not listen to you... so she got a little bit on the strong side of giving directives" (lines 139-140). Initially, Kavi could not understand why her 
mentor was being so forceful and confrontational in fact Kavi's first impression of her mentor was extremely negative. She shared:

My goodness... every day she's pounding and pounding, she had six investigative officers, 8 for the background and 6 of us, and she was one of those that had a high turnover cause nobody stayed with her....I was the only one that lasted. (Lines 320-326).

Kavi felt very stressed, yet she stayed on while others left. She was committed to her job, and those they worked to protect, even though her mentor was very difficult. Kavi added, "As frustrated as I was with her because she was pounding me, 'Do this, do this, do this', I respected her so highly to the point that whenever she said jump I would say 'how high"' (lines 144-146). Kavi often left work in tears because of her mentor.

Kavi's mentor sought to be competent and successful she therefore needed to see that all rules were followed to the letter, particularly because legislation was so specific in social services. Ensuring her staff functioned effectively was reflective of her leadership and control, even if it meant being harsh and confrontational to her staff. Anu as well felt imposed upon to some extent, however in her case it was more subtle. For her, mentoring was a new experience and she could not understand why her supervisor was constantly pushing her to take certain actions, and follow certain paths. Anu's supervisor's role was actually unrelated to Anu's academic program, yet the supervisor exerted pressure on Anu to assume certain academic responsibilities:

She pushed me. So that's the most difficult, because at that time feeling really totally overwhelmed about thinking about stuff like dissertation or internship...not really thinking ahead like that...[being pushed] at times felt overwhelming, and at times felt like I was doing these things more for her than for myself. (Lines 153-157) 
Anu felt overwhelmed and confused, like more clarity or direction was needed, and because of their busy environment they never really discussed whether Anu sought this type of guidance, or whether she was prepared to have her supervisor in this role.

In contrast to Indo-Caribbeans, East Indians directly from India retain attitudes that stem from a large power distance society reflective of the highly stratified, hierarchical caste system within Indian society (Agarwal, 2000; Hofstede, Hofstede \& Minkov, 2010). Coming directly from India, the supervisor retained the cultural characteristics inherent to Indian society. She retained attributes which emphasized that less powerful people are dependent on those who are more powerful, more educated individuals should assume authoritarian practices, and that an ideal supervisor is benevolent toward others. It is likely that these views lead Anu's supervisor to assume the stance and role as mentor, and to push her to engage in the academic endeavors that would benefit her success. Anu came to appreciate and accept her guidance since it helped her progress academically.

Disconnected and distanced. Disconnected and distanced refers to participants' feelings of separation and disengagement when mentors were unresponsive, unsupportive, or close-minded because of assumptive thinking, the lack of empathy, or hectic schedules. Female protégés including Nira, Sita, Rani, Prema experienced this with their White female mentors, as did Bina with her Hispanic female mentor.

Nira's mentor, her faculty advisor, rarely attended meetings of the 200-member student organization that Nira lead. As a result she questioned Nira's leadership, assuming that Nira could not manage such a large group and that participation would decrease. Nira described this as, "Definitely the hardest time for me in my mentoring 
experience" (lines 144-147). Her mentor's attitude and hectic schedule exacerbated the disconnect that existed between them.

Her mentor, a White female academic, was constantly involved with university business in her role as an administrator, faculty member and researcher. To retain her rank as faculty she needed to maintain high-level involvement, which detracted from the time and attention she could extend toward her protégé. Unlike this mentor, Nira felt that her other mentor who was Black-Jamaican was more understanding, supportive and sensitive to Nira's needs because of their common Caribbean background.

Sita felt that her socio-economic status and ethnicity as a poor Indo-Caribbean in Texas distanced her from her mentor. She felt that because her mentor was a wealthy White woman, she perhaps had "little reference to struggling herself" (line 313), so she could not understand why Sita needed to attend a less costly graduate program. Sita shared "basically her moral of the story was you get what you pay for... well I get what I can afford and I don't think she understood that” (lines 98-100). Sita's mentor assumed Sita was wealthy like other East Indians who migrated directly to Texas from India, and so she could afford to accept voluntary positions to gain experience in her field versus paid positions which could earn an income.

This mentor served as a university administrator and was so focused on building her own career that she rarely learned about her students' backgrounds. Sita felt that her mentor never understood her needs and so Sita chose to disregard her advice and worked out-of-field after she graduated so she could earn money to repay her student loans.

Rani was an ethnic minority along with $80 \%$ of the service level employees at the hotel where she worked. The minority service level employees sought her assistance 
more than her mentor's because they felt accepted by Rani and that she had a better rapport and was more empathetic toward them. This caused a rift between herself and her mentor who was the human resources manager at that office:

All of a sudden upper management was like, "Why is Rani dealing with these problems?" Came to the point where [the service level staff] didn't feel comfortable going to them, because they couldn't relate.... So that became a problem in the office...then within management itself...now they started not teaching me...stopped trying to explain things...now it was a closed-door meeting between two directors. When it used to be the three of us. (Lines 178-194)

Her mentor became more collegial and supportive toward her White male colleague and stopped training her or providing opportunities for her to learn.

In a multicultural society such as the U.S., ethnic minorities often lean toward each other for assistance and support because of their shared identity (Holland \& Lachicotte, 1998; Phinney, 1996b). The mentor however appeared defensive, and interacted less with the protégé, and also re-directed her attention to another colleague who was a White male, thereby neglecting the developmental needs of her protégé.

Addressing and confronting the mentor's prejudice in this scenario would remove mental barriers that negatively influence others' actions, motivation and achievement (Fennimore, 1994). However, rarely do minority individuals respond in these scenarios for fear that they are retaliated against, or that they alienate others. The prospect of worsening the situation, creating discomfort or losing emotional control exacerbates the stress, and may even cause hopelessness. In this case Rani resigned since she preferred to be in a comfortable and developmental work environment.

Bina felt distanced when her mentor, a Hispanic female school principal was upset or aggravated, and hence seemed unapproachable. Although Bina kept her distance 
at stressful moments, she saw how her mentor was aggressive to others, and this led to Bina's care and restraint, "I've seen her be aggressive with other people...my attitude has a lot [to do] with my relationship with her" (lines 476-477). She cautioned, "You have to choose your moments to say something" (lines 616-620). While Bina could contend with her mentor's moments of stress, there are numerous situations within the Pre-K environment and others where workplace stress increases aggression.

Prema on the other hand felt forced to distance herself from her White female mentor who became so comfortable with her that she started sharing too much information about her own personal life. Prema said:

"[My mentor shared] really detailed things about her personal life.... every time I was with her I became like this person that she could just dump on... and so invariably I would walk away from time with her feeling drained. (Lines 286294)

For Prema it was unnatural for personal details to be brought into the work environment. Prema expected her mentor to display qualities and attitudes that she could emulate, instead she felt that her mentor was overstepping her boundaries as a colleague and a professional. The mentor's self-interest led her to relieve her stress by "dumping" on her protégé. Prema shared:

I had to confront her on it at one point. And so it became very awkward. But... she realized it, and she realized that she could not go that deep with me. And so I could feel her pulling back. And so it was very awkward for a while for quite a while. But then after that I think she realized that she needed to have better boundaries about this. And so then we were able to go past that and become friends again. (Lines 298-304)

Had the mentor sought to discuss work related insights or concerns, Prema may have felt more valued as those concerns would be within her professional domain. According to Kalbfleisch and Davies (1993) interpersonal model of mentoring in some mentoring 
relationships deeply personal friendships develop at the later stages through close, interactive, strategic and routine communication that becomes personalized and intensified. In this scenario, Prema and her mentor were able to regain their friendship after they dealt with the misunderstandings and miscommunications.

While most protégés experienced some degree of struggle or challenge within their mentoring relationships, for some challenges proved to be source of frustration, while for others, challenges were viewed as situational shortcomings or opportunities for improvement. Mentors who caused protégés to feel imposed upon and embattled or disconnected and distanced appeared to lack sensitivity to cultural differences. They also did not appear cognizant of how their own personal or professional challenges influenced their behaviors toward others. While there are no universal approaches to understanding culture, these participants' experiences indicate that cross-cultural interaction requires mentors' sensitivity, concern and understanding toward those who were not raised in U.S. society. This represents a cultural gap regarding understanding protégés who are from cultures different from their mentors, the intercultural sensitivity that is required, and the cultural differences that exist. Unfortunately, protégés in this study did not discuss these struggles or challenges with their mentors and so they continued through the duration of these relationships.

The theme of guru-shishya: learning and discipleship informed the manner in which participants perceived mentors' guidance related to work, skill acquisition, and social or emotional support. Although ideal mentors also provide care, nurturance and guardianship, pressures within mentors' and protégés' personal or professional lives can detract from their sense of safety, well-being and progress within the cross-cultural 
mentoring relationship (Daloz 1986; Dilani, 2009; Noddings, 2005). Psychosocial support was instrumental in building learning centered cross-cultural mentoring relationships where the exchange of knowledge could occur.

Table 7 includes a summary of the findings that emerged within the theme of Guru-Shishya: Learning and Discipleship.

Table 7

Summary of Guru-shishya: Learning and Discipleship

\begin{tabular}{ll}
\hline Theme & Description \\
\hline Guru-shishya & $\begin{array}{l}\text { Guru-shishya: Learning and Discipleship refers to the manner in } \\
\text { which protégés perceived mentors' guidance related to work, skill } \\
\text { acquisition, and social or emotional support. Interactions with } \\
\text { mentors influenced professional competence, shared values, and } \\
\text { sociability. }\end{array}$ \\
Subthemes &
\end{tabular}

Anugraha or Anugraha or mentors' dispositions - mentors' attitudes within mentors' mentoring relationships -- how mentors behaved toward protégés as dispositions they imparted developmental types of guidance that ideally contributed to sustainable relationships and outcomes.
a. conferred positive energy
b. increased visibility

Leaving in Leaving in tears - the struggles and sense of opposition that arose tears within participants' mentoring relationships.
a. imposed upon and embattled
b. disconnected and distanced.

\section{Samavartan Sanskar: Building Coherence}

Samavartan sanskar refers to the sense of coherence that protégés' achieved as a result of their enhanced academic and professional capabilities. The sense of coherence is a salutogenic or life-orienting factor which presupposes that personal fortitude, selfworth, strength, cultural stability, sense of control, learned resourcefulness and social 
support are central to understanding, managing, and finding meaning in one's life (Antonovsky, 1979). Participants built coherence through learning-centered, professional or social interactions with mentors both professionally and relationally, in that they learned skills and practices that enhanced their professional roles and relationships. Symbolically samavartan sanskar represents the learner or seeker of knowledge attaining liberation from earthly existence or moksha through the auspices of a learned guru (Vaswani, 2008). Samavartan sanskar: building coherence manifested as: (a) indebtedness to the guru, and (b) reciprocity.

\section{Indebtedness to the Guru}

Indebtedness to the guru refers to protégés' appreciation toward mentors who enriched their personal and professional lives. Although participants did not explicitly describe their gratitude as indebtedness, they were all appreciative of mentors' guidance, acceptance and recognition of their successes. Mutuality and recognition within crosscultural mentoring relationships engendered meaningfulness, which, within cross-cultural mentoring relationships builds satisfaction, worth and purpose in the lives of protégés and (Antonovsky, 1987). Symbolically indebtedness to the guru represents the sacred thread of debt owed to the succession of gurus who have guided and enriched the learner, leading him toward a productive life. Indebtedness to the guru stemmed from participants' (a) acceptance, (b) achievement, reward and continuous improvement, and (c) personal value.

Acceptance. Acceptance refers to mentors' and participants' ability to mutually appreciate similarities and differences. Mutual appreciation engendered stronger connections or bonds within mentoring dyads. Keya and Nira reported feeling connected 
to their mentors because of a shared West Indian (Caribbean) background, although their mentors were Afrocentric (African descent) who migrated from Jamaica and they were Indo-centric (Indian descent). Keya said, "we both understand the hardships from living in third world countries and understand that hard work brings success" (lines 27-29). She recognized their mutual drive to succeed. Nira shared that because her mentor was West Indian, they often discussed shared cultural experiences, "She enjoyed me so much...because of my ability to express my cultural influence on my thoughts" (lines 171-172). Nira bonded with her mentor because of the acceptance she felt with her. Similarly, Mrita felt accepted by her Black Cherokee mentor even though they were from different backgrounds, with different levels of expertise. She shared:

She never made me feel diminished or she never demeaned me in any way. There was always just a sense of joking about, not in a bad way, but where we came from, or what our backgrounds were. But we never really focused on it as a difference or a similarity. We just accepted each other, who we were. (Lines 253-260)

They shared a common outlook that helped to build the sense of acceptance within their relationship, "we always, both of us, tended to not look at the background of a person really, even though we knew the background did shape that person. But what we saw in each other right there was the person herself" (lines 183-185). Being a naturally quiet and work-oriented person, Mrita felt that her mentor made it a point to connect with her, and to build a sense of community.

Mrita's mentor was accepting of other races and ethnicities. She shared that her mentor was responsive and appreciative of her colleagues' competence, interpersonal interactions and professionalism, and this determined whether they earned her esteem. Hard work and professional competence are valued traits within Black Cherokee culture. 
Aalia felt kinship because of the shared immigrant experience between herself and her Jewish-American mentor, she explained:

When you are in the U.S. you find that...former immigrants... when they meet, they link together...they share similar customs... are very family oriented, and they love to eat, and have good food, and sit down....To me those are things that reminded me of my own family so I was able to really identify very well with those things. (Lines 249-256)

Aalia's Caribbean cultural experiences included frequent social gatherings that were extensive and even communal, especially since Caribbean families are known to be huge. Indian cultural and religious celebrations as well span up to a week, for instance the Navaratri celebration which runs 9 nights and 10 days, or marriage celebrations that extend for 5 to 7 days with thousands of guests. Hence Indo-Caribbean participation in communal events are appreciated by many. Being a student away from home, Aalia enjoyed the community which she knew from her homeland. Aalia was also invited to her mentor's home to celebrate Passover, their Jewish feast. She explained:

I know he had never invited another student to his house. I think he felt very comfortable with me...I think he wanted his kids to grow up knowing someone who was Muslim, knowing someone who was maybe Muslim and liberal...like a different approach...but still very successful in different ways. (Lines 256-264)

Because of the political relations stemming from Islamic driven terrorist events of 9/11 and ongoing Arab/Israeli political strife, Aalia felt privileged to be welcomed into her mentor's home although she was Muslim. This meant she was accepted and valued. Feeling accepted broadens protégés perspectives, inspires productivity, and leads to increased emotional satisfaction, (Brinson \& Kottler, 1993). In these cross-cultural mentoring relationships, protégés felt recognized, valued and welcomed by their mentors. 
Achievement, reward and continuous improvement. Achievement, reward and continuous improvement refer to participants being recognized by mentors for their accomplishments and progress. Being validated for accomplishments within Indian tradition is a mark of prosperity and right conduct. Post indenture, Indo-Caribbeans "reinvented their culture" so rather than viewing material achievement as maya or illusion, for many it became a mark of success (Roopnarine, 2007, p. 119). Participants reported that mentors' recognition of their achievements, hard work and professional accomplishments was meaningful.

Bela reported how she felt rewarded by her mentors. She explained, "I would receive an award, or I'd receive a compliment, or I would be the first one picked on the case" (lines 166-168). Being rewarded was very meaningful for her because growing up, her parents typically would not give her that "pat on the back," she said, "So this was different to me...it made me wanna do more, because I actually got recognition when I did something" (lines 162-164).

Although Bela's parents often boasted about her accomplishments to the family, they never commended her on her academic or professional achievements as they considered it her responsibility to be successful. Likely, because of how much they sacrificed for her, they felt that her accomplishments were their reward, not hers. Her mentors however, both White males, were cognizant of how significant her achievements were as a scholar and practitioner. Their recognizing her accomplishments inspired her to work harder, and justified the hard work and effort she placed on studies.

Aalia experienced a strong sense of appreciation from her mentor's interest in her academic achievements. Throughout her program she was extremely goal-oriented, and 
kept a spreadsheet of her grades to verify that she was always moving towards the requirements to achieve the magna cum laude designation at graduation, as well as departmental honors. She learned that her mentor also kept a massive spreadsheet, "He would keep track of my grades, like 'OK Aalia you need an A in this, and you need'...I was just as much into this as him" (lines 715-717). Her mentor was equally interested in her success as she was. She learned she was awarded departmental honors from him before it was official, and for her that was tremendous. As a student coming from a quiet, poverty stricken countryside in the Caribbean, recognition and support for her achievements meant the world.

Bina's hard work was also recognized by her mentor:

Over the years she's gotten to know me, to know my work ethic, she's given me more and more responsibility, she's always to the best of her ability rewarded me more as the years have gone by...she's challenged me more. (Lines 497-503)

Bina's strong work ethic was rewarded in that she was given more opportunities for growth, and the freedom and autonomy to implement programs that would benefit her students. To her, this opportunity to continuously improve her practice was more valuable than monetary reward.

By recognizing Bina's hard work, her mentor affirmed Bina's competence as being reflective of their interdependent relationship, and Bina's authenticity and meaningfulness in "contributing to the growth and development of others" (Portman \& Garrett, 2005, p. 9).

Being rewarded or recognized by mentors built participants sense of coherence because they saw how their efforts and hard work resulted in academic and professional reward. In this sense, they understood how their efforts influenced the outcomes 
achieved Antonovsky (1987). Comprehensibility — understanding how one's efforts relates to or predicts outcomes and results, and manageability_having the skills and support to handle or control things, leads to meaningfulness. Meaningfulness being the belief that one's effort or sources of satisfaction are worthwhile and serve a specific purpose in one's life.

Personal value. Personal value refers to mentors' influence on participants' quality of life, at home and at work, either emotionally or physically. In these instances, participants chose to make their own decisions or learned how to make meaning within their personal lives.

Kavi explained how 5 years in social services drained her emotionally because of the work-related cases, and overly demanding schedules. She shared, "[Some of the] cases, got to be really gruesome emotionally, I had little ones...sometimes I was out all night...my family came first, you need to spend that time so I transferred to another nonprofit" (lines 9-12). Kavi's mentor was understanding and accommodating when she requested a transfer, recognizing that family was a priority for Kavi.

Supervisors who also serve as mentors may be more accommodating since they may have a closer connection with the protege, and so may be more empathetic. Kavi's mentor, a Black woman, also realized and appreciated Kavi's years of hard work and commitment to her job-characteristics she valued from her own work ethic. This mentor actually assisted Kavi in finding a new position.

Rani reported that her mentor taught her everything she needed to know in the hotel industry, and also how to be a career woman who was also a mom and a wife. For Rani, being successful in her family life was just as important as being successful in her 
professional life. Her mentor, a White female, also a working parent, was empathetic and supportive of Rani in her role as a new parent. Learning to juggle parenthood and a career can be challenging, and so providing advice to Rani enhanced her well-being in knowing her child was cared for even though she worked fulltime.

Nira's own sense of personal value and autonomy encouraged her to make the critical decisions in her life in spite of recommendations from her mentor. She became a parent during her undergraduate program, so she had to accommodate her family needs as well as her professional needs. She explained:

Ultimately the decisions that I had to make in my life were going to be life changing and everlasting. And I had to be sure that what I was doing was for me, and not just because somebody that I looked up to and respected was telling me to do it...I was definitely taking what they were saying seriously and into due consideration....[But] I wanted to make sure that my decisions were my own. (Lines 153-160)

Nira felt more kinship and connection with her Black-Jamaican mentor because of their similar backgrounds; however, in becoming a single parent, she was defensive about accepting guidance or input from anyone. In Nira's situation, she knew she could count on her family's support, because unlike Bela's parents, Nira's were somewhat more accepting of her pregnancy, possibly because they were younger than Bela's parents who were older and possibly more traditional in their beliefs. Although participants were influenced in different ways, they generally felt that their quality of life was important, and often made critical decisions on whether to remain in certain positions, to relocate, to follow mentors' advice or not.

Reciprocity. Reciprocity refers to the interchange of information reported by participants when they brought new knowledge to the mentoring table. Since this study 
was conducted from the perspective of only the Indo-Caribbean protégés, reciprocity discussed in this section only pertains to the actual information that was shared by participants. Participants shared information on innovative professional practices, Eastern culture, history and technology with mentors.

As a novice surgeon Bela explained that she read a lot and so would share new insights, and suggest new surgical methods with her mentors. They were sometimes resistant to innovative ideas particularly because of legal issues inherent to medical practice. While Bela was excited and intrigued by learning so much new material, she was appreciative that they cautioned her rather than allowed potential problems to arise.

Prad, having taught at the university level, and conducted experiments and research protocols, brought years of experience to the mentoring table. He also shared his knowledge of East Indian culture with his mentors to explain how Eastern practices aligned with Western practices, such as how Westernized use of personality profiles mirrored the Eastern practice to "see your patra" (line 493) by reading the stars (or Indian astrology) to determine one's "latent energies or tendencies" (lines 134-135), to explore one's personality and future. For Prad, drawing parallels between his ethnic culture and his professional life in the U.S. provided an avenue for him to retain his ethnic identity. His mentors learned about his culture as a result, so from this Prad gained a sense of worth and esteem for his identity because of the new information he shared.

As a student in the field of international relations, Aalia shared her research with her mentor, a well-published authority in his field, in an effort to prove that video footage of a human rights violation was inaccurately reported. She enlightened him based on knowledge from someone in the region, and her actual research: 
I had a friend whose father was from there, and went and did all the research, showed [my mentor] all the U.N. reports, Amnesty International reports, human rights watch reports and he actually apologized in front of the entire class, and said that it's good to have more information. (Lines 141-145)

Here the mentor obtained new knowledge applicable to future discussions of the particular violation. Because of his knowledge and authority in the field, Aalia felt rewarded that she could provide such crucial information to her mentor. As a reputable instructor it was crucial he provide accurate information. He used this experience as a teachable moment for his students and proteges.

Mrita worked in information technology and frequently showed her mentor how to navigate various computer programs. Often her mentor would be trying for hours trying to figure them out and Mrita would teach her what to do within minutes. Her mentor frequently joked that she would have to take Mrita with her if she ever left the organization given how much she valued Mrita's knowledge and expertise and her ability to share her knowledge. Mrita's mentor recognized the competence and expertise of her protégé as a woman in a male dominated field.

Reciprocity built mutual understanding between participants and their mentors through the joint exchange of knowledge, and reflected what Golian and Galbraith (1996) referred to as the essence of a good mentoring relationship.

The theme of samavartan sanskar: building coherence, informed the learningcentered, professional and social interactions with mentors that engendered and affirmed protégés' understanding, managing, and finding meaning. Mentors or gurus were recognized for enriching protégés personal and professional lives. For protégés crosscultural mentoring provided an opportunity for them to build a better life in the U.S. 
because of their academic and professional accomplishments. Table 8 includes a summary of findings in the theme of Samavartan sanskar: Building coherence.

Table 8

Summary of Samavartan sanskar: Building coherence

\begin{tabular}{|c|c|}
\hline Theme & Description \\
\hline $\begin{array}{l}\text { Samavartan } \\
\text { sanskar: } \\
\text { Building } \\
\text { coherence }\end{array}$ & $\begin{array}{l}\text { Samavartan sanskar: Building coherence - Samavartan sanskar refers } \\
\text { to the sense of coherence that protégés' achieved as a result of their } \\
\text { enhanced academic and professional capabilities. The sense of } \\
\text { coherence is a salutogenic or life-orienting factor which presupposes } \\
\text { that personal fortitude, self-worth, strength, cultural stability, sense of } \\
\text { control, learned resourcefulness and social support are central to } \\
\text { understanding, managing, and finding meaning in one's life. }\end{array}$ \\
\hline
\end{tabular}

Subthemes

Indebtedness Indebtedness to the guru refers to protégés' appreciation toward to the guru mentors who enriched their personal and professional lives.

Reciprocity refers to the interchange of information reported by Reciprocity participants when they brought new knowledge to the mentoring table.

\section{Summary}

This chapter presented the findings of the phenomenological study on the perceptions of Indo-Caribbean protégés regarding their cross-cultural mentoring experiences in the United States. Three themes emerged from this data analysis: (a) sitting at the feet of gurus (b) guru-sishya: learning and discipleship, and (c) samavartan sanskar: building coherence. A summary of the themes and sub-themes is presented in Table 9. Chapter 5 contains answers to the research questions in this study, implications, and recommendations for further research. 
Table 9

Summary of Themes

\begin{tabular}{ll}
\hline Theme & Description \\
\hline "Sitting at the & "Sitting at the feet of gurus" within participants' personal spaces \\
feet" of gurus & $\begin{array}{l}\text { helped them learn bhakti or devotion and surrender to others. This } \\
\text { theme informs ways that participants' families and Indo-Caribbean } \\
\text { heritage shaped their attitudes toward academic achievement and } \\
\text { obtaining new knowledge, making them more accepting of guidance } \\
\text { from others. } \\
\text { (a) Indebtedness to parents and family } \\
\text { (b) Sampradāya or East Indian traditions } \\
\text { (c) Sources of wisdom--Western experiences } \\
\text { Guru-shishya } \\
\begin{array}{l}\text { Guru-shishya refers to the path of learning and discipleship reflecting } \\
\text { the manner in which protégés perceived mentors' guidance related to }\end{array} \\
\text { work, skill acquisition, and social or emotional support. Interactions } \\
\text { with mentors influenced professional competence, shared values, and } \\
\text { sociability. } \\
\text { (a) Anugraha--mentors' dispositions } \\
\text { (b) Leaving in tears } \\
\text { Samavartan }\end{array}$ \\
$\begin{array}{l}\text { Samavartan sanskar: Building coherence - Samavartan sanskar refers } \\
\text { to the sense of coherence that protégés' achieved as a result of their } \\
\text { enhanced academic and professional capabilities. The sense of }\end{array}$ \\
coherence is a salutogenic or life-orienting factor which presupposes \\
that personal fortitude, self-worth, strength, cultural stability, sense of \\
control, learned resourcefulness and social support are central to \\
understanding, managing, and finding meaning in one's life. \\
(a) Indebtedness to the guru \\
(b) Reciprocity
\end{tabular}




\section{CHAPTER V}

\section{Discussion}

This chapter is divided into three sections which form the discussion based on the findings of this study. The first section presents responses to the research questions based on the findings of the study. The second section addresses the implications and recommendations for further research. A summary section concludes this chapter.

\section{Responses to the Research Questions}

The primary research question of this study was as follows: How do IndoCaribbean protégés in the United States perceive the effects of their cross-cultural mentoring experiences? The following subsidiary questions also guided the study: What factors do Indo-Caribbean protégés report that facilitate their successful crosscultural mentoring relationships?

What challenges do Indo-Caribbean protégés encounter within their cross-cultural mentoring relationships?

What mentoring strategies and practices do Indo-Caribbean protégés believe will help to enhance their professional development?

The discussion begins with responses to the secondary research questions followed by the response to the primary research question. Participants in this study were Indo-Caribbeans, that is, of Indian ancestry, who migrated from, or were born to Indian parents from Trinidad, Guyana, and Jamaica, and were protégés in cross-cultural mentoring relationships in the United States. 


\section{Response to Subsidiary Question 1: What factors do Indo-Caribbean protégés report that facilitate their successful cross-cultural mentoring relationships?}

Successful cross-cultural mentoring relationships were those in which protégés were able to achieve their academic and professional goals as a result of mentors' positive dispositions, or attitudes. Mentors' dispositions contributed to sustainable and productive cross-cultural relationships developed through encouragement and support, advocacy, care, nurturance and trust that influenced protégés' receptivity within their relationships.

By providing a safe and trusting environment mentors influenced protégés' thinking, feeling, beliefs, and interpersonal interactions through shared developmental relationships (Rogoff, 1995), creating meaning, depth, mutuality and interpersonal comfort within their relationships (Ugrin, Odom, \& Pearson, 2008; Washbern-Moses, 2008). Minority mentors, those who were Black, Black-Jamaican, Hispanic, Indian or Black Cherokee were more nurturing and emotionally supportive than White mentors. White mentors focused primarily on preparing protégés to be competent professionals.

Mentors were caring and nurturing when they were dependable, warm, compassionate, understanding, and complimentary of protégés. By interacting with protégés in this manner, mentors encouraged them to be open to learning and guidance, and accepting, and appreciative of mentors' support (Galbraith \& Cohen, 1995). Protégés felt secure to express their needs and to ask for the guidance they needed.

Protégés shared that mentors advocated for them by helping them build interpersonal connections, learn to prioritize and to self-advocate where they previously lacked the confidence or foundational skills to do so. Protégés developed self-confidence 
when mentors accepted their individuality, affirmed their growth and strengths, recommended them to faculty and administration, and counseled them when they needed the impetus to move forward or to resolve challenges. Aalia shared of her White mentor, "He just saw something special in me within all my classes, and he was able to nurture that by placing a huge amount of pressure on me to live up to his standards" (lines 104106). In doing so, her mentor encouraged her to develop the skills and knowledge she needed to excel in her field. Through interpersonal contact, emotional support at stressful moments and recognition of protégés' accomplishments mentors enhanced protégés' efficacy, enabling them to pursue their goals without fear or perceived limitations (Bandura, 1977; Cranton, 2002; Kaye \& Jacobson, 1996).

Protégés also described mentors' struggles and personal challenges which made them empathetic as they helped protégés step out of their comfort zones to take risks in areas that were unfamiliar or previously intimidated them. By seeing Black and Hispanic mentors overcome their own personal or professional challenges, protégés built selfdeterminism, self-esteem and a sense of control (Branch, 1994). Black mentors were at times more rigid with rules and procedures, but extremely protective of their mentees. For instance Kavi repeatedly shared that she felt safe because of her mentor's guidance so she could "sleep at night" (lines 92-95). Whereas the Hispanic mentor was more supportive toward her protégé having to retrain and recertify so she could teach in the United States, an experience shared by many Hispanic immigrants (Bell, 2011).

Mentors' positive dispositions served as a proactive strategy that engendered a process of change through personal agency as opposed to mere engagement (Beard, Murrell, \& Thomas, 2007; Clark, 1993). Protégés gained the sense that they could 
manage and maintain control of what took place within their lives. From the encouraging, supportive, caring, nurturing, and trust filled relationships with mentors protégés developed the foundations they needed to be successful in graduate school and in their careers.

\section{Response to Subsidiary Question 2: What challenges do Indo-Caribbean protégés encounter within their cross-cultural mentoring relationships?}

Challenges within protégés' cross-cultural mentoring relationships were the struggles and sense of opposition they experienced when mentors' attitudes, actions and responses made them feel imposed upon, embattled, disconnected and distanced. Being imposed upon and embattled reflects the forceful and unexpectedly aggressive natures that some protégés perceived regarding their mentors. Disconnected and distanced reflects protégés' feelings of separation and disengagement when mentors were unresponsive, unsupportive, or close-minded because of assumptive thinking, the lack of empathy, or hectic schedules. For protégés feeling distanced inhibited interaction, interpersonal comfort, and freedom of expression.

While protégés tried to remain focused on their academic and professional goals, when confronted by such difficulties, they at times found it difficult to maintain objectivity. They allowed negative feelings and emotions to detract from their mindfulness toward their goals, potentially because Indo-Caribbeans tend to be nonconfrontational, avoid opposition or conflict in favor of comfortable and amicable relationships, are co-operative, and conformist (Glasgow, 2006). Mentors at times became negligent in their attitudes toward protégés especially in cases when mentors were overly immersed with making progress in the field or advancing their own personal 
achievements. White female mentors in particular seemed more conscious that they be perceived as progressive, competent leaders so they could become recognized (Health Resources and Services Administration, 1995). Arti's White mentor for instance was so consumed with her progress as a woman in the medical sciences that Arti felt the sense of constant battle throughout her 2-year residency.

Protégés felt distanced when Black and Hispanic female mentors were under pressure or stressed, appeared anxious or upset, or were constantly harsh. Protégés felt the need to be selective of when they could approach or discuss ideas when they perceived the mentors were upset or aggressive. At times protégés would endure anxiety filled days because they felt they needed to wait until the mentors' mood improved.

Although mentors in most cases were agreeable, at some point, female mentors, whether White, Black, Hispanic, or Indian appeared insensitive or exhibited aversive or authoritarian attitudes toward protégés. Protégés in fact reported experiencing more challenges with female mentors as opposed to male mentors. For instance, a negative response from one mentor felt derogatory and demotivating to the mentee who sought guidance in selecting a graduate school, and could not afford a more costly or recognized program.

Other mentors assumed that protégés were not competent to handle leadership roles and so undermined protégés' confidence. Such actions by mentors hindered protégés as they sought to gain new experiences, shifts in perception, and growth (BlakeBeard, Murrell, \& Thomas, 2007; Kegan, 1982). While the actions and responses of authentic mentors are to challenge the creative freedoms and autonomy of protégés, if 
they are genuinely seeking to support protégés they should be cautious to not ignore, antagonize or mistreat protégés (Freire, 1997).

Aversive attitudes can incite action, inaction, and aggressive or passive responses from protégés (Beyene, Anglin, Sanchez, \& Ballou, 2002). When confronted by adversarial attitudes protégés who tend to be more passive may suppress their responses to avoid being disrespectful toward mentors, which potentially restricts their own development, vision and growth. Protégés can also interpret negative or aversive actions as defensive, retaliatory or even biased especially if the protégé is an ethnic minority, hence creating resistance, and building barriers within the learning environment (Johnson-Bailey \& Cervero, 2002). Based on this study, mentors needed to recognize that negative actions are reflected as aggression, hostility or antagonism. Benishek, Bieschke, Park, and Slattery (2004) suggest that mentors should work to build a relational exchange that respects differences, examines tensions, and immediately addresses them.

Understanding and appreciating how diverse cultures interpret attention, mutuality, support, and interpersonal comfort is critical to reducing challenges within cross-cultural mentoring relationships (Ugrin, Odom, \& Pearson, 2008). Caribbean cultures recognize "hard work, delayed gratification, or personal austerity" (Henke, 2001, p. 52) as the means to maintain control of their academic achievement and professional success. Protégés in this study made accommodations for mentors' aversive behaviors and actions, and adjusted their attitudes and approaches toward mentors, since the most crucial factor was that the protégés achieved their goals regardless of the challenges within their mentoring relationships. 


\section{Response to Subsidiary Question 3: What mentoring strategies and practices do Indo-Caribbean protégés believe will help to enhance their professional}

development?

Professional development is a form of continuing education that occurs in the workplace and ideally combines the academic and practical knowledge of employees at different levels with the knowledge from trainers and supervisors (Cervero, 2000). Professional development within mentoring relationships takes the form of hands-on, field-specific guidance and knowledge, and the competencies needed to become more visible within the U.S. work environment. Within Western cultures becoming visible or recognized in one's field signifies professional success (Fogarty \& Dirsmith, 2001).

For Indo-Caribbeans gaining professional competence reflects an historical precedent of defying the stigmas developed by the caste system practiced in India. Migration to the West dispelled the caste system and enabled everyone to obtain an education so they would not be perceived as inferior to the Brahmin or elite castes (Crowley, 1990). Indian families continue to encourage children to become successful professionals and productive members of society. Conversely, mentors from various races and ethnicities also recognized the value of professional development.

Mentors focused on developing protégés' functional and professional competence, cultural competence, and interpersonal competence. Functional and professional competence meant protégés became more effective with the physical, task related expertise needed in their roles (DiMaggio, 1991). Cultural competence meant protégés built more relational dimensions to negotiate, manage conflict, appear more confident, and interact in a manner that is respected and recognized in the U.S. workplace 
(DiMaggio \& Powell, 1991). Interpersonal competence improved protégés verbal, interpersonal communication, attitudes and accommodations or responses toward others in an effort to generate mutuality and understanding, particularly in challenging situations (Katz, 1975). Consequently, protégés became less passive, more accepting and flexible.

Functional and professional competence was prioritized by White mentors, more than other races, particularly in medical and scientific fields. Mentors helped protégés become more perceptive of patient needs, whether financially, familial, social or psychological; for instance a medical practitioner has to be aware of all risks inherent to treating the individual (Passarelli, 2008). They also introduced protégés to more complex and analytical scenarios to expand their problem solving capabilities and knowledge of regulatory standards in these fields.

By learning about the inherent natures of their various fields from their mentors, including the cultures, expectations and challenges, protégés became more inquisitive and independent in order to obtain the information, experiences, critical thinking skills, and judgment needed within their various organizations. For instance, in IT, scientific research, social services and the PreK environment protégés learned appropriate behaviors to handle challenges, personality conflicts, and difficult decisions (Ugrin, Odom, \& Pearson, 2008). Mentors' who were Black, Black-Jamaican, Black Cherokee and Hispanic may have relied on their prior experiences and personal challenges as minorities to help guide protégés in developing these new skills.

To improve interpersonal competence mentors encouraged memberships within professional organizations, and supportive peer networks to enhance the team driven environment characteristic of the U.S. workplace (Marquardt, 2002). Hispanic, Black 
Cherokee and Indian mentors encouraged protégés to become more involved and collaborative. Protégés, particularly those who subscribed to a more individualist nature and preferred independent, direct, task and goal orientation learned to build collegial, socially accepting and integrative relationships in which they could interact and delegate effectively (Hofstede, 1997; Portman \& Garrett, 2005; Rogoff, 1995).

Mentors also provided direct, specific and personalized support, used metaphors or analogies to be more explanatory and understandable, provided feedback and discussed strategies and recommendations to equip protégés to interact more confidently. Gaining confidence helped protégés interact outside of their comfort zones, handle differences, overcome isolation, become role models, navigate new scenarios and interact more dynamically (Brinson \& Kottler, 1993; Hershey \& Blanchard, 1995; Mahn \& JohnSteiner, 2002; Vygotsky 1962).

While it may be argued that mentors fulfilled the responsibilities inherent with being supervisors, as opposed to true mentors, the functions, guidance and support afforded to protégés in this study go beyond the typical functions of supervisors or managers in the working world. According to Marquardt and Loan (2006), todays evolving environments require managers to be inspirational, nurturing and motivational in order to enhance the development of employees. While managers can efficiently lead or coach, they may fall short in creating an authentic bond that incites action, continuous learning and transformation in the workplace.

Protégés, through interactions with mentors in this study became more articulate, focused, openly interactive, engaging, and diplomatic, and found new ways to express themselves, not typical of introverted and passive Indo-Caribbean culture. As mentors 
focus on building protégés strengths, self-efficacy, resourcefulness and resilience within the professional environment, they instilled in them the sense that they were in control of their futures (Antonovsky, 1987; Bandura, 1977).

\section{Response to Primary Question: How do Indo-Caribbean protégés in the United States perceive the effects of their cross-cultural mentoring experiences?}

Indo-Caribbean protégés in this study perceived their cross-cultural mentoring experiences in the U.S. to be both influential and supportive of their academic and professional success. Mentors implemented and practiced mentoring strategies that demonstrated high levels of support and challenge, which inspired growth and confirmation (Daloz, 1986). With mentors' support, protégés were able to traverse from being students and novices to effective and well-respected professionals, knowledgeable of the functional and cultural expectations within the U.S. workplace (Lave \& Wenger, 1991). White mentors could be viewed as more instrumental and intent on instilling professional competence, while racial and ethnic minority mentors appeared somewhat more empathetic and focused on the interpersonal and cultural competence protégés needed to progress in the U.S. workplace.

Mentors actions helped protégés assimilate into the U.S. academic and professional environment where they progressed toward "upward socioeconomic mobility, increasing acculturation, decreasing discrimination, and greater psychological well-being" (Rumbaut, 1994, p. 774). Protégés learned to overcome cultural and societal hurdles in order to function and thrive in their various U.S. environments, whether as students or working professionals. By assuming a somewhat bi-cultural ethnicity from being American, whether by birth or by naturalization, and by retaining their Indo- 
Caribbean heritage, protégés developed a double-consciousness which encouraged them to accept their new selves within the U.S., and to follow the required interaction and behavioral protocols so that they could "fit in" at work or school.

Protégés persisted toward achieving their own goals and professional expectations in spite of the adversarial challenges they at times endured within their mentoring relationships. Insensitivity or exclusionary behaviors from mentors may form roadblocks and conflicting emotions that negatively influence protégés' learning and receptivity (Galbraith \& Cohen, 1995; Lee \& Sheared, 2002). However, the deference and respect that protégés learned from various gurus within their families helped them overlook the negative dispositions and opposition they sometimes experienced. Protégés instead focused on the acceptance, guidance, feedback, competence, interpersonal comfort and confidence--the more developmental factors within their cross-cultural relationships and overcame suppressed emotions, adversarial feelings, and misleading assumptions (Kegan, 1982; Seepersad, Hagood-Elliott, Lewis, \& Strickland, 2007).

In contrast to the calm Caribbean lifestyle, the U.S. work environment was inherently busy and demanding because of academic and professional requirements combined with mentors' seemingly aggressive attitudes. Protégés who migrated to the U.S., developed the tenacity to manage the rigorous academic and professional practices inherent to life in the United States because of the support and possibly also the opposition from mentors. Cross-cultural mentoring relationships became a vehicle for Indo-Caribbean protégés to gain new knowledge, develop competence, and find meaning within their lives regardless of their personal or professional challenges. While their success is reflective of the resolve and persistence brought by their ancestors to the 
Western world, it also represents the sense of coherence that minority populations struggle with after migrating to the U.S. (Billings \& Hashem, 2010; Myers, 2004). The sense of coherence presents connections between resilience, social support, cultural competence, availability of resources and individual-centered professional growth as salutogenic factors that may enhance the lives of ethnic minorities and immigrants in the United States (Ying, Lee, \& Tsai, 2000).

Salutogenesis is the study of health origins and causes that focuses on ways to "create, enhance, and improve physical, mental and social well-being" (Becker, Glascoff, \& Felts, 2010) and typically informs issues related to health and wellness. The study of salutogenesis as it relates to well-being or welfare of racial and ethnic minority protégés in cross-cultural mentoring relationships represents a potential contribution to the literature. Gaining understanding or constructing new knowledge, learning to manage academic or professional roles with guidance of others, and finding meaning by developing internal value, contribute to protégés' well-being within their personal and professional lives (John-Steiner \& Mahn, 1996; Merriam \& Caffarella, 1999). In this sense, Indo-Caribbean protégés' cross-cultural mentoring relationships provided the sense of coherence as a salutogenic or life-orienting factor (Antonovsky, 1979) that instilled competence, endurance, cultural stability and social support which enhanced their academic and professional growth in the United States.

Figure 2 below represents the themes that emerged from this study, informing the foundational, relational and developmental factors within Indo-Caribbean protégés' cross-cultural mentoring relationships. 
Figure 2. Foundational, Relational and Developmental Factors in Protégés Cross-Cultural Mentoring Relationships

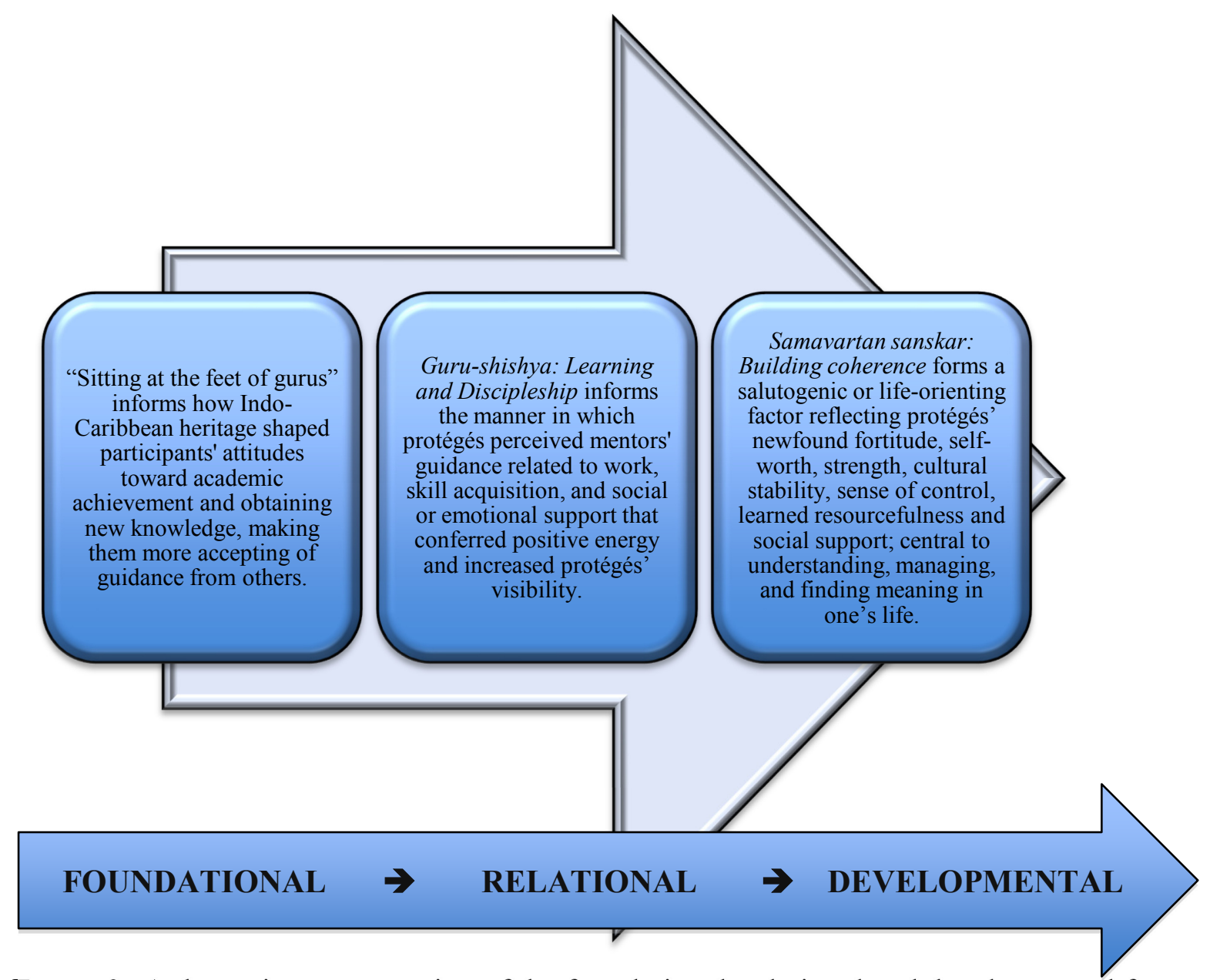

Figure 2. A thematic representation of the foundational, relational and developmental factors within Indo-Caribbean protégés' and mentees' cross-cultural mentoring relationships. 


\section{Implications}

This study has implications for those who participate in cross-cultural mentoring relationships, whether as mentors among university faculty and administration, as managers and supervisors within academic or professional environments. The findings related to how mentors and protégés from different racial or ethnic cultures influence each other support the need for adult educators, administrators, managers and academic advisors to inculcate functional and professional competence, cultural competence, and interpersonal competence as they support and guide protégés in pursuit of academic and professional goals in the United States.

As a less visible immigrant culture, it is possible for mentors to overlook cultural differences, and assume that protégés and mentees are all the same. However, because of socio-historic and cultural differences, protégés from cultures different from their mentors may have different expectations, ideals, relational bonds, and communication patterns.

Given the increasing diversity within U.S. academic and professional environments, it is useful to understand these and other immigrants' perceptions regarding their social and cultural identities, goals, expectations, values, and beliefs (Kochan \& Pascarelli, 2004). Faculty, advisors, religious leaders, and supervisors may benefit from increased cultural competence and intercultural sensitivity as they continue to serve as mentors in multi-cultural environments.

Developing cultural competence and intercultural sensitivity enables mentors to be more understanding and perceptive toward "subtle differences in nonverbal behavior or communication style[s]...[so they can] see a culturally different person as equally 
complex" as themselves (Bennett, 2004, p. 73). For example, being perceptive to facial expressions or interpersonal reactions may help mentors recognize the effects of their words and actions. This allows mentors to observe a culturally different perspective from which they may consistently support protégés with different values, beliefs, and attitudes than their own, so they could be more supportive and empathetic toward them.

The findings from this study imply that cross-cultural mentoring relationships may be an informative platform for reflective practice through which adult educators may examine espoused theories regarding culturally integrative and responsive practices in relation to their own mentoring practices (Cervero, 1989). By reflecting upon interpersonal and cross-cultural relationships, mentors may come to understand how cultural competence influences multicultural classrooms and learners. Understanding the needs of learners in a culturally pluralistic society with multitudes of foreign-born students, immigrants and professionals allows mentors to be more supportive and responsive to protégés developmental and relational needs. Cross-cultural mentorships require culturally integrative mentoring practices, tools to help identify roles, responsibilities and best practices to provide learner-centered guidance, to accommodate feedback and to help minority learners build connections and community (White, 2006).

\section{Recommendations for Future Research}

Future research on cross-cultural mentoring can build on the findings of this study by examining the cross-cultural mentoring experiences of Indo-Caribbean protégés in U.S. states with larger minority and immigrant populations. Such a study may inform whether intercultural sensitivity and attitudes enhance cross-cultural mentoring relationships with respect to increased racial and ethnic diversity. 
Further exploration of cross-cultural mentoring experiences among IndoCaribbean protégés using research methods such as surveys, case studies, and ethnographies may enhance the level of detail needed to inform their experiences in various settings are also recommended. Since Indo-Caribbeans enroll and work in a range of academic and professional environments in the U.S., such research may provide insights on their career and academic development, protégé versus mentee differences, salutogenic support structures, and the attitudes of mentors who contribute to the U.S. learning landscape.

Finally, the perceived differences between use of the terms protégé and mentee may also be explored. In this study it was observed that some participants maintained longitudinal mentoring relationships for 2 years to over 20 years, and appeared to master a preponderance of mentors' knowledge. Other participants maintained short-term relationships for 1 to 2 years in more psychosocially supportive relationships that appeared to focus on more immediate learning outcomes. Further research is needed to explore whether the terms protégé and mentee may be used to distinguish those on the receiving end of a mentoring relationship based on the level of mastery and the capabilities they have acquired as a result of the mentoring relationship.

Since mentoring is a widely discussed developmental phenomenon (Hargreaves \& Fullan 2000; Merriam, Thomas \& Zeph 1987), changing U.S. demographics require that we scrutinize culturally diverse relationships more closely to learn of ways to meet the needs of all learners. Cultural differences that stem from ethnic and cultural perspectives are ingrained in individuals' cultural identity and can enable enduring adult learning experiences through social, cognitive and behavioral interactions that form connections 
and affirm or contest cultural assumptions (Jeria, 2002; Lee \& Sheared, 2002; Vygotsky, 1979). Cross-cultural mentoring relationships should engage learners more deeply by cultivating an atmosphere that inspires them to engage with and support each another in an effort to enhance academic performance and professional development (Kuh 2001).

\section{Summary}

Chapter 5 concluded the study with responses to the research questions, implications and recommendations for future research. The purpose of this phenomenological study was to explore the perceptions of Indo-Caribbean protégés regarding the effects of their cross-cultural mentoring experiences in the United States.

This study illuminated the values, beliefs, attitudes and culture of Indo-Caribbean protégés and mentees within cross-cultural mentoring experiences in relation to the supports and challenges within their academic and professional spaces. Cross-cultural mentoring relationships for protégés in this study emphasized the resolve and persistence brought by their ancestors to the Western world, and reinforces the urgent need for a sense of coherence among minority immigrant populations (Billings \& Hashem, 2010; Myers, 2004). With increased resilience, social support, cultural competence, resources and professional growth ethnic minorities and immigrants may one day achieve the American Dream. 


\section{REFERENCES}

Agarwal, A. (2000). Can Hindu beliefs and values help India meet its ecological crisis. In C. K. Chapel \& M. E. Tucker (Eds.), Hinduism and ecology: The intersection of earth, sky, and water (pp. 165- 182). Cambridge, MA: Harvard University Press.

Albertini, V. L. (2001). Influences on immigrant students' perceptions of the chances of making it in the United States (Doctoral dissertation). Retrieved from ProQuest Dissertations and Theses database. (UMI No. 3006849)

Alfred, A. V. (2002). The promise of sociocultural theory in democratizing adult education. New Directions for Adult and Continuing Education, 96, 3-13. doi:10.1002/ace.74

Alfred, M. V. (2003). Sociocultural contexts and learning: Anglophone Caribbean immigrant women in U.S. postsecondary education. Adult Education Quarterly, 53(4), 242-60. doi:10.1177/0741713603254028

Allahar, A. (2005). Ethnicity, class and nationalism: Caribbean and extra-Caribbean dimensions. Lanham, MD: Rowman \& Littlefield.

Allport, G. (1954). The nature of prejudice. Reading, MA: Addison Wesley.

American Community Survey. (2011). Congressional Research Service presentation of 2008 American Community Survey data, 2011. The U.S. Foreign-Born Population: Trends and Selected Characteristics.

American College Personnel Association. (1996). The Student Learning Imperative. Washington, DC: American College Personnel Association.

Amstutz, D. (1999). Adult learning: Moving toward more inclusive theories and practices. In T. C. Guy (Ed.), Providing culturally relevant adult education: A challenge for the twenty-first century. New Directions for Adult and Continuing Education, 82, 19-31. San Francisco, CA: Jossey-Bass.

Andersen, S. R., Belcourt, G. M., \& Langwell, K. M. (2005). Building healthy tribal nations in Montana and Wyoming through collaborative research and development. American Journal of Public Health, 95(5), 784-789. doi:10.2105/AJPH.2004. 051032

Anderson, E. M., \& Shannon, A. L. (1988). Toward a conceptualization of mentoring. Journal of Teacher Education, 39(1), 38-42. doi: 10.1177/002248718803900109

Antonovsky A. (1979). Health, stress and coping. San Francisco, CA; Jossey-Bass. 
Antonovsky, A. (1996). The salutogenic model as a theory to guide health promotion. Health Promotion International, 11(1), 11-18.

Appiah, K. A. (2005). The ethics of identity. Princeton, NJ: Princeton University Press.

Ash, A. S., Carr, P. L., Goldstein, R., \& Friedman, R.H. (2004). Compensation and advancement of women in academic medicine: Is there equity? Annals of Internal Medicine, 141(3), 205-215. Available online via website http://www.acp-mdwim.org/PDF\%20Documents/equitywomen.pdf

Astin, A. (1985). Achieving educational excellence: A critical assessment of priorities and practices in higher education. San Francisco, CA: Jossey-Bass.

Awokoya, J. T., \& Clark, C. (2008). Demystifying cultural theories and practices: locating Black immigrant experiences in teacher education research. Multicultural Education, 16(2), 49-58.

Bandura, A. (1977). Social learning theory. New Jersey, NJ: Prentice-Hall Inc.

Banks, J. A., \& Banks, C. A., (1995). Handbook of research on multicultural education. New York, NY: MacMillan.

Barker, M. J. (2007). Cross-cultural mentoring in institutional contexts. The Negro Educational review, 58(1/2), p. 85-103.

Barrett, K. (2010). Work experiences of professional West Indian immigrant women in the United States: An exploratory study (Doctoral dissertation). Retrieved from ProQuest Dissertations and Theses database. (UMI No. 3414097)

Battaglia, B. A. (1994). Skills of managing multicultural teams: Vol. 4. Cultural Diversity at Work. Seattle, WA: Gil Deane Group.

Bauer, T. (1999). Perceived mentoring fairness: relationships with gender, mentoring type, mentoring experience, and mentoring needs. Sex Roles, 40(3-4), 211-25.

Becker, C. M., Glascoff, M. A. W. Felts, M. (2010) Salutogenesis 30 years later: Where do we go from here? International Electronic Journal of Health Education. 13(1) $25-32$.

Bell, M. (2011). Diversity in organizations. Mason, OH: South-Western, Cengage Learning.

Benishek, L. A., Bieschke, K. J., Park, J., \& Slattery, S. M. (2004). A multicultural feminist model of mentoring [Supplemental material]. Journal of Multicultural Counseling and Development, 32, 428-442. 
Berger, K. S. (2005). The developing person through childhood. New York: Worth Publishers.

Bennett, M. J. (2004). Becoming interculturally competent. In J. S. Wurzel (Ed.), Toward multiculturalism: A reader in multicultural education (pp. 62-77). Newton, MA: Intercultural Resource Corporation.

Bennett, J. M., \& Bennett, M. J. (2003). Developing intercultural sensitivity: An integrative approach to global and domestic diversity. In D. Landis, J. Bennett, \& M. J. Bennett (Eds.), Handbook of intercultural training (pp. 147-165). Thousand Oaks, CA: Sage.

Bernal, D. D., Alemn, E., \& Carmona, J. F. (2008). Transnational and transgenerational Latina/o cultural citizenship among kindergarteners, their parents, and university students in Utah. Social Justice, 35(1), 28-49.

Bernard, H. R., \& Gravlee, C. G. (2005). Skin color, culture, and blood pressure in southeastern Puerto Rico. Social Forces, 83(3), 949-970.

Beyene, T., Anglin, M., Sanchez, W., \& Ballou, M. (2002). Mentoring and relational mutuality: Protégés' perspectives. Journal of Humanistic Counseling, 41(1), 87102.

Bhatia, S. (2007). American karma: Race, culture, and identity in the Indian diaspora. New York, NY: New York University Press.

Billings, J., \& Hashem, F. (2010). Salutogenesis and the promotion of positive mental health in older people. Presented at EU Thematic conference "Mental Health and Well-being in Older People - Making it Happen" 19th- 20th April 2010, Madrid, Spain. Available on website http://ec.europa.eu/health/mental_health/docs/older_salutogenesis.pdf

Birbalsingh, F. (1997). From pillar to post: The Indo-Caribbean diaspora. Toronto, Canada: TSAR.

Bisnauth, D. A. (1993). Caribbean profile. In O. L. Bolioli (Ed.), The Caribbean, culture of resistance, spirit of hope (pp. 13-19). New York, NY: Friendship Press.

Blake, R. R. \& Mouton, J. S. (1964). The managerial grid: Key orientations for achieving production through people. Houston, TX: Texas Gulf Publishing.

Blake-Beard, S. D. (1999). The costs of living as an outsider within: An analysis of the mentoring relationships and career success of Black and White women in the corporate sector. Journal of Career Development, 26(1), 21. doi:10.1177/089484539902600103 
Blake-Beard, S. D., Murrell, A. J., \& Thomas, D. A. (2007). Unfinished business: The impact of race on understanding mentoring relationships. In B. R. Ragins \& K. E. Kram (Eds.), The handbook of mentoring at work: theory, research, and practice (pp. 223-248). Thousand Oaks, CA: Sage.

Bogdan, R., \& Biklen, S. K. (1982). Qualitative research for education: An introduction to theory and methods. Boston, MA: Allyn and Bacon.

Bogdan, R., \& Biklen, S. K. (1992). Qualitative research for education. Boston, MA: Allyn \& Bacon.

Bogdan, R., \& Biklen, S. K. (2006). Qualitative research for education: An introduction to theories and methods. Boston, MA: Allyn \& Bacon.

Bond, M., Gray, J., Baxley, S., Cason, C., \& Denke, L. (2008). Voices of Hispanic students in baccalaureate nursing programs: Are we listening? Nursing Education Perspectives, 29(3), 136-42.

Boswell, T. D. \& Jones, T. (2007). Caribbean Hispanics: Puerto Ricans, Cubans, and Dominicans. In I. M. Miyares and C. A. Airriess (Eds.), Contemporary ethnic geographies in America (pp. 123-150). Lanham, MA: Rowman and Littlefield Publishers, Inc.

Bowman, M., Frank, E., \& Allen, D. (2002). Women in medicine: Career and life management. New York, NY: Springer-Verlag New York.

Brathwaithe-Gardner, A. (2006). Transcending historical relationships: A qualitative study of the experiences of White men who mentor Black men. (Doctoral dissertation). Retrieved from ProQuest Dissertations and Theses database. (UMI No. 3254489)

Branch, C. W. (1994). Ethnic identity as a variable in the learning equation. In E. R. Hollins, J. E. King, \& W. C. Hayman (Eds.), Teaching diverse populations: Formulating a knowledge base (pp. 207-224). Albany, NY: State University of New York Press.

Branley, B. R. (2008). Visual rhetoric in transcultural communication in sixteenth century New Spain: The engravings of Fray Diego Valades (Doctoral dissertation). Retrieved from ProQuest Dissertations and Theses database. (UMI No. 3346749)

Bridging Refugee Youth and Children's Services (2005). Determining Child Abuse and Neglect Across Cultures. Available from website

http://www.brycs.org/documents/upload/brycs_spotapr2005.pdf 
Brinson, J., \& Kottler, J. (1993). Cross-cultural mentoring in counselor education: A strategy for retaining minority faculty. Counselor Education and Supervision, $32(4), 241-254$.

Brislin, R. (1999). Communicating information about culture and personality in formal cross-cultural training programs. In Y. Lee, C. R. McCauley and J. G. Draguns (Eds.), Personality and person perception across cultures (pp. 255-178), Hillsdale, NJ: Lawrence Erlbaum Associates.

Brohman, J. (1995). Universalism, Eurocentrism, and ideological bias in development studies: From modernization to neoliberalism. Third World Quarterly, 16(1), 121140 .

Brown, N. S. (1995). The role of mentoring in the adult development of professional Asian-American women: A cross-ethnic cross-gender study (Doctoral dissertation). Retrieved from ProQuest Dissertations and Theses database. (UMI No. 9627715)

Brown, S. V. (1988). Increasing minority faculty: An elusive goal. A research report of the Minority Graduate Education Project. Princeton, NJ: Graduate Record Examinations Board.

Brubacher, J. S. \& Rudy, W. (1997). Higher education in transition: A history of American colleges and universities (4th ed.). New Brunswick, NJ: Transaction.

Brubaker, R. (2004). Ethnicity without groups. London, England: Cambridge University Press.

Bullough, R. V., Jr. (2005). Teacher vulnerability and teachability: A case study of a mentor and two interns. Teacher Education Quarterly, 32(2), 23-40

Butterfield, S. P. (2004). Being racialized ethnics: Second generation West Indian immigrants in New York City. In J. Krase \& R. Hutchinson (Eds.), Race and ethnicity in New York City (pp. 107-136). San Diego, CA: Elsevier.

Caffarella, R. S. (1992). Psychosocial development of women: Linkages to teaching and leadership in adult education. Teaching and Leadership in Adult Education Information Series, 350. Office of Educational Research and Improvement, Washington, DC.

Camarota, S. (2007). Immigrants in the United States, 2007: A profile of America's foreign-born population. Backgrounders and reports. Retrieved April 4, 2010, from website http://www.cis.org/immigrants_profile_2007

Caribbean Community (CARICOM) Secretariat, (2011). Caribbean Examinations 
Council (CXC). Retrieved May 5, 2012 from website

http://www.caricom.org/jsp/community/cxc.jsp?menu=community

Carter, D. A. (2000). African American students' perceptions of cross-cultural mentoring relationships (Doctoral dissertation). Retrieved from ProQuest Dissertations and Theses database. (UMI No. 9965962).

Cassara, B. B. (1990). Adult education in a multicultural society. London, New York: Routledge.

Cavazos, A. G., \& Cavazos, J. (2010). Understanding the experiences of Latina/O Students: A qualitative study for change. American Secondary Education, 38(2), 95-109.

Center for Immigration Studies. (1995). Three decades of mass immigration the legacy of the 1965 Immigration Act. Available from website http://www.cis.org/articles/1995/back395.html

Cervantes-Rodríguez, M., Grosfoguel R., \& Mielants, E. (2009). Caribbean migration to Western Europe and the United States: Essays on incorporation, identity, and citizenship. Philadelphia, PA: Temple University Press.

Cervero, R. M. (2000). Trends and issues in continuing professional education. New Directions for Adult and Continuing Education, 86, 3-12.

Chalmers, F. G. (2002). Celebrating pluralism 6 years later: visual transculture/s, education, and critical multiculturalism. Studies in Art Education (43)4, 293-306. doi: $10.2307 / 1320979$

Chan, A. (2008). Best practices of outstanding mentors in psychology: An ecological, relational, and multicultural model (Doctoral dissertation). Retrieved from ProQuest Dissertations and Theses database. (UMI No. 3313810)

Cheng, L. L. (1990). Recognizing diversity: A need for a paradigm shift. American Behavioral Scientist, 34(2), 263- 278. doi: 10.1177/0002764290034002014

Chickering, A. (1969). Education and identity. San Francisco, CA: Jossey-Bass.

Clark, M. (1993). Transformational learning. New Directions for Adult and Continuing Education, 57, 47-56. San Francisco, CA: Jossey-Bass.

Cleminson, A., \& Bradford, S. (1996). Professional education. Journal of Vocational Education and Training, 48(3), 249-259. 
Clutterbuck, D. (2002). What every diversity mentor should know about stereotyping. In D. Clutterbuck and B. R. Ragins (Eds.), Mentoring and Diversity: An international perspective, pp. 114-120. Oxford: Butterworth-Heinemann.

Cohen, N. H. (2003). The journey of the principles of adult mentoring inventory. Adult Learning, 14(1), 4-12.

Cole, D. (2001). Balancing two worlds: Issues facing Black faculty in higher education. Black Issues in Higher Education, 17(24), 96.

Colley, H. (2000). Exploring myths of mentor: A rough guide to the history of mentoring from a Marxist feminist perspective. Paper presented at the British Education Research Association Annual Conference, Cardiff University, Cardiff, UK.

Congress of the United States. (2006). Immigration policy in the United States. http://www.cbo.gov/ftpdocs/70xx/doc7051/02-28-Immigration.pdf

Congressional Research Service (2011). The U.S. foreign-born population: Trends and selected characteristics. CRS Report for Congress 7-5700, R41592. Retrieved from www.crs.gov

Cooper, D. L., \& Miller, T. K. (1998). Influence and impact: professional development in student affairs. New Directions for Student Services, 84, 55-69.

Corbin, J., \& Strauss, A. (2008). Basics of qualitative research (3rd Ed.). Los Angeles, CA: Sage.

Cornell, S., \& Hartmann, D. (1998). Ethnicity and race: Making identities in a changing world. Thousand Oaks, CA: Pine Forge Press.

Cox, T., Jr. (1993). The multicultural organization. Academy of Management Executive, $5(2), 34-47$.

Cranton, P. (2002). Teaching for transformation in contemporary viewpoints on teaching adults effectively. New Directions for Adult and Continuing Education, 93, 5-91.

Cranton, P., \& King, K. P. (2003). Transformative learning as a professional development goal. New Directions for Adult and Continuing Education, 98, 3137.

Craton, M. (1997). Empire, enslavement and freedom in the Caribbean. Princeton: Markus Wiener Publishers.

Creswell, J. W. (1994). Research design: Qualitative and quantitative approaches. Thousand Oaks, CA: Sage. 
Creswell, J. W. (1998). Qualitative inquiry and research design: Choosing among five traditions. Thousand Oaks, CA: Sage.

Creswell, J. W. (2003). Research design: Qualitative, quantitative, and mixed methods approaches $\left(2^{\text {nd }}\right.$ ed.). Thousand Oaks, CA: Sage.

Creswell, J. W. (2005). Educational research: planning, conducting, and evaluating quantitative and qualitative research. New Jersey: Pearson Prentice Hall.

Creswell, J. W. (2007). Qualitative inquiry and research design: Choosing among five traditions (2nd ed.). Thousand Oaks: Sage.

Crocitto, M. M., Sullivan, S. E., \& Carraher, S. M. (2005). Global mentoring as a means of career development and knowledge creation: A learning-based framework and agenda for future research. Career Development International, 10(6), 522.

Cross T. L., Bazron, B. J., Dennis, K. W., \& Isaacs, M. R. (1989). Towards a culturally competent system of care: A monograph on effective services for minority children who are severely emotionally disturbed. Washington, D.C.: Georgetown University Child Development Center, CASSP Technical Assistance Center.

Cross. S. A., and Lincoln, Y. S. (2005). Cross-race faculty mentoring. Change, 37(2), 4450 .

Crowley, D. J. (1990). The remigration of Trinidad East Indians. In R. Sanjek (Ed.), Caribbean Asians: Chinese, Indian, and Japanese experiences in Trinidad and the Dominican Republic (pp. 82-95). New York, NY: Asian/American Center at Queens College, CUNY.

Crutcher, B. N. (2007). Mentoring across cultures. The Education Digest, 73(4), 21-5 D.

Daloz, L. A. (1986). Effective teaching and mentoring: Realizing the transformational power of adult learning experiences. San Francisco: CA: Jossey-Bass, Inc.

Daloz, L. A., (1999). Mentor: Guiding the journey of adult learners. CA: Jossey-Bass, Inc.

Daloz, L. A., Keen, P., Keen, C. H., Parks, J. P., \& Daloz. S. (1996). Lives of commitment. Change 28(3), 11-15.

Davidson, M.N. \& Foster-Johnson, L. (2001). Mentoring in the preparation of graduate researchers of color. Review of Educational Research, 71(4), 549-74. doi:10.3102/00346543071004549 
Deardorff, D. K. (2004). In search of intercultural competence. International Educator, 13(2), 13-16.

DeLapp, T., Hautman, M. A., \& Anderson, M. S. (2008). Recruitment and retention of Alaska natives into Nursing (RRANN). Journal of Nursing Education, 47(7), Jl.

Delgado, R. \& Stefancic, J. (Eds.). (1997). Critical White studies: Looking behind the mirror. Philadelphia, PA: Temple University Press.

Delpit, L. (1995). Other people's children: Cultural conflict in the classroom. New York: The New Press.

Dewey, J. (1916). Democracy and education: An introduction to the philosophy of education. New York: The Macmillan company.

Dickey, C. A. (1996). The role of quality mentoring in the recruitment and retention of women students of color at the University of Minnesota (Doctoral dissertation). Retrieved from ProQuest Dissertations and Theses database. (UMI No. 9619266)

Dilani, A. (2009). Psychosocial supportive design: A salutogenic approach to the design of the hospital environment. In R. Del Nord (Ed.), Proceedings of the 28th International public health seminar. The culture for the future of healthcare architecture (pp. 67-80). Florence, Italy: TESIS Center.

DiMaggio, P. (1988). Interest and agency in institutional theory. In L. Zucker (Ed.). Institutional patterns and organizations (pp. 3-21). New York, NY: Ballinger.

DiMaggio, P. \& Powell, W. (1991). Introduction. In W. Powell \& P. DiMaggio (Eds.), The new institutionalism in organizational analysis (pp. 1-38). Chicago, IL: University of Chicago Press.

Dirkx, J. M. \& Deems, T. A. (1994). The influence of self-other relationships in constructivist approaches to adult learning. In L. Martin (Ed.). Proceedings of the Thirteenth Annual Midwest Research to Practice Conference in Adult, Continuing, and Community Education (pp. 48-53). University of WisconsinMilwaukee.

Dolan, T. (2007). Is Cross-Race Mentoring a Negative? The Education Digest, 73(4), 2630 .

Dresser, R. (1998). Time for new rules on human subjects research? Hastings Center Report, 28(6), 23-24. 
Dyal, J.A. (1984). Cross-cultural research. In H. M Lefcourt (Ed.), Research with the locus of control construct: Extensions and limitations, 3, 209-306. New York: Academic Press.

Elmer, M. I. (1986). Intercultural effectiveness: Development of an intercultural competency scale (Doctoral dissertation). Retrieved from Proquest Dissertations and Theses database. (UMI No. 8625019).

Erikson, E. H. (1963). Childhood and society. New York: Norton.

Erikson, E. H. (1968). Identity: Youth and crisis. New York: W. W. Norton

Erikson, E. H. (1980). Identity and life cycle. New York: Norton.

Fassinger, R. E. (1997, August). Dangerous liaisons: Reflections on feminist mentoring. Invited "Woman of the Year" Award address presented at the annual meeting of the American Psychological Association, Chicago, IL.

Fearon, J. D. (1999). What is identity (as we now use the word)? Retrieved from http://www.stanford.edu/ jfearon/papers/iden1v2.pdf

Feldman-Abe, J. K. (2002). We're all foreigners here: What adult mentors learn from youth in urban schools (Doctoral dissertation). Retrieved from ProQuest Dissertations and Theses database. (UMI No. 3045711)

Fennimore, B. S. (1994). Addressing Prejudiced Statements: A Four-Step Method That Works! Childhood Education, 70(4), 202-204.

Floyd, T. S. (1973). The Columbus dynasty in the Caribbean, 1492-1526. Albuquerque: University of New Mexico Press.

Fogarty, T. J, Dirsmith, M. W. (2001). Organizational socialization as instrument and symbol: An extended institutional theory perspective. Human Resource Development Quarterly, 12(3), 247-266.

Foner, N. (1999). The immigrant family: Cultural legacies and cultural changes. In C. Hirschman, P. Kasinitz, \& J. DeWind (Eds.), Handbook of international migration: The American experience (pp. 237-256). New York, NY: Russell Sage Foundation.

Foner, N. (2001). New immigrants in New York. New York: Columbia University Press.

Frable, D. E. S. (1997). Gender, racial, ethnic, sexual, and class identities. Annual Review of Psychology, 48(1), 139-162. doi:10.1146/annurev.psych.48.1.139 
Freire, P. (1973). Education for critical consciousness. New York, NY: Continuum/Seabury Press.

Freire, P. (1997). Mentoring the mentor: A critical dialogue with Paulo Freire. New York, NY: Peter Lang Publishing.

Freire, P. (1998). Teachers as cultural workers: Letters to those who dare teach (translated by Donald Macedo, Dake Koike and Alexandre Oliviera. Colorado: Westview Press.

Freire, P. (2006). Pedagogy of the oppressed. New York, NY: The Continuum International Publishing Group Inc.

Freire, P., \& Macedo, D. (1987). Literacy: Reading the word and the world. London: Routledge and Kegan Paul Ltd.

Freeman, K. (1999). No services needed? The case for mentoring high-achieving African American students. Peabody Journal of Education, 74(2), 15-26. doi: 10.1207/s15327930pje7402_3.

Galbraith, M. W. \& Cohen, N. H. (1995). Issues and challenges confronting mentoring. New Directions for Adult and Continuing Education, 66, 89-93.

Galbraith, M. W., \& Zelenak, B. S. (1991). Adult learning methods and techniques. In M.W. Galbraith (Ed.), Facilitating adult learning (pp. 103-133). Malabar, FL: Krieger.

Gay, G. (2000). Culturally responsive teaching: Theory, research, and practice. Multicultural Education Series, 8. New York: Teachers College Press.

Gentner, D. \& Stevens, A. (1983). Mental models. Hillsdale, NJ: Erlbaum.

Ghosh, M. (2008). Effects of acculturation on young adult South AsianIndians. (Doctoral dissertation). Retrieved from ProQuest Dissertations and Theses database. (UMI No. 3286265)

Giles, G. W. (1998). The relationship of intercultural competence to ministry effectiveness in the Christian college context (Doctoral dissertation). Retrieved from ProQuest Dissertations and Theses database. (UMI No. 9826877)

Gilkes, A. D. (2002). Ethnic identification and success achievement: The West Indian experience. Paper presented at the Symposium of Caribbean Immigration across Generations Considering Gender and Identities in Transition. The $73^{\text {rd }}$ Annual Convention of the Eastern Psychological Association, Boston, MA. 
Giroux, H. A. (1992). Border crossings: Cultural workers and the politics of education. London: Routledge.

Glasgow, P. P. (2006). The impact of culture on the mentoring process of students of African and East Indian heritage in postsecondary institutions in Trinidad (Doctoral dissertation). Retrieved from ProQuest Dissertations and Theses database. (UMI No. 3211938)

Glesne, C. (1999). Becoming qualitative researchers: An introduction ( ${ }^{\text {nd }}$ ed.). New York: Longman.

Gloria, A. M., \& Ho. T. A. (2003). Environmental, social, and psychological experiences of Asian American students: Examining issues of academic persistence. Journal of Counseling and Development, 81(1), 93-105.

Golde, C. M. (2005). The role of the department and discipline in doctoral student attrition: Lessons from four departments. The Journal of Higher Education, 76(6), $669-700$.

Golian, L. M., \& Galbraith, M. W. (1996)- Effective mentoring programs for professional library development. In D. Williams \&E. Garten (Eds.) Advances in library administration and organization (pp. 95-124). Greenwich, CT: JA1 Press.

Goodenough, W. (1970). Description and comparison in cultural anthropology. Cambridge: Cambridge University Press.

Gopaul-McNicol, S. A. (1993). Working with West Indian Families. New York: Guilford Press.

Gosine, M. (1999). Sojourner to Settler: The Indian migrant in the Caribbean and the Americas. New York: Windsor Press.

Graf, S. C., Mullis. R. L., \& Mullis, A. K. (2008). Identity formation of United States American and Asian Indian adolescents. Adolescence, 43, 57-69.

Gravlee, C. C. (2005). Ethnic classification in southeastern Puerto Rico: The cultural model of "color". Social Forces, 83(3), 949-971.

Greene, K. A. I. (2002). In the minority in graduate school. The Chronicle of Higher Education, 49(11), B14.

Greenleaf, R. K. (1977). Servant leadership: journey into the nature of legitimate power and greatness. In D. M. Frick and L. C. Spears (Eds.), On becoming a servant leader (pp. 343-372). San Francisco: Jossey-Bass. 
Gudykunst, W. B. \& Kim, Y. Y. (1984). Communicating with strangers: An approach to intercultural communication. Reading, MA: Addison-Wesley.

Guest, G., Bunce, A., \& Johnson, L. (2006). How many interviews are enough? And experiment with data saturation and variability. Field Methods, 18(1), 59-82.

Gupta, R. M. (2005). Walking a theological tightrope: Controversies of sampradaya in eighteenth century Caitanya Vaisnavism. ISKCON Communications Journal, 11. Available online http://content.iskcon.org/icj/11/04-gupta.html

Hansman, C. (2003). Reluctant mentors and resistant protégés: Welcome to the "real" world of mentoring. Adult Learning, 14(1), 14-16.

Hanson, G. (1990). Sumner Welles and the American system: The United States in the Caribbean, 1920-1940 (Doctoral dissertation). Retrieved from ProQuest Dissertations and Theses database. (UMI No. 9123586).

Hargreaves, A., \& Fullan, M. (2000). Mentoring in the new millennium. Theory into Practice, 39(1), 50-56.

Harre, R. \& Lamb, R. (1986). The dictionary of personality and social psychology. MA: The MIT Press.

Harris, M. (1964). Patterns of race in the Americas. New York, NY: W. W. Norton \& Company, Inc.

Harris, M. (Ed.). (1980). The epistemology of cultural materialism. Cultural Materialism: The Struggle for a Science of Culture (pp. 29-45). New York: Random House.

Harris, M. (2001). Cultural materialism: the struggle for a science of culture. Walnut Creek: Rowman and Littlefield Publishers Inc.

Haynes, D. M. (2002). History: The Missing Link in Making Young Scientists and Scholars. Black Issues in Higher Education, 19(21), 122.

Herzig, A. H. (2002). Where have all the students gone? Participation of doctoral students in authentic mathematical activity as a necessary condition for persistence toward the Ph.D.. Educational Studies in Mathematics, 50(2), 177212.

Hektner, J. M., \& De Jong, J.A. (2007). Developing a prevention plan for an American Indian boarding school: Strengthening positive peer culture. Journal of American Indian Education, 46(1), 41-59.

Henke, H. (2001). The West Indian Americans. Westport, CT: Greenwood Press. 
Henke, H., \& Reno, F. (2003). Modern political culture in the Caribbean. Kingston: University of West Indies Press.

Henderson, S. J., \& Chan, A. (2005). Career happiness among Asian Americans: The interplay between individualism and interdependence. Multicultural Career Counseling. Journal of Multicultural Counseling and Development, 33(3), 13092.

Hersey, P., \& Blanchard, K. H. (1995). Situational Leadership. In J. T. Wren (Ed.), The Leader's Companion (pp. 207-211). New York: The Free Press.

Herzig, A. H. (2002). Where have all the students gone? Participation of doctoral students in authentic mathematical activity as a necessary condition for persistence toward the Ph.D.. Educational Studies in Mathematics, 50(2), 177212.

Hofstede, G. (1997). Cultures and organization: Software of the mind. London: McGrawHill.

Hofstede, G. (2012). National culture. Available from website http://geerthofstede.com/united-states.html

Hofstede, G., Hofstede, G, J., \& M. Minkov (2010). Cultures and Organizations: Software for the Mind (Kindle Location 395). Kindle Edition. Retrieved from http://www.amazon.com/Cultures-Organizations-Software-Mindebook/dp/B001C31FRG/ref=tmm_kin_title_0?ie=UTF8\&m=AG56TWVU5XWC 2

Holland, D., \& Lachicotte, W. Jr. (2007). Vygotsky, Mead, and the new sociocultural studies of identity. In H. Daniels, M. Cole \& J. V. Wertsch (Eds.), The Cambridge companion to Vygotsky (pp. 101-135). New York: Cambridge University.

Holland, D., \& Quinn, N. (1987). Cultural models in language and thought. In Ronald W. Casson, (ed.), American Anthropologist, 89(4), 1007. doi:10.1525/aa.1987.89.4.02a00810

Holmes, S. L., Land, L. D., \& Hinton-Hudson, V. D. (2007). Race still matters: Considerations for mentoring Black women in academe. Negro Educational Review, 58(1/2), 105.

Holst, J. D. (2006). Paulo Freire in Chile, 1964-1969: Pedagogy of the oppressed in its sociopolitical economic context. Harvard Educational Review, 76(2), 243. 
Holt, J. L., Mahowald, B. G., \& DeVore, C. J. (2002). What helps students of color succeed? Resiliency factors for students enrolled in multicultural educators programs. Retrieved from Cambridge Scientific Abstracts database. (ED473903).

hooks, b. (1994). Teaching to transgress. New York: Routledge.

Horwedel. D. M. (2005). SACNAS mentors the next generation of minority scientists. Diverse Issues in Higher Education, 22(19), 8.

Hraba, J., \& Hoiberg, E. (1983). Ideational origins of modern theories of ethnicity: Individual freedom vs. organizational growth. Sociological Quarterly, 24(3), 381391.

Hughes, R. L. (2002). Whistling Dixie, raising the confederate flag and other welcoming mats: African-American students talk about change at big Texas state university. Retrieved from Cambridge Scientific Abstracts database. (ED462041).

Hum, T. (2004). Immigrant global neighborhoods in New York City. In J. Krase and R. Hutchinson (Eds.), Race and ethnicity in New York City, (pp. 25-56). San Diego: Elsevier.

Humes, K. (2009, August, 31). Letter to Priya Murthy. United States Department of Commerce, Economics and Statistics Division, Population Division, Washington: DC.

Hurte, V. J. (2002). Mentoring: The forgotten retention tool. Black Issues in Higher Education, 19(18), 49.

Hycner, R. H. (1999). Some guidelines for the phenomenological analysis of interview data. In A. Bryman \& R. .G. Burgess (Eds.), Qualitative research, 3, (143-164). London: Sage.

Inzerille, G., \& Rosen, M. (1983). Culture and organizational control. Business Research, 17(1), 281-292.

Irvin, S. (2007). The role of culturally endorsed implicit leadership theories in intercultural mentoring relationships (Doctoral dissertation). Retrieved from ProQuest Dissertations and Theses database. (UMI No. 3264261)

Ishiyama, J. (2007) Expectations and perceptions of undergraduate research mentoring: Comparing first generation, low income White/Caucasian and African American students. College Student Journal, 41(3), 540-9. 
Jackson, J. F. L. (2001). Retention of African American administrators at predominantly White institutions: Using professional growth factors to inform the discussion. Retrieved from Cambridge Scientific Abstracts database. (ED457818).

Jackson, S., \& Harris, S. (2007). African American female college and university presidents: Experiences and perceptions of barriers to the presidency. Journal of Women in Educational Leadership, 5(2), 119-37.

Jacobi, M. (1991). Mentoring and undergraduate academic success: A literature review. Review of Educational Research, 61(4), 505-532. doi:10.3102/00346543061004505

Jeria, J. (2002). The quest for visibility in adult education: The Hispanic experience. New Directions for Adult and Continuing Education, 82, 49-65. doi:10.1002/ace.8204

John-Steiner, V., \& Mahn, H. (1996). Sociocultural approaches to learning and development: A Vygotskian framework. Educational Psychologist, 31, 191-206.

John-Steiner, V., Panofsky, C. P., \& Smith, L. W. (1994). Sociocultural approaches to language and literacy: An interactionist perspective. Cambridge: Cambridge University Press

Johnson, V. M. (1992). The migration experience: Social and economic adjustment of British West Indian immigrants in Boston, 1915-1950 (Doctoral dissertation). Retrieved from ProQuest Dissertations and Theses database. (UMI No. 9314170).

Johnson-Bailey, J., \& Cervero, R. M. (1997). Negotiating power dynamics in workshops. New Directions for Adult and Continuing Education, 76, 41-50.

Johnson-Bailey, J., \& Cervero, R. (2000). Race and Adult Education: A Critical Review of the North American Literature. In T. Sork, V. Lee-Chapman, and R. St. Clair (Eds.), Proceedings of the 41st Annual Adult Education Research Conference. Vancouver: University of British Columbia.

Johnson-Bailey, J., \& Cervero, R. M. (2002). Cross-cultural mentoring and learning in adulthood. In M. V. Alfred (Ed.), Learning and sociocultural context: Implications for adults, community, and workplace education. New Directions for Adult and Continuing Education, 96, 15-26. San Francisco, CA: Jossey Bass.

Johnson-Bailey, J., \& Cervero, R. M. (2002). Cross-cultural mentoring as a context for learning. New Directions for Teaching and Learning, 96, 15-26. doi:10.1002/ace.7

Johnson-Bailey, J., \& Cervero, R. M. (2008). Different worlds and divergent paths: 
Academic careers defined by race and gender. Harvard Educational Review, 78(2), 311-332.

Jordan, J. V. (1997). Women's growth in diversity: More writings from the Stone Center. New York, NY: Guilford Press.

Kalbfleisch, P. J., \& Davies, A. B. (1993). An interpersonal model for participation in mentoring relationships. Western Journal of Communication, 57, 399-415.

Kalbfleisch, P. J., \& Keyton, J. (1995). Power and equality in mentoring relationships. In P. J. Kalbfleisch \& M. J. Cody (Eds.), Gender, power and communication in human relationships (pp. 189-212). Hillsdale, NJ: Lawrence Erlbaum.

Katz, L. G. (1995) Talks with teachers: A collection. Norwood, NJ: Ablex Pub. Corporation.

Kasinitz, P. (1992). Black immigrants and the politics of race. Ithaca: Cornell University Press.

Katz, L. G. \& Rathz, J. D. (1986). Dispositional goals for teacher education: Problems of identification and assessment. Paper presented at the World Assembly of the International Council on Education for Teaching, Kingston, Jamaica.

Katz, R. (1975). Organizational stress and early socialization experiences. In. T. Beehr \& R. Bhaget (Eds.), Human stress and cognition in organizations (pp. 117-140). New York, NY: Wiley.

Katzenstein, P. (1996). The culture of national security: Norms and identity in world politics. New York: Columbia University Press.

Kaye, B., \& Jacobson, B. (1996). Reframing mentoring. Training and Development, $50(8), 44-47$.

Kegan, R. (1982). The evolving self: Problem and process in human development. Cambridge, MA: Harvard University Press.

Keller, A. S. (1990). Cultural policy and educational change in the 1990s. Education and Urban Society, 22, 413-424. DOI: 10.1177/0013124590022004008

Keefe, S., \& Padilla, A. (1987). Chicano identity. Albuquerque, NM: University of New Mexico Press.

Kerka, S. (1998). New perspectives on mentoring. Retrieved from ERIC Clearinghouse on Adult Career and Vocational Education database. (ED418249). 
Kim, H. H. (2007). A study of the relationship between academic mentoring and the development of intercultural competence in a multicultural higher educational context (Doctoral dissertation). Retrieved from ProQuest Dissertations and Theses database. (UMI No. 3302484)

Kim, S. S., \& Gelfand, M. J. (2003). The influence of ethnic identity on perceptions of organizational recruitment. Journal of Vocational Behavior 63, 396-416. doi:10.1016/S0001-8791(02)00043-X

Kochan, F. K., \& Pascarelli, J. T. (2003). Global perspectives on mentoring: Transforming contexts, communities, and cultures. Greenwich: CT: Information Age Publishing.

Kram, K. E. (1985). Mentoring at work. Glenview, IL: Scott, Foresman.

Kram, K. E. (1988). Mentoring at work: Developmental relationships in organizational life. Lanham, England: University Press of America.

Kram, K. E., \& Ragins, B. R. (2007). The landscape of mentoring in the $21^{\text {st }}$ century. In B. R. Ragins and K. E. Kram (Eds.), The Handbook of Mentoring at work: Theory, research, and practice (pp. 659-692). CA: Sage Publications Inc.

Krase, J. \& Hutchinson, R. (2004). Race and ethnicity in New York City. San Diego: Elsevier Inc.

Krefting, L. (1999). Rigor in qualitative research: The assessment of trustworthiness. In A. K. Milinki (Ed.), Cases in qualitiative research: research reports for discussion and evaluation (pp. 173-181). Los Angeles: Pyrczak Publishing.

Kunselman, J., Hensley, C., \& Tewksbury, R. (2003). Mentoring in academe: Models for facilitating academic development. Journal of Criminal Justice Education, 14(1), 17

Kvale, S. (1996). Interviews. An introduction to qualitative research interviewing. CA: Sage.

Ladson-Billings, G. (1992). Culturally relevant teaching: The key to making multicultural education work. In C.Grant (Ed.), Research and multicultural education (pp.106121). Washington, DC: Falmer Press.

Ladson-Billings, G. (1992). Reading between the lines and beyond the pages: A culturally relevant approach to literacy teaching. Theory Into Practice, 31(4), 312-320. doi:10.1080/00405849209543558 
Ladson-Billings, G. (1994). Who will teach our children: Preparing teachers to successfully teach African American Students. In E. R. Hollins, J. E. King, \& W. C. Hayman (Eds.), Teaching diverse populations: Formulating a knowledge base (pp. 129-144). Albany: State University of New York Press.

Ladson-Billings, G. (1994). The dreamkeepers: Successful teachers of African American children. San Francisco: Jossey-Bass.

Ladson-Billings, G. (2006). It's not the culture of poverty, it's the poverty of culture: The problem with teacher education. Anthropology Education Quarterly, 7(2), 104. doi:10.1525/aeq.2006.37.2.104

Langer, E. (1993). A mindful education. Educational Psychology, 28(1), 43-50.

Lave, J., and Wenger, E. (1991) Situated learning: Legitimate peripheral participation. New York: Cambridge University Press.

Lee, W. (1999). Striving toward effective retention: the effect of race on mentoring African American students. Peabody Journal of Education, 74(2), 27-43. doi: 10.1207/s15327930pje7402_4

Lee, Y., McCauley, C. R., \& Draguns, J. G. (1999). Personality and person perception across cultures. New Jersey: Lawrence Erlbaum Associates, Publishers.

Levine, L. W. (1977). Black culture and Black consciousness: African American folk thought from slavery to freedom. New York: Oxford University Press.

Levesque, L. L., O'Neill, R. M., Nelson, T., \& Dumas. C. (2005). Sex differences in the perceived importance of mentoring functions. Career Development International, 10(6/7), 429-443.

Lee, M. \& Sheared, V. (2002). Socialization and immigrant students' learning in adult education programs. New Directions For Adult And Continuing Education, 96, 27-36. Wiley Periodicals Inc.

Levinson, B. A., Foley, D. E. \& Holland, D. C. (1996). The cultural production of the educated person: Critical ethnographies of schooling and local practice. Albany: State University of New York Press

Levinson, D. J., Darrow, C. N., Klein, E. B., Levinson, M. H. \& McKee, B. (1978). The seasons of a man's life. New York: Ballantine.

Lew, J. W., Chang, J. C., \& Wang, W. (2005). UCLA Community college review: The overlooked minority: Asian Pacific American students at community colleges. Community College Review 33(2), 64. 
Liang, B., Tracy, A., Kauh, T., Taylor, C., \& Williams, L. M. (2006). Mentoring Asian and Euro-American college women. Journal of Multicultural Counseling and Development, 34(3), 143-155.

Lincoln, Y. S., \& Guba, E. G. (1985). Naturalistic Inquiry. Newbury Park, CA: Sage Publications.

Linton, R. (1936). The study of man: An introduction. New York: Appleton-CenturyCrofts, Inc.

Logan, J. R. (2003). How race counts for Hispanic Americans. Lewis Mumford Center. Available from website http://mumford.albany.edu/census/BlackLatinoReport/BlackLatinoReport.pdf

Lords, E. (2001). Recruiting talent [Minority Research Scholars Program]. Black Issues in Higher Education, 18(8), 26-8.

Loveless, L. C., McCue, C. P., Surette, R. B. \& Norris-Tirrell, D. (1996). Immigration and its impact on American cities. CT: Praeger Publishers.

Lowe, S.M. (2005). Integrating collectivist values into career counseling with Asian Americans: A test of cultural responsiveness. Journal of Multicultural Counseling and Development, 33(3), p 134- 145.

Lowenthal, D. (1972). West Indian societies. London, New York: Oxford University Press.

Luna, G. \& Cullen, D. (1998). Do graduate students need mentoring? College Student Journal, 32(3), 322-30.

Ranmath, V. (2010). Why Hindus bow at the feet of respected elders. Available from website http://kevinji.20m.com/rich_text_1.html

Mahn, H., \& John-Steiner, V. (1998). Introduction. Mind, Culture and Activity, 5(2), 8188.

Marquardt, M. J., \& Loan, P. (2006). The manager as mentor. Westport, CT: Praeger Publishers.

Marshall, C., \& Rossman, G. B. (2006). Designing qualitative research (4th ed.). Thousand Oaks, CA: Sage.

Marquardt, M. J. \& Loan, P. (2006). The manager as mentor. Connecticut: Praeger Publishers. 
Mayo, J. R., Murguia, E., \& Padilla, R. V. (1995). Social integration and academic performance among minority university students. Journal of College Student Development, 36, 542-552.

McAllister, G. \& Irvine, J. J. (2000). Cross cultural competency and multicultural teacher education. Review of Educational Research, 70(1), 3-24.

McEwen, M. K. (2003). New perspectives on identity development. In S. R. Komives \& D. B. Woodard, Jr. (Eds.), Student services: A handbook for the profession (pp. 203-233). San Francisco: Jossey Bass.

Mcqueary-Smith, B. (2001). Turning stumbling blocks into stepping stones. Black Issues In Higher Education, 18(4), 32.

Mckenzie, V. M. (1984). Ethnocultural factors in counseling with male West Indian American adolescents (intercultural, communication training) (Doctoral dissertation). Retrieved from ProQuest Dissertations and Theses database. (UMI No. 8500762).

Mehta, B. J. (2004). Diasporic (dis)locations: Indo-Caribbean women writers negotiate the kala pani. Kingston, Jamaica: University of the West Indies Press.

Melendez, E., \& Suarez, C. (2001). Opening doors for Hispanics: An assessment of the HACU-ETA demonstration project. Retrieved from New School University, Robert J. Milano Graduate School of Management and Urban Policy website: http://www.newschool.edu/milano.

Menchaca, V. D., Estrada, V. L., Cavazos, C., \& Ramirez, D. (2000). Changing the face of educational leadership: A unique method of mentoring Hispanic doctoral students. Retrieved from Cambridge Scientific Abstracts database. (ED454004).

Merisotis, J. P. (2005). Vital speeches of the day. Black Issues in Higher Education, $71(17), 538$.

Merriam, S. B. (1983). Mentors and protégés: A critical review of the literature. Adult Education Quarterly, 33(3), 161-173.

Merriam, S. B., \& Associates. (2007). Non-Western perspectives on learning and knowing. Malabar, FL: Krieger.

Merriam, S. B., \& Caffarella, R. S. (1999). Learning in adulthood: A comprehensive guide. San-Francisco: Jossey Bass.

Merriam, S. B., Thomas, T. K. \& Zeph, C. P. (1987). Mentoring in higher education: What we know now. The Review of Higher Education, 11(2), 119-210. 
Mezirow, J. (1991). Transformative dimensions of adult learning. San Francisco: JosseyBass.

Mezirow, J. (1997). Transformative learning: Theory to practice. In P. Cranton (ed.), Transformative learning in action: Insights from practice. New Directions for Adult and Continuing Education, 74, 5-12. San Francisco: Jossey-Bass.

Miller, D. C., \& Salkind, N. J. (2002). Handook of research design and social measurement (6th ed.). Thousand Oaks, CA: Sage.

Miles, M. B., \& Huberman, A. M. (1994). Qualitative data analysis: An expanded sourcebook $\left(2^{\text {nd }}\right.$ ed.). Thousand Oaks, CA: Sage.

Ministry of External Affairs. (2000). Report of the High Level Committee on the Indian Diaspora. Retrieved April 4, 2010 from website http://indiandiaspora.nic.in/contents.htm

Minnich, E. K. (2005). Transforming knowledge. Philadelphia: Temple University Press.

Minow, M. (1990). Making all the difference: Inclusion, exclusion, and American law. Ithaca, NY: Cornell University Press.

Mitchell, N. (2005). Academic achievement among Caribbean immigrant adolescents: The Impact of generational status on academic self-concept. Professional School Counseling, 8(3), 209-18.

Model, S. (2008). West Indian Immigrants: A Black success story? New York: The Russell Sage Foundation.

Morse, J. M. (1994). Designing funded qualitative research. In N. K. Denzin \& Y. S. Lincoln (Eds.), Handbook of qualitative research (pp. 220-235). Thousand Oaks, CA: Sage.

Morse, J. M. (1995). The significance of saturation. Qualitative Health Research, 5, 147149.

Moustakas, C. (1994). Phenomenological research methods. Thousand Oaks, CA: Sage.

Mullen, C. A. (2005). Mentorship. New York: Peter Lang.

Mullen, C. A. (2007). Trainers, illusionists, tricksters, and escapists: Changing the doctoral circus. The Educational Forum, 71(4), 300-315. 
Munguia, D. (2001). A mentoring model of how to train successor leaders: A Latin American perspective (Doctoral dissertation). Retrieved from ProQuest Dissertations and Theses database. (UMI No. 3022691)

Mutchnick, R., \& Mutchnick, E. (1991). The mentoring of graduate students: A conceptual framework for same-gender and cross-gender mentor-protégé relationships. Criminal Justice Policy Review, 5(4), 291-306.

Myers, H. F. (2004). New Directions. Issues of gender, ethnicity, discrimination, and acculturation. Available from website www.mhsip.org/pdfs/myers.pdf.

National Articulation and Transfer Network (NATN). (2002). Building an alternative pathway for underserved student populations to access Historically Black Colleges and Universities (HBCU), Hispanic Serving Institutions (HSI) \& Tribal Colleges and Universities (TCU), City College of San Francisco. Retrieved from Cambridge Scientific Abstracts database. (ED465409).

National Maternal and Child Health Resource Center on Cultural Competency. (1997). Journey towards cultural competency: Lessons learned. Vienna, VA: Maternal and Children's Health Bureau Clearinghouse. Texas Department of Health.

Nettles, M. T. \& Millett, C. M. (1999). The human capital liabilities of underrepresented minorities in pursuit of science, mathematics, and engineering doctoral degrees. National Center for Postsecondary Improvement. (ED440576).

Newby, T. J., \& Corner, J. (1997). Mentoring for increased performance: Benefits and key principles. Performance Improvement, 36(4), 10-13.

Nicola, G. R. (1990). The mentor relationships: A proper factor in the becoming of certain eminent Romanian personalities. Revue-Romaine des Science Sociales Serie de Psychologie, 34(2), 135-145.

Nieto, S. (2002). Language, culture, and teaching: critical perspectives for a new century. New Jersey: Lawrence Erlbaum Associates.

Nielsen, S. M. \& Rocco, T. S. (2002). Joining the conversation: Graduate students' perceptions of writing for publication. Paper presented at the Annual Meeting of the Adult Education Research Conference, Raleigh, NC.

Noddings, N. (1984). Caring: A feminine approach to ethics and moral education. Berkeley: University of California Press.

Noddings, N. (2005). The challenge to care in schools: An alternative approach to education. New York: Teachers College Press. 
Nolan, J. (1999). Cross-cultural counseling: An Oakland model (Occasional Paper \#5) Berkeley, CA: Western Institute for Social Research

Ogbu, J. (1983) Minority status and schooling in plural societies, Comparative Education Review, 27(2), 168-190. doi:10.1086/446366

Ogbu, J. (1990) Minority status and literacy in comparative perspective, Daedalus, 11(2), $141-168$.

Okawa, G. Y. (2002). Diving for pearls: Mentoring as cultural and activist practice among academics of color. College Composition and Communication, 53(3), 507533. doi: $10.2307 / 1512136$

Paglis, L. L., Green, S. G., \& Bauer, T. N. (2006). Does adviser mentoring add value? A longitudinal study of mentoring and doctoral student outcomes. Research in Higher Education, 47(4), 451-476. doi:10.1007/s11162-005-9003-2

Palmer, A. (1983). Afro-Caribbean women in the United States: Images and reality (RHES Occasional Papers, No. 1). Washington, DC: Smithsonian Institute, Research on Immigration and Ethnic Studies. (ED240180).

Parham, T. A., \& Helms, J. E. (1985). Relation of racial identity attitudes to selfactualization and affective states of Black students. Journal of Counseling Psychology, 32(3), 431-440. doi:10.1037/0022-0167.32.3.431

Parks, S. (1986). The critical years: the young adult search for a faith to live by. San Francisco: Harper.

Parks, S. D. (2000). Big questions, worthy dreams: mentoring young adults in their search for meaning, purpose, and faith. San Francisco: Jossey-Bass.

Pascarella, E. T., Terenzini P. T., (1991). How college affects students. San Francisco: Jossey-Bass.

Passarelli, T. (2008). Complementary and alternative medicine in the United States. MPHP 439 4/2008. Available from website http://www.cwru.edu/med/epidbio/mphp439/complimentary_meds.pdf

Patterson, O. (2000). Taking culture seriously: A framework and an Afro-American illustration. In L.E.Harrison \& S. P. Huntington (Eds.), Culture matters: How values shape human progress (pp. 202-218). New York: Basic Books.

Patton, M. (1990). Qualitative evaluation and research methods. Newbury Park, CA: Sage Publications. 
Patton, M. Q. (2002). Qualitative research and evaluation methods ( $3^{\text {rd }}$ ed.). Thousand Oaks, CA: Sage.

Perez, B. (1998). Sociocultural contexts of language and literacy. Mahwah, NJ: Lawrence Erlbaum.

Pew Hispanic Center (2011). Statistical portrait of the foreign-born population in the United States, 2009. Tabulations of 2009 American Community Survey. Available online at http://pewhispanic.org/factsheets/factsheet.php?FactsheetID $=69$

Piaget, J. (1950). The psychology of intelligence. New York, NY: Routledge.

Phinney, J. S. (1991). Ethnic identity and self-esteem: A review and integration. Hispanic Journal of Behavioral Sciences, 13(2), 193-208. doi:10.1177/07399863910132005

Phinney, J. S. (1992). The multigroup ethnic identity measure: A new scale for use with diverse groups. Journal of Adolescent Research, 7, 156-176.

Phinney, J. S. (1996a). Understanding ethnic diversity: The role of ethnic identity. American Behavioral Scientist, 40(2), 143-152.

Phinney, J. S. (1996b). When we talk about American ethnic groups, what do we mean? American Psychologist, 51, 918-927.

Phinney, J. S., \& Alipuria, L. (1990). Ethnic identity in college students from four ethnic groups. Journal of Adolescence, 13, 171-183.

Pollock, M. (2008). From shallow to deep: Toward a thorough cultural analysis of school achievement patterns. Anthropology \& Education Quarterly, 39(4), 369-380. doi:10.1111/j.1548-1492.2008.00028.x

Portman, T. A. A. \& Garrett, M. T. (2005). Beloved women: Nurturing the sacred fire of leadership from an American Indian perspective. Journal of Counseling and Development, 83(3), 284-91. doi:10.3102/00346543061004505

Pratt, D. D., \& Nesbit, T. (2000). Discourses and cultures of teaching. In A. L. Wilson \& E. R. Hayes (Eds.), Handbook of adult and continuing education (pp. 117-131). San Francisco: Jossey-Bass.

Premdas, R. R. (1995). Ethnic identity in the Caribbean: Decentering a myth. Working paper no. 234, St Augustine: University of the West Indies.

Quinn, N., \& Holland, D. (1987). Culture and cognition. In D. Holland \& N. Quinn (Eds.), Cultural models in language and thought (pp. 3-40). New York: 
Cambridge University.

Ragins, B. R. (1997). Antecedents of diversified mentoring relationships. Journal of Vocational Behavior, 51, 90-109.

Ragins, B. R. (2002). Understanding diversified mentoring relationships: Definitions, challenges and strategies. In D. Clutterbuck and B. R. Ragins (Eds.), Mentoring and Diversity: An international perspective, pp. 23-53. Oxford: ButterworthHeinemann.

Ragins, B. R., Cotton, J. L., \& Miller, J. S. (2000). Marginal mentoring: The effects of type of mentor, quality of relationship, and program design on work and career attitudes. Academy of Management Journal, 43(6), 1177-1194.

Ragins, B. R. \& Scandura, T. A. (1999). Burden or blessing? Expected costs and benefits of being a mentor. Journal of Organizational Behavior, 20, 493-509.

Ramdin, R. (2000). Arising from bondage: a history of the Indo-Caribbean people. New York: New York University Press.

Ramaswami, A. (2009). A cross-cultural examination of the relationship between mentor-protégé similarity and mentor behavior in India and the U.S. (Doctoral dissertation). Retrieved from ProQuest Dissertations and Theses database. (UMI No. 3358939).

Ratner, C. (1991). Vygotsky's sociohistorical psychology and its contemporary applications. New York: Plenum Press.

Reddick, R. J. (2006). The gift that keeps giving: Historically Black College and university-educated scholars and their mentoring at predominately White institutions. Educational Foundations, 20(1/2), 61-84.

Redmond, P. S. (1990). Mentoring and Cultural Diversity in Academic Settings. American Behavioral Scientist, 34, 188. doi: 10.1177/0002764290034002007

Relph, E. (1976). Place and placelessness. London: Pion.

Reyes, E. A. (2004). Whose culture is it, anyway? The Chronicle of Higher Education, $51(17), \mathrm{B} 5$.

Rhone, A. (2007). Caribbean-Immigrant educators: More than an ocean of difference. Childhood Education, 84(1), 44-47. 
Rickard, K. (2010). Critical success factors in e-mentoring for small business. In D. Clutterbuck \& Z. Hussain, Virtual Coach, Virtual Mentor (pp. 85-108). USA: Information Age Publishing Inc.

Risku, M. (2002). A Bridge Program for educationally disadvantaged Indian and African Americans, The University of Minnesota. Retrieved from Cambridge Scientific Abstracts database. (ED477417).

Roach, R. (2001). Mellon makes its mark. Black Issues in Higher Education, 18(11), 3841.

Roach, R. (2001). Young Black men speak on college and life. Black Issues in Higher Education, 18(6), 25-7.

Roach, R. (2005). Transformative connections. Black Issues in Higher Education, 22(2), $32-5$.

Roberts, G. W., \& Byrne J. A. (1966). Summary statistics on indenture and associated migration affecting the West Indies, 1834-1918, Population Studies, 20, 125-134. doi: $10.2307 / 2172617$

Rodriguez, Y. E. G. (1995). Mentoring to diversity: a multicultural approach. New Directions for Adult and Continuing Education, 66, 69-77.

Roeder, K. R. (2006). A qualitative analysis of cross-cultural mentoring relationships: Examining elements of status and race in a university social work program (Doctoral dissertation). Retrieved from ProQuest Dissertations and Theses database. (UMI No. 3239151).

Rogoff, B. (1986). Adult assistance of children's learning. In T. E. Raphael (Ed.), The contexts of school-based literacy (pp. 27-40). New York: Random House.

Rogoff, B. (1995). Observing sociocultural activity in three planes: Participatory appropriation, guided participation, and apprenticeship. In J. Wertsch, P. del Rio, \& A. Alvarez (Eds.), Sociocultural studies of the mind. Cambridge, UK: Cambridge University Press.

Rogoff, B. (2003). The cultural nature of human development. New York: Oxford University Press.

Rogoff, B., \& Chavajay, P. (1995). What's become of research on the cultural basis of cognitive development? American Psychologist, 50(10), 859-877. doi: 10.1037/0003-066X.50.10.859 
Roland, K. A. (2008). Educating for inclusion: Community building through mentorship and citizenship. Journal of Educational Thought, 42(1), 53-67.

Rong, X. L., \& Brown, F. (2001). The effects of immigrant generation and ethnicity on educational attainment among young African and Caribbean Blacks in the United States. Harvard Educational Review, 71(3), 536-565.

Roopnarine, L. (2007). Indo-Caribbean indenture: Resistance and accommodation, 1838-1920. Kingston, Jamaica: University of the West Indies Press.

Rose, A. D. (2000). Which way adult education? The complexities of culture and action. Adult Learning, 11(1), 30-31.

Rosenbaum, M. (1988). Learned resourcefulness, stress and self-regulation. In S. Fisher $\& \mathrm{~J}$. Reason (Eds.), Handbook of life-stress, cognition and health, learned resourcefulness: On coping skills, self-control and adaptive behavior (pp. 483496). Chichester, West Sussex: John Wiley.

Rosser, S. (2007). Leveling the playing field for women in tenure and promotion. National Women's Studies Association (NWSA) Journal, 19(3), 190-8.

Rothenberg, P. (2005). Beyond borders: thinking critically about global issues. New York: Worth Publishers.

Rubin, H. J., \& Rubin, I. S. (1995). Qualitative interviewing: The art of hearing data. Thousand Oaks, CA: Sage.

Rumbaut, R. (1994). The crucible within: Ethnic identity, self-esteem, and segmented assimilation among children of immigrants. Special Issue: The New Second Generation. International Migration Review, 28(4), 748-794. doi: $10.2307 / 2547157$

Rumbaut, R. (1997). Paradoxes (and orthodoxies) of assimilation. Sociological Perspectives, 40(3), 483-511.

Rumbaut, R. G. (2004). Ages, life stages, and generational cohorts: Decomposing the immigrant first and second generations in the United States. International Migration Review, 38(3),1160-1205. doi:10.1111/j.1747-7379.2004.tb00232.x

Rumbaut, R. G. (2005). Sites of belonging: Acculturation, discrimination and ethnic identity among children of Immigrants. In T. S. Weisner (ed)., Discovering successful pathways in children's development: Mixed methods in the study of childhood and family life (pp. 111- 164). Chicago: The University of Chicago Press. 
Rusbult, C. E., Martz, J. M., \& Agnew, C. R. (1998). The Investment Model Scale: Measuring commitment level, satisfaction level. Quality of alternatives, and investment size. Personal Relationships, 5, 357-391.

Rushing, J. H. (2006). Erotic mentoring: Women's transformations in the university. Walnut Creek, CA: Left Coast Press Inc.

Rushton, S. (2003). Two preservice teachers' growth in self-efficacy while teaching in an inner-city school. The Urban Review, 35(3), 167-89.

Salkind, N. J. (2004). An introduction to theories of human development. Thousand Oaks, CA: Sage Publications.

Salzman, M. (2000). Promoting multicultural competence: A cross-cultural mentorship project. Journal of Multicultural Counseling and Development, 28(2), 119-124.

Samuel, J. P. (1993). The effect of mentoring upon discipleship training in an Indian Bible college (Doctoral dissertation). Retrieved from ProQuest Dissertations and Theses database. (UMI No. 9407554).

Sandelowski, M. (1986). The problem of rigor in qualitative research. Advances in Nursing Science, 8(3), 27-37.

Santos, S. J., \& Reigadas, E. T. (2005). Understanding the student-faculty mentoring process: Its effects on at-risk university students. Journal of College Student Retention, 6(30), 337.

Scandura, T.A., \& Pellegrini, E. K. (2007). Workplace mentoring: Theoretical approaches and methodological issues. In T. D. Allen, and L. T. Eby, (Eds.), The Blackwell handbook of mentoring: A multiple perspectives approach (pp. 20712091). Malden, MA, US: Blackwell Publishing.

Schiller, N. G., Basch, L., \& Blanc-Szanton, C. (1992). From immigrant to transimmigrant: Theorizing transnational migration. Anthropological Quarterly, 68(1), 48-63.

Schilling, T. (2008). An examination of resilience processes in context: The case of Tasha. The Urban Review, 40(3), 296-316.

Schlossberg, N. K. (1989). Marginality and mattering: Key issues in building community. In D. C. Roberts (Ed.), Designing campus activities to foster a sense of community (New Directions for Student Services, No. 48, pp. 5-15). San Francisco: Jossey-Bass.

Schriner, C. L. (2004). Clinical nurses transitioning into a faculty role: A cultural 
analysis of the nursing profession, the academic discipline of nursing, and the academic professorate (Doctoral dissertation). Retrieved from ProQuest Dissertations and Theses database. (UMI No. 3160368).

Schuerkens, U. (2004). Global forces and local life-worlds. Thousand Oaks: Sage Publications Ltd.

Schwandt, T. A. (2007). Dictionary of qualitative inquiry, (3rd edition). Thousand Oaks, CA: Sage.

Schweibert, V., Deck., M., Bradshaw, M., Scott, P., \& Harper, M. (1999). Women as mentors. Journal of Humanistic Counseling, Education and Development, 37(4), 241.

Seepersad, R., \& Bailey-Watson, M. (2007). Mentor in the third age: A learning perspective. In S. M. Nielsen \& M. S. Plakhotnik (Eds.), Proceedings of the Sixth Annual College of Education Research Conference: Urban and International Education Section (pp. 96-101). Miami: Florida International University. http://coeweb.fiu.edu/research_conference/

Seepersad, R., Hagood-Elliott, K., Lewis, K., \& Strickland, S. L. (2007). Cross-cultural mentoring: Exploration through the lens of African American students. In S. M. Nielsen \& M. S. Plakhotnik (Eds.), Proceedings of the Sixth Annual College of Education Research Conference: Urban and International Education Section (pp. 102-107). Miami: Florida International University. http://coeweb.fiu.edu/research_conference/

Shi, S., Mishra, U., \& Bonk, C. J. (2004). Linkage between instructor moderation and student engagement in synchronous computer conferences. Association for Educational Communications and Technology, Chicago, IL.

Shiw-Parsad, B. (1999). Marital violence within East Indian households in Guyana: A cultural explanation. In R. Kanhai (Ed.), Matikor: The politics of identity for IndoCaribbean women (pp. 40-61). St. Augustine, Trinidad and Tobago: University of the West Indies, School of Continuing Studies

Shohat, E. \& Stam, R. (1994). Unthinking Eurocentrism: Multiculturalism and the media. London: Routledge.

Shultz, E. L., Colton, G. M., \& Colton, C. (2001). The Adventor program: Advisement and mentoring for students of color in higher education. Journal of Humanistic Counseling, Education and Development, 40(2), 208-18.

Shyam, G. (2008). Identity, social roots and empowerment: A study of the low castes diaspora in the West Indies. In J. Fernandez (Ed.), Diasporas: Critical and inter- 
disciplinary perspectives (pp. 151-164). Oxford, United Kingdom; InterDisciplinary Press. Available online http://www.inter-disciplinary.net/at-theinterface/diversity-recognition/diasporas/project-archives/1st/

Singh, V. D. (1988). V. S. Naipaul: An exile at home. Retrieved from ProQuest Dissertations and Theses database. (UMI 8903708).

Singh, D. K., \& Stoloff, D. L. (2003). Mentoring faculty of color. Paper presented at the Annual Meeting of the American Association of Colleges for Teacher Education, Orleans, LA.

Singaravélou. (1990). Indians in the French Overseas Departments: Guadeloupe, Martinique, Réunion. In C. Clarke, C. Peach and S. Vertovec (Eds.), South Asians Overseas: Migration and Ethnicity (pp. 75-88). Cambridge: Cambridge University Press.

Single, P. B., \& Single, R. M. (2005). Mentoring and the technology revolution: How face-to-face mentoring sets the stage for e-mentoring. In F. K. Kochan and J. T. Pascarelli (Eds.), Creating successful telementoring programs (pp. 7-28). USA: Information Age Publishing Inc.

Sosik, J. J. \& Godshalk, V. M. (2000). The role of gender in mentoring: Implications for diversified and homogenous mentoring relationships. Journal of Vocational Behavior 57(1), 102-22.

Softky, E. (2000). Identity matters. Black Issues in Higher Education, 16(25), 27.

Staikidis, K. (2006). Personal and Cultural Narrative as Inspiration: A Painting and Pedagogical Collaboration with Mayan Artists. Studies in Art Education, 47(2), 118-139.

Stanley, C. A. (2006). Coloring the Academic Landscape: Faculty of Color Breaking the Silence in Predominantly White Colleges and Universities. American Educational Research Journal, 43(4), 701-36

Stanley, C. A. (2005). Cross-race faculty mentoring. Change, 37(2), 44-50.

Stanley, C. A. (2006). Coloring the Academic Landscape: Faculty of Color Breaking the Silence in Predominantly White Colleges and Universities. American Educational Research Journal, 43(4), 701-36

Stannard, D. (1992). American Holocaust: The conquest of the New World. New York: Oxford University Press.

Suckert, M. W. (2008). Generational differences in values among Minnesota K--12 
educational leaders (Doctoral dissertation). Retrieved from ProQuest Dissertations and Theses database. (UMI No. 3353645)

Sultana, R. G. (1996). Towards an Understanding of the Dynamics of Mutual Disregard between Teachers and Teacher Educators. European Journal of Teacher Education, 19(3), 303-304.

Taylor, G. S. (1995). An assessment of the Minority Mentorship Project: Educating teachers for culturally responsive classrooms (Doctoral dissertation). Retrieved from ProQuest Dissertations and Theses database. (UMI No. 9534441)

Taylor, M. (2001). Polyrhythm in worship: Caribbean keys to an effective word of God. In B. K. Blount and L. Tubbs Tisdell (Eds.), Making room at the table: An invitation to multicultural worship (pp. 108-128). Louiseville: Westminister John Knox Press.

Thaker, S. N. (2007). Hinduism and learning. In S. B. Merriam \& Associates. (Eds.), Non-Western perspectives on learning and knowing (pp. 57-73). Malabar, FL: Krieger.

The CIA World Factbook. (2009). U.S. Department of State, area handbook of the U.S. Library of Congress. Available online at website https://www.cia.gov/library/publications/the-world-factbook/fields/2075.html

Thomas, D. A. (1993). Racial dynamics in cross-race developmental relationships. Administrative Science Quarterly, 38, 169-194.

Thomas-Hope, E. (2000). Trends and patterns of migration to and from the Caribbean. Chile: International Organization of Migration.

Tinker, H. (1974). A new system of slavery: The export of Indian Labor Overseas, 18301920. London: Oxford University Press.

Tinto, V. (1975). Dropouts for higher education: A theoretical synthesis of recent research. Review of Educational Research, 45, 89-125.

Tinto, V. (1993). Leaving college: Rethinking the causes and cures of student attrition (2nd ed.). Chicago: The University of Chicago Press.

Tinsley, A. (1985). Upward mobility for women administrators. Journal of the National Association of/for Women Deans, Administrators, and Counselors, 49(1), 5-13.

Tisdell, E. J. (1995). Creating inclusive adult learning environments: Insights from multicultural education and feminist pedagogy (Information Series No. 361). Columbus, OH: ERIC Clearinghouse on Adult, Career, and Vocational Education 
Tisdell, E. J. (2000). Feminists pedagogies. In E. Hayes, D. Flannery \& Associates (Eds.). Women as learners (pp. 155-184). San Francisco: Jossey-Bass.

Toporek, R. L. (2005). Multicultural career counseling [Symposium]. Journal of Multicultural Counseling and Development, 33(3), p. 130-192.

Torres, V. (2004). The diversity among us: Puerto Ricans, Cuban Americans, Caribbean Americans, and Central and South Americans. New Directions for Student Services, 105, 5-16. doi:10.1002/ss.112

Tsai, J. L., Ying, Y., \& Lee, P. A. (2000). Cultural orientation and racial discrimination: Predictors of coherence in Chinese American young adults. Journal Of Community Psychology, 28(4), 427-442.

Tylor, E. (1871). Primitive culture. New York: J.P. Putnam’s Sons.

Ugrin, J. C., Odom, M.D., \& Pearson, J. M. (2008). Exploring the importance of mentoring for new scholars: A social exchange perspective. Journal of Information Systems Education, 19(3), 343-350.

Ulmer, T. A. (2008). Examination of cross cultural motivating factors in educational pursuit (Doctoral dissertation). Retrieved from ProQuest Dissertations and Theses database. (UMI No. 3320695).

United Nations Educational, Scientific and Cultural Organization (UNESCO). (2002). Universal Declaration on Cultural Diversity, Adopted by the $31^{\text {st }}$ Session of the General Conference of UNESCO, Paris. Retrieved online from website www.unesco.org/culture

United Nations Secretariat (2005). Expert group meeting on international migration and development in Latin America and the Caribbean. Population Division. Department of Economic and Social Affairs, United Nations Secretariat Mexico City. Available online http://www.un.org/esa/population/meetings/IttMigLAC/P09_ECLAC(Port\%20of $\% 20$ Spain).pdf

United Nations Secretariat (2006). Expert group meeting on international migration and development in Latin America and the Caribbean. Population Division. Department of Economic and Social Affairs United Nations Secretariat Mexico City. Available online http://www.un.org/esa/population/meetings/IttMigLAC/P09_ECLAC(Port\%20of $\% 20$ Spain).pdf

Ury, W. (2000). The third side: Why we fight and how we can stop. New York, NY: Penguin. 
U.S. Census Bureau. (2008). 2008 American Community Survey 1-Year Estimates. United States - Selected Population Profile in the United States. Available online at http://factfinder.census.gov/servlet/DatasetMainPageServlet?_program=ACS

U.S. Census Bureau. (2010). 2010 Census constituent FAQs. Available online at website http://2010.census.gov/partners/pdf/ConstituentFAQ.pdf

U.S. Department of Commerce. (2011). Women in STEM: A Gender Gap to Innovation. ESA Issue Brief \#04-11. Retrieved from website http://www.esa.doc.gov/sites/default/files/reports/documents/womeninstemagap toinnovation8311.pdf

U.S. Department of Education. (1995). The Condition of Education. NCES 95273 Washington, DC: USGPO. Available from website http://nces.ed.gov/pubs95/95273.pdf

U.S. Department of Homeland Security. (2010). Office of Immigration Statistics, 2009 yearbook of immigration statistics. Retrieved from website http://www.dhs.gov/xlibrary/assets/statistics/yearbook/2009/ois_yb_2009.pdf

U.S. Department of Justice. (1998). 1998 statistical yearbook of the Immigration and Naturalization Service. Retrieved from United States Department of Justice, Immigration and Naturalization Service website http://www.dhs.gov/xlibrary/assets/statistics/yearbook/1998/1998yb.pdf

U.S. Immigration and Naturalization Service. (1997). Immigrants admitted by region and selected country of birth. Retrieved from website http://www.ins.usdoj.gov/stats

U.S. Immigration and Naturalization Service. (2000). Statistical yearbook of the Immigration and Naturalization Service, 1998, U.S. Government Printing Office: Washington, D.C. Retrieved April 4, 2010 from website http://www.dhs.gov/xlibrary/assets/statistics/yearbook/1998/1998yb.pdf

U.S. Office Of Management And Budget. (1997). Revisions to the Standards for the Classification of Federal Data on Race and Ethnicity. Federal Register Notice 0 ctober 30, 1997. R etrieved on line via w ebsite http://www.whitehouse.gov/omb/fedreg_1997standards

van Manen, M. (1990). Researching lived experiences: Human science for an action sensitive pedagogy. New York: State University of New York Press.

van Manen, M. (1991). The tact of teaching: The meaning of pedagogical thoughtfullness. New York: State University of New York Press. 
Vaswani, J. P. (2008). Perfect relationship guru and disciple. New Delhi, India: Gardner's Books. Available online http://tiny.cc/g963aw

Venugopal, C. N. (1998). Religion and Indian society; A sociological perspective. New Delhi, India: Gyan Publishing House. Available online http://books.google.com/books/about/Religion_and_Indian_society.html?id=yRP FGT8crakC

Verma, M. (2008). Indo-Caribbean Hindu practice in Queens: Ethnomethods of constituting place, practice and subjects (Doctoral dissertation). Retrieved from ProQuest Dissertations and Theses database. ( UMI No. 3333454).

Vertovec, S. (1992). Hindu Trinidad: Religion, ethnicity and socio-economic change. London: Macmillan.

Vertovec, S. (2000). The Hindu Diaspora: Comparative patterns. London: Routledge.

Vickers, P. J. (2002). The colonial mind in post-secondary education. McGill Journal of Education 37(2), 241-54.

Vickerman, M. (2007). Non-Hispanic West Indians in New York City. In I. M. Miyares and C. A. Airriess (Eds.), Contemporary ethnic geographies in America (151174). Lanham, MA: Rowman and Littlefield Publishers, Inc.

Vygotsky, L. S. (1962). Thought and language. (E. Handfmann \& G. Vakar, Trans.). Cambridge, MA: MIT Press.

Vygotsky, L. S. (1979). Consciousness as a problem of psychology of behavior. Soviet Psychology, 17, 5-35. (Original work published 1925).

Vygotsky, L. S. (1997). Educational psychology (R. Silverman, Trans.). Boca Raton, FL: St. Lucie.

Waldinger, R. \& Der-Martirosian, C. (2001). The immigrant niche: Pervasive, persistent and diverse. In R. D. Waldinger (ed.), Strangers at the gates: New immigrants in urban America, (228-271). California: University of California Press

Ward, C. (2004). Psychological Theories of culture contact and their implications for intercultural training and interventions in D. Landis, J. M. Bennett, \& M. J. Bennett (Eds.), Handbook of intercultural training (pp. 185-216). Thousand Oaks: Sage Publications.

Warner, R. S. \& Wittner, J. G. (1998). Gatherings in diaspora: Religious communities and the new immigration. Philadelphia, PA : Temple University Press. 
Waterman, S. J. (2007). A complex path to Haudenosaunee degree completion. Journal of American Indian Education, 46(1), 20-40.

Wertsch, J. V. (1991). Voices of the mind: A sociocultural approach to mediated action. Cambridge, MA: Harvard

White, C. S. (2006). Graduate student mentor program: Exploring what a diverse student population needs (Doctoral dissertation). Retrieved from ProQuest Dissertations and Theses database. (UMI No. 3230496)

Wilson, M. (2000). Reversing the plight of African American male college students. Black Issues in Higher Education, 17(18), 176.

Wilson, P. F. (1999). Principled mentoring: Identifying core values for the practice of mentoring (Doctoral dissertation). Retrieved from ProQuest Dissertations and Theses database. (UMI No. 9926475)

Wilks, J. E. (2008). Impact of pluralistic mentoring at the United States Air Force Academy (USAFA) (Doctoral dissertation). Available from ProQuest Dissertations and Theses database. (UMI No. 3320577)

Wittmer, J. (1992). Valuing diversity in the schools: The counselor's role. ERIC digest No. EDO-CG-92-9) ERIC/CAPS, 2108. School of Education, University of Michigan, Ann Arbor, MI.

Wlodkowski, R. J. (1997), Motivation with a Mission: Understanding Motivation and Culture in Workshop Design. New Directions for Adult and Continuing Education, 76, 19-31.

Wong, L. C. J. (2000). What helps and what hinders in Cross-cultural clinical supervision: A critical incident study (Doctoral dissertation). Available from ProQuest Dissertations and Theses database. (UMI No. NQ61204).

World Directory of Minorities. (2008). East Indians of the Caribbean. Retrieved online June 2010, from website http://www.faqs.org/minorities/South-and-CentralAmerica/East-Indians-of-the-Caribbean.html

Wright-Harp, W., \& Cole, P. A. (2008). A mentoring model for enhancing success in graduate education. Contemporary Issues In Communication Science and Disorders, 35, 4-16.

Yeh, C. J., Ching, A. M., Okubo, Y., \& Luthar, S. S. (2007). Development of a mentoring program for Chinese immigrant adolescents' cultural adjustment. Adolescence, 42(168), 733-748. 
Young, I. M. (1990). Justice and the politics of difference. New Jersey: Princeton University Press.

Young, J. R. (2003). Black students lack mentors in schools, study finds. The Chronicle of Higher Education, 49(21), A38.

Zachary, L. J. (2000). The mentor's guide: Facilitation effective learning relationships. San Francisco: Jossey-Bass. 


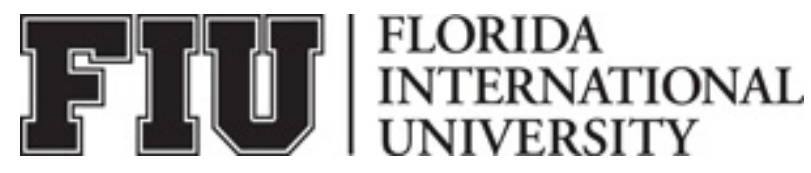

\author{
Appendix A \\ Invitation to Potential Indo-Caribbean Protégés who have Participated in \\ Cross-cultural Mentoring Experiences
}

Hello, my name is Rehana Seepersad, and I am a doctoral candidate at Florida International University in the College of Education's Adult Education and Human Resource Development program.

The purpose of this study is to explore the perceptions of Indo-Caribbean protégés regarding the effects of their cross-cultural mentoring experiences in the United States. The goal of the study is to understand the nature of their mentoring relationships with a mentor whose ethnicity is different than their own.

You are being invited to participate in this study because it is believed you meet the criteria of the study. Criteria include (a) being Indo-Caribbean, (b) having ancestors who served as indentured laborers in the Caribbean, (c) having lived in the United States for three years or more, (d) having completed a baccalaureate degree or beyond in the United States, and (e) having had a mentor from a culture different from their own for a minimum of one year.

If you meet these criteria and decide to be in this study, you will be one 15 participants in this research study. Participation in this study will take 60 to 90 minutes of your time. If you agree to be in the study, I will ask you to participate in a digitally recorded interview. The face-to-face (or electronic interface such as Skype or iChat) interview will be guided by a list of questions. You will be asked to answer questions about your perceptions of your past cross-cultural mentoring experiences.

If you are interested in participating in this study, please send me an email at email@fiu.edu. If you know someone who meets the criteria above and who you feel may be interested in participating in this study, please give him/her my email address or phone number $(\mathrm{xxx}) \mathrm{xxx}-\mathrm{xxxx}$, to contact me directly.

Sincerely,

Rehana Seepersad

Doctoral Candidate

Florida International University 


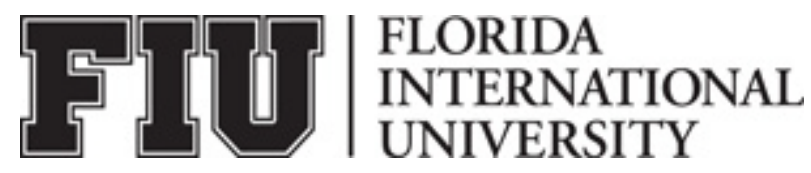

Appendix B

Adult Consent to Participate in a Research Study

Island Diasporas: Perceptions of Indo-Caribbean Protégés regarding the Effects of their

Cross-Cultural Mentoring Experiences in the United States

You are being asked to be in a research study. The purpose of this study is to explore the perceptions of Indo-Caribbean protégés regarding their cross-cultural mentoring experiences in the United States.

If you decide to be in this study, you will be one of 15 people in this research study. Your participation will require 60 to 90 minutes of your time, within a single interview session.

If you agree to be in the study, you will be asked to participate in a digitally recorded interview. The face-to-face (or electronic interface) interview will take place at a mutually agreed location and time, and will be guided by a list of questions. You will be asked to answer questions about your perceptions of your past cross-cultural mentoring experiences with a mentor who was from an ethnicity that differed from your own.

There are no known risks related to this study.

Although there is no direct gain from the study, you may benefit in the sense that:

- You will come to understand your perceptions regarding cross-cultural mentoring experiences and how your ethnicity influenced your feelings and interactions.

- Mentors, educators and administrators who read this study will gain a deeper understanding of the needs of Indo-Caribbean immigrants in cross-cultural mentoring relationships.

There are no known alternatives available to you, other than not taking part in this study. However, any significant new findings developed during the course of the research which may relate to your willingness to continue participation will be provided to you.

The records of this study will be kept private and will be protected to the fullest extent provided by law. In any sort of report we might publish, we will not include any information that will make it possible to identify a subject. Research records will be stored securely and only the researcher will have access to the records. Your records may also be reviewed for audit purposes by authorized University or other agents who will be bound by the same provisions of confidentiality. 
There is no payment or reimbursement for your participation, and you will not be responsible for any costs to participate in this study.

Your participation in this study is voluntary. You are free to participate in the study or withdraw your consent at any time during the study. Your withdrawal or lack of participation will not affect any benefits to which you are otherwise entitled. The investigator reserves the right to remove you without your consent at such time that they feel it is in the best interest.

If you have any questions about the purpose, procedures, or any other issues relating to this research study you may contact Rehana Seepersad at (xxx) xxx-xxxx, or email@fiu.edu.

If you would like to talk with someone about your rights of being a subject in this research study or about ethical issues with this research study you may contact Dr. Patricia Price, the Chairperson of the FIU Institutional Review Board (IRB) at 305-3482618 or $305-348-2494$.

I have read the information in this consent form and agree to participate in this study. I have had a chance to ask any questions I have about this study, and they have been answered for me. I understand that I am entitled to a copy of this form after it has been read and signed.

Signature of Participant

Printed Name of Participant

Signature of Person Obtaining Consent
Date

Date 


\section{APPENDIX C}

\section{SEMI-STRUCTURED INTERVIEW GUIDE}

\section{Background Information of Participants}

- Tell me about yourself.

- Tell me about your culture.

- Tell me about your family.

- Tell me how your culture has influenced your life.

\section{Perceptions of the Cross-Cultural Mentoring Experience}

\section{The mentoring experience}

1. Tell me about your mentoring experience.

2. Tell me about a mentor in your life.

3. Tell me about ways the mentor helped you.

4. Tell me about the most important or meaningful aspect of your mentoring relationship.

5. Tell me about the most difficult aspect of your mentoring relationship.

- Tell me how you felt about your mentor's recommendations and guidance.

\section{Culture, identity and qualities}

6. Tell me how your culture influenced the mentoring relationship.

7. Tell me how your mentor's culture influenced the relationship.

8. Tell me about the racial, ethnic or cultural differences between you and your mentor.

9. Tell me about the mentor's strongest qualities.

10. Tell me about the mentor's weakest qualities.

11. Tell me about the your strongest qualities.

12. Tell me about your weakest qualities. 


\section{Communication within the relationship}

13. Tell me about your communication style.

14. Tell me about your mentor's communication style.

15. Tell me about how these communication styles changed over time.

- Give me an example of feedback your mentor provided.

- Tell me how you dealt with or responded to the feedback.

\section{Relational aspects of the mentoring relationship}

16. Tell me assumptions your mentor made about you.

- Tell me about assumptions you made about your mentor.

17. Tell me about how these assumptions changed the relationship.

18. Tell me about challenges in your mentoring relationship.

\section{Professional development}

19. Tell me about how the mentor assisted your professional development and growth.

20. Tell me how the mentoring relationship hindered your professional development and growth.

21. Tell me what else your mentor could have done to help you grow professionally.

22. Tell me about cross-cultural differences in terms of your professional development and growth.

\section{Final thoughts}

23. Tell me about memorable moments in the mentoring relationship

24. Tell me about your present relationship with this mentor.

25. Tell me how you felt about the mentoring relationship.

- Tell me about anything else you would like to share about your mentoring relationship.

- What question do you think I should have asked?

VITA 


\section{REHANA SEEPERSAD}

1999-2002

B. Sc., Business Administration

Nova Southeastern University

Fort Lauderdale, Florida

2003-2005

M.B.A., Business Administration

Nova Southeastern University

Fort Lauderdale, Florida

\section{PUBLICATIONS AND PRESENTATIONS}

Seepersad, R., (2012). Mentoring experiences of Indo-Caribbean immigrants in the United States. In S. M. Nielsen, M. S. Plakhotnik \& D. M. Pane (Eds.), Proceedings of the Twelfth Annual College of Education Research Conference: Urban and International Education Section (pp. 168-174). Miami: Florida International University. http://coeweb.fiu.edu/research_conference/

Seepersad, R. (2011). Caribbean Women: New Immigrants' Mentoring Challenges and Transformations. Presented at The Eleventh Annual Women, Sexuality, and Gender Student Conference, Florida International University, Miami.

Seepersad, R. \& Banerjee, R. (2009). Review of Non-Western Perspectives on Learning and Knowing, by Sharan B. Merriam and Associates. Malabar, FL: Krieger publishing Company, 2007. Adult Education Quarterly, Volume 59(3), 269-271.

Seepersad, R., \& Bailey-Watson, M. (2007). Mentor in the third age: A learning perspective. In S. M. Nielsen \& M. S. Plakhotnik (Eds.), Proceedings of the Sixth Annual College of Education Research Conference: Urban and International Education Section (pp. 96-101). Miami: Florida International University. http://coeweb.fiu.edu/research_conference/

Seepersad, R., Hagood-Elliott, K., Lewis, K., \& Strickland, S. L. (2007). Cross-cultural mentoring: Exploration through the lens of African American students. In S. M. Nielsen \& M. S. Plakhotnik (Eds.), Proceedings of the Sixth Annual College of Education Research Conference: Urban and International Education Section (pp. 102-107). Miami: Florida International University. http://coeweb.fiu.edu/research_conference/

Seepersad, R., Shuck, B., Albornoz, C., Clayton J, \& Clayton, H. (2007). Review of the book Understanding and promoting transformative learning: A guide for educators of adults. New Horizons in Adult Education and Human Resource Development, 21(3/4), 51-54. Available on website http://education.fiu.edu/newhorizons/ 
Seepersad, R. (2007). Review of Erotic mentoring: Women's transformations in the university by Janice Hocker Rushing. In Mentoring and Tutoring: Partnership in Learning, 15(4), 1361-1267.

Plakhotnik, M.S., Delgado, A., \& Seepersad, R. (2006). Autobiographical Exploration of Self as Adult Educators and Adult Learners. Proceedings of the Midwest Research-to-Practice Conference in Adult, Continuing, and Community Education (pp. 163-168). St Louis, MO: The University of Missouri. Available online at http://www.lulu.com/items/volume_29/459000/459372/3/print/459372.pdf 